THE ROLE OF PROSTAGLANDINS IN THE UTERO-OVARIAN AXIS OF THE CYCLING AND EARLY

PREGNANT MARE

\author{
By \\ MICHAEL WALTER VERNON
}

A DisSERTATION PRESENTED TO THE GRADUATE COUNCIL OF THE UNIVERSITY OF FLORIDA

IN PARTIAL FULFILLMENT OF THE REQUIREMENTS FOR THE DEGREE OF DOCTOR OF PHILOSOPHY

UNIVERSITY OF FLORIDA

1979 
Dedicated to

Matt and Ann,

my parents. 


\section{ACKNOWLEDGEMENTS}

The author wishes to express his appreciation to his major advisor, Dr. Daniel C. Sharp, and the members of his graduate committee, Dr. Fuller W. Bazer, Dr. Donald Caton, Dr. Michael J. Fields, and Dr. William W. Thatcher, for their guidance and direction in the research and preparation of this manuscript. The author is also indebted to the many individuals who assisted in surgery and herd maintenance. He is especially indebted to Dr. Richard L. Asquith, Michael Zavy, Richard Mayer, Maryann Simone11i, Samuel Strauss, Kathy and Matthew Seamans, and Thomas Wise. Appreciation is also expressed to Dr. C.J. Wilcox for his statistical analyses; Wiley Grubaugh and Debbie Starr for their technical assistance; and Beverly Martin and Tamara Divito for their continuous encouragement. Finally, the author wishes to express his gratitude to AdeIe Koehler for her expert typing of this manuscript. 
TABLE OF CONTENTS

$\underline{\text { Page }}$

ACKNOWLEDGEMENTS. . . . . . . . . . . . . . . . . . iii

LIST OF TABLES. . . . . . . . . . . . . . . . . . . vi

LIST OF FIGURES . . . . . . . . . . . . . . . . . . viii

ABSTRACT. . . . . . . . . . . . . . . $\mathrm{x}$

CHAPTER

I INTRODUCTION . . . . . . . . . . . . . . . I

i I Literature ReVIEW. . . . . . . . . . . . . 5

Control of Luteolysis. . . . . . . . . . . 5

The Uterus as a Source of the Luteolysin . . . 6

PGF as the Luteolysin. . . . . . . . . . . . 8

Steroid Modulation of PGF Production . . . . . . 13

The Membrane Receptor for Prostaglandins . . . 14

Mechanism of Action of PGF . . . . . . . . . . 17

II THE ENDOMETRIAL PGF IN THE

INTACT PREGNANT AND CYCLING MARE . . . . . . . 21

Materials and Methods. . . . . . . . . . 21

Test Animals. . . . . . . . . . . 21

Surgery . . . . . . . . . . . . . 23

Incubation Procedure. . . . . . . . . . 24

Radioimmunoassay for PGF. . . . . . . 25

Statistical Design. . . . . . . . . . 30

Results and Discussion . . . . . . . . . . . . 31

iv STEROID MODULATION OF EQUINE ENDOMETRIAL

$\mathrm{PGF}$. . . . . . . . . . . . . . . . 52

Materials and Methods. . . . . . . . . . . 52

Results and Discussion . . . . . . . . . . . 54

$V$ THE LOCAL EFFECTS OF THE EMBRYO ON THE EQUINE

ENDOMETRIAL PGF. . . . . . . . . . . . . . 65

Materials and Methods. . . . . . . . . 66

Results and Discussion . . . . . . . . . 67 
VI THE LOCALIZATION OF PGF IN THE PERFUSED

EQUINE OVARY. . . . . . . . . . . . . . . . . . 73

Materials and Methods... . . . . . . . 73

Results and Discussion. . . . . . . . . . . . 79

VII SPECIFIC BINDING OF PGF TO THE EQUINE

CORPUS LUTEUM . . . . . . . . . . . . . . 85

Materials and Methods . . . . . . . . . . . 85

PGF Binding to Luteal Tissue . . . . . . 85

Receptor Characterization... . . . . . 87

PGF Binding in Pregnant and Non-Pregnant

Mares.............. 90

Results and Discussion. . . . . . . . . . 91

VIII SUMMARY AND CONCLUSIONS . . . . . . . . . 116

APPENDIX COMMERCIAL SOURCES OF MATERIALS CITED . . . 134

LIST OF REFERENCES . . . . . . . . . . . . . . . . 135

BIOGRAPHICAL SKETCH. . . . . . . . . . . . 146 
LIST OF TABLES

$\underline{T a b} 1 \mathrm{e}$

$\underline{\text { Page }}$

III-1. Analysis of Variance Table for the Endometrial PGF Study in Non-Pregnant Mares. . . . . . 32

II-2. Analysis of Variance Table for the Endometrial PGF Study in Pregnant Mares. . . . . . . . 33

III-3. Endometrial. PGF Concentrations in Non-Pregnant Mares After In Vitro Incubation. . . . . . 34

III-4. Endometrial PGF Concentrations in Pregnant Mares After In Vitro Incubation. . . . . . . 35

IV-1. Analysis of Variance Table for the Experiment on the Steroid Modulation of Endometrial PGF . 55

IV-2. Effect of Exogenous and In Vitro Steroid Treatments upon Endometrial PGF Production Capacities . . . . . . . . . . . . 56

IV-3. Probabilities of a Greater F Statistic for the Orthogonal Contrasts Between the Exogenous Treatments.................

IV-4. Probabilities of a Greater F Statistic for the Orthogonal Contrasts Between the In Vitro Treatments . . . . . . . . . . . . . .

V-1. Analysis of Variance Table for the Experiment on the Embryonic Influence on Endometrial PGF.

V-2. Local Influence of Embryo upon Endometrial PGF Production Capacities. . . . . . . . . 70

VI-1. Analysis of Variance Table for the Experiment on the $:$ Localization of $3_{\mathrm{H}-\mathrm{PGF}}$ in the Perfused Equine Ovary................. . 80

VI-2. Amount of ${ }^{3} \mathrm{H}-\mathrm{PGF}$ Localized within Various Tissues of the Perfused Ovary. . . . . . .

VII-1. Analysis of Variance Table for the Binding of PGF to the Corpus Luteum of the Non-Pregnant Mare 
VII-2. Analysis of Variance Table for the Binding of PGF to the Corpus Luteum of the Pregnant Mare................. 93

VII-3. Receptor Dissociation Constants and Binding Capacities of Mare Corpora Lutea... . . 99

VII-4. Relative Affinities of Various Prostaglandins for the PGF Receptor . . . . . . . . 101

VII-5. Weights of Corpora Lutea (CL), Percent PGF Bound Specifically to Luteal Membrane Preparation (MP), and Concentration of MP Protein/CL Throughout the Estrous Cycle and Early Pregnancy. . . . . . . . . . 102 


\section{LIST OF FIGURES}

$\underline{\text { Figure }}$

III-1. Recovery of $\mathrm{PGF}_{2 \alpha}$ added to endometria prior to extraction. . . . . . . . . . . 29

III-2. Production capacities of endometrial PGF during the estrous cycle and early pregnancy. 37

III-3. Regression curves for production capacities of endometrial PGF during the estrous cycle and early pregnancy. . . . . . . . . . . 39

III-4. Endometrial PGF content during the estrous cycle and early pregnancy. . . . . . . . . . 41

III-5. Regression curves for endometrial PGF content during the estrous cycle and early pregnancy.

III-6. Production capacities of endometrial PGF of the estrous cycle after in vitro estrogen and progesterone........... . 45

III-7. Regression curves for endometrial PGF production after in vitro estrogen and progesterone . . . . . . . . . 47

IV-1. Effects of exogenous and in vitro steroid treatments upon endometriaT PGF production . . 61

V-1. Local influence of embryo upon endometrial PGF production . . . . . . . . . . . 72

VI-1. Diagram of the apparatus utilized in the perfusion of the equine ovary with tritiated PGF. . . . . . . . . . . . 76

VI-2. Localization of tritiated PGF within various tissues of the perfused equine ovary. . . . 84

VII-1. Listing of the chemical structures of the $\mathrm{PGF}_{2} \alpha$ analogues used in the cross-reactivity study.................. 
VII-2. (A) Rate of association of PGF to a Day 14 and Day 8 luteal membrane preparation; (B) Rate of dissociation of PGF from the luteal membrane preparation; (C) Dose-response relationship between the luteal membrane preparation, $3_{\mathrm{H}-}$ PGF, and various amounts of radioinert PGF . . 95

VII-3. Scatchard plot of the interactions between the luteal membrane preparation and various

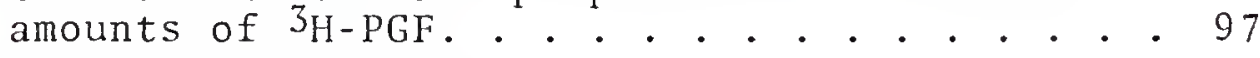

VII-4. Weight of corpora lutea in non-pregnant and early pregnant mares . . . . . . . . 104

VII-5. Regression curves for the corpora lutea weights from non-pregnant and pregnant mares . 106

VII-6. Concentrations of protein in the luteal membrane preparation from the non-pregnant and pregnant mares . . . . . . . . . 110

VII-7. Regression curves for the concentrations of protein within the luteal membrane preparation of the non-pregnant and pregnant mare . . 112

VII-8. Specific binding of PGF to the luteal cell membrane preparation of non-pregnant and early pregnant mare. . . . . . . . . . 114

VIII-1. Concentrations of estrone in the peripheral plasma and uterine flushings of the nonpregnant and pregnant mare . . . . . . . 120

VIII-2. Concentrations of estradiol in the peripheral plasma and uterine flushings of the nonpregnant and pregnant mare . . . . . . . 122

VIII-3. Diagram of the proposed interrelationships between the ovary and uterus of the nonpregnant mare. ............ . 129

VIII-4. Diagram of the proposed interrelationships between the ovary and uterus of the pregnant mare 
Abstract of Dissertation Presented to the Graduate Council of the University of Florida in Partial Fulfillment of the Requirements for the Degree of Doctor of Philosophy

\title{
THE ROLE OF PROSTAGLANDINS IN THE UTERO-OVARIAN AXIS OF THE CYCLING AND EARLY \\ PREGNANT MARE
}

\author{
By \\ Michael Walter Vernon \\ June, 1979
}

Chairman: Dr. Daniel C. Sharp

Major Department: Animal Science

The interrelationships between the equine ovary and uterine prostaglandins were studied. Since little is known about the endogenous levels of prostaglandin $F_{2 \alpha}$ (PGF) in the equine uterus, endometrial strips ( $300 \mathrm{mg}$ ) collected from pregnant (P) and non-pregnant (NP) pony mares on various days post-ovulation were incubated ( $2 \mathrm{hr} @ 37 \mathrm{C})$. With PGF quantified by radioimmunoassay, endometrial PGF content and production were found to increase from the early stages of the estrous cycle until Day 16 and then declined. Thus maximal PGF concentrations occurred at a time that corresponds to the expected time of luteolysis, i.e., Day 14. In P mares, PGF content and production capacity increased during the first 16 days of pregnancy in a pattern similar to that of the NP animal; however, PGF continued to increase on Days 18 and 20. Since luteostasis is required for maintenance of pregnancy, these latter findings appear to be contrary to our concept of luteal physiology. 
When ovariectomized mares were injected, daily, for 3 weeks with $(50 \mu \mathrm{g}) 17 \beta$-estradiol (E2), (50 mg) progesterone (P4), or E2 plus P4 (1 week of E2 followed by 2 weeks of P4), endometrial production of PGF was stimulated by all in vivo treatments. Additionally, when endometria from these same animals were incubated in vitro with 3 levels of E2 (1000, 10, $1 \mathrm{ng})$ and one level of P4 $(1.0 \mu \mathrm{g})$, P4 was without effect while E2 dramatically increased PGF production in a dosedependent fashion. In this manner, maximal PGF production occurred in animals receiving exogenous (systemic) P4 and in vitro $\mathrm{E} 2$.

Incubation of NP endometria collected on various days post-ovulation, with $(1.0 \mu g)$ E2 or $(1.0 \mu g)$ P4, indicated that in vitro E2 had 1ittle or no effect on the early stages of the estrous cycle, but was stimulatory on Days 16 and 20, while in vitro P4 was without effect on all days studied. Thus, in vitro stimulation of E2 may be effective only on a uterus that has had prior prolonged systemic P4 exposure. The local effect of the embryo on PGF production was studied by incubating endometria from gravid and non-gravid horns of Day 12 and 18 NP mares. The PGF production in the gravid horn of $P$ mares was higher than the non-gravid horn, while horn differences were not seen in NP mares. A local embryonic influence on uterine PGF production is apparent. Specific binding of PGF to CL from $P$ and NP mares was examined. Studies of the rates of association and dissociation indicated that ${ }^{3}$ H-PGF was bound specifically and 
reversibly to a luteal cell membrane preparation (MP) that was isolated by high speed $(100,000 \mathrm{~g})$ ultracentrifugation. Cross reactivity studies implicated the $9 \alpha-\mathrm{OH}$ and 5,6 cis double bond as major contributors to PGF receptor recognition. The membrane preparation appeared to contain at least two receptor populations, having dissociation constants (Kd) of: $\mathrm{Kd}_{1}=4.19 \times 10^{-11}[\mathrm{M}] ;$ and $\mathrm{Kd}_{2}=9.11 \times 10^{-10}[\mathrm{M}]$. Binding of PGF to CL of the NP mare increased from Day 4 after ovulation, to reach maximal levels by Day 12 and declined thereafter. In pregnancy the binding of PGF continued to increase until Day 18, before it declined on Day 20. The reduction in binding by Day 16 in the NP mare may reflect the process of luteolysis, while high PGF binding capacity of CL between Days 16 and 18 of pregnancy indicated that luteal maintenance during pregnancy is not associated with a reduction of PGF binding capacities. 
CHAPTER I

INTRODUCTION

The mare (Equus caballus) is a seasonally polyestrus mammal that has an estrous cycle of approximately 22 to 24 days. In most cases, the cycle is comprised of 6 days of estrus followed by 16 days of diestrus with 1 uteal regression occurring approximately 14 days after ovulation (Hafez, 1974). At the time of luteolysis, peripheral progesterone levels drop (Sharp \& Black, 1973) and histological degeneration of luteal cells is pronounced (van Niekerk et al., 1975). If fertilization occurs, the process of luteolysis is averted and the corpus luteum (CL) with its progesterone secretion is retained (Hafez, 1974).

Uterine prostaglandin $F_{2 \alpha}$ (PGF) has been proposed as the luteolytic factor of the mare. In support of this hypothesis, it has been demonstrated that luteal regression coincides with the time of maximal concentrations of PGF in the uterine vein (Douglas \& Ginther, 1976) and uterine lumen (Zavy et a1., 1978). Furthermore, exogenous PGF will induce premature luteal regression (Douglas \& Ginther, 1972; Ginther \& Meckley, 1972; Oxender et a1., 1975) and hysterectomy will delay luteolysis (Ginther \& First, 1971). 
The PGF content of the endometrium has also been shown to be temporally related to the process of luteolysis in the non-pregnant cow, ewe, mouse, pig, rat, monkey, and woman (Chapter II). However, in the early stages of pregnancy PGF content is high (Lewis et a1., 1977; Carminati et al., 1975). Since luteostasis is required for maintenance of pregnancy, these latter findings appear to be contrary to luteal physiology. In contrast, incubated homogenized Day 15 pregnant guinea-pig uteri have been shown to produce only $10 \%$ of the PGF that is produced by non-pregnant uteri (Walker E Poyser, 1974).

The PGF content or production of the equine endometrium has as of yet not been studied. This lack of information along with the above perplexing findings of the pregnant animal prompted some of the work presented in this dissertation. Chapter III deals with experiments performed to determine the PGF content and production capabilities of equine endometrium during the estrous cycle and early pregnancy.

The observation that PGF was secreted in a pattern that was temporally associated with the reproductive status of the animal implied that uterine PGF production was under the control of extra-uterine factors. It is now apparent that the ovarian steroids, estrogen and progesterone, enhance the ability of the endometrium to produce PGF (Castracane $\xi$ Jordan, 1975). Estrogen has been demonstrated to increase the concentration of PGF within the uterine flushings of the progesterone primed uterus of the pig (Frank et al., 1978) 
and cow (W. Thatcher, G. Lewis, \& F. Bartol, personal communication). To further assess the modulating effect of estrogen and progesterone, a study was conducted to determine the effects of exogenous (systemic) and in vitro steroids on the ability of the equine endometrium to produce PGF (Chapter IV).

In the pregnant animal, the high levels of PGF contained within the endometrium may be a reflection of endogenous steroid enhancement, since this is a time when both systemic Iuteal progesterone (Allen \& Hadley, 1974) and local fetal estrogen are high. In our laboratory, the incubated equine conceptus has been shown to produce estrone and estradiol (Mayer et a1., 1977) and to possibly convert ${ }^{3}$ H-progesterone into

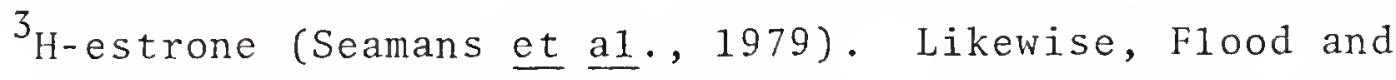
Marrable (1975) have observed, histochemically, the presence of a variety of hydroxysteroid dehydrogenase (HSD) enzymes within the Day 13 equine conceptus. But of particular interest was the appearance of high levels of $17 \beta-H S D$ only on those parts of the uterine endometrium directly opposed to the trophoblast (Flood et al., 1979). This is suggestive of a local conceptus influence on the endometrium. Since the PGF production capacity of the equine endometrium may be locally enhanced by fetal estrogens, the PGF production of the endometrium associated with the conceptus was compared with the PGF production of the endometrium contralateral to the conceptus (Chapter V). 
The PGF induced luteal regression probably involves a direct biochemical interaction with luteal cells. This has been supported by the observation that PGF stimulates the membrane-associated adenyl cyclase system (Marsh, 1971) and that the addition of cyclic adenosine monophosphate to cultures of porcine (Channing \& Seymour, 1970) and monkey (Channing, 1970) granulosa cells stimulates progesterone production. Although the mechanism of action of PGF is not well understood, the involvement of the adenyl cyclase system suggests that the mode of action of PGF is mediated through a membrane receptor. Luteal PGF membrane receptors have been isolated and biochemically characterized in the cow (Kimball E Lauderdale, 1975; Rao, 1976), ewe (Powell et al. , 1974), mare (Kimba11 \& Wyngarden, 1977), and woman (Rao, 1977). It is likely that the PGF membrane receptor may play a role in luteal regression in the cycling mare, or in prevention of luteal demise in the pregnant mare. Therefore, studies were conducted to characterize the equine Iuteal PGF receptor and to assess its possible role in the cycling and early pregnant mare (Chapters VI \& VII). 
CHAPTER II

LITERATURE REVIEW

\section{Control of Luteolysis}

Control of luteolysis was first thought to reside solely within the adenohypophysis. Nalbandov (1961) set forth the theory that the corpus luteum (CL) appeared to have a limited life expectancy that was extended (rescued) in pregnancy by a pituitary luteotrophin. The major experimental evidence for this theory was the demonstration that an injection of progesterone into the pregnant guinea-pig was effective in reducing the size of the $C L$ only if administered within one day of breeding. Progesterone injection on any other day post-mating had no effect on CL size. Assuming that progesterone had a negative feedback on the pituitary, he proposed that "there is discharge of luteotropin hormone over a relatively short period of time, lasting in pigs or guineapigs not longer than 2 to 3 days after ovulation. This single release is sufficient to maintain the $\mathrm{CL}$ for their normal Iifespan during the cycle. No further release of hypophyseal luteotropin occurs unless the female becomes pregnant" (Nalbandov, 1961; p. 138). 
Short (1964) postulated that luteal regression in the non-pregnant animal was the result of a uterine luteolysin. He indicated that Nalbandov's theory did not explain the luteotropic effect of hysterectomy (see next section) nor did it explain the results of an experiment in ewes by Innskeep and co-workers (1962) in which CL of different age on the same ovary regressed in unison at the expected time of 1uteolysis. Short championed a hypothesis, on scant experimentation, that has since been shown to be correct. He stated that "the progesterone secreted by the corpus luteum could stimulate the uterus, for example the uterine glands, to secrete a luteolysin. This substance would be liberated into the circulation and would have a direct effect on the ovary, suppressing the activity of the corpus luteum" (Short, 1964; p. 329). Thus control of luteolysis was now felt by some to be under uterine control.

\section{The Uterus as a Source of the Luteolysin}

A relationship between the uterus and CL was first realized when Leo Loeb (1923) reported that extirpation of the guinea-pig's uterus increased the 1 ifespan of the CL from 15 days to 60 to 80 days. Since that time, the luteostatic response of hysterectomy (HYX) has been observed in the rat (Durrant, 1926), mouse (Anderson et al., 1969), sheep (Ca1dwe11 \& Moor, 1971), rabbit (Asde11 \& Hammond, 1933), cow (Wiltbank \& Casida, 1956), pig (du Mesnil du Buisson, 
1966), and horse (Ginther, 1967), but not in the monkey or human (Wiqvist et a1., 1970). Furthermore, uterine transplants to ectopic sites can, at least partially, reverse the effect of HYX (Caldwell, 1970). In the case of the mare, HYX on the second day after the end of an estrus period. maintained CL weight at $3300 \mathrm{mg}$ on Day 30 post-surgery, while sham HYX mares had a significantly lower luteal weight of $309 \mathrm{mg}$ on Day 30 post-surgery (Ginther \& First, 1971).

In nearly all species studied, a unilateral, i.e. local, relationship has been demonstrated between the uterus and the CL. After a unilateral hysterectomy (UHYX), luteal regression was observed only when the UHYX was contralateral to the CL and vascular continuity between the uterus and CL was unbroken (Ginther, 1967). However, UHYX of the rabbit (Ginther, 1967) and mare (Ginther \& First, 1971) was ineffective in altering the 1 ifespan of the CL. When mares were UHYX or HYX on the second day after estrus mean weights of luteal tissue, 30 days later, in the HYX, UHYX ipsilateral to CL, UHYX contralateral to CL, and sham HYX were $3337 \mathrm{mg}$, $2237 \mathrm{mg}$, $3006 \mathrm{mg}$, and $503 \mathrm{mg}$, respectively (Ginther \& First, 1971). Since there was no significant difference in the response of $\mathrm{CL}$ to uterine surgery, the uterine influence was thought to follow a systemic vascular route.

Denamur and co-workers (1966) were able to prolong secretion of ovine luteal progesterone by HYX at mid-cycle. However, subsequent hypophysectomy on Day 20 post-ovulation 
resulted in a rapid decline in progesterone secretion, commencing $48 \mathrm{hr}$ after the operation (Denamur et al., 1966). Thus in the case of the HYX ewe, maintenance of the CL requires daily, basal output of pituitary luteotropin. However, this luteotropin plays a permissive role since luteal regression can be evoked at any time with exogenous PGF (see next section).

\section{$\underline{\text { PGF as the Luteolysin }}$}

Luteolytic substances of uterine origin have been shown to influence CL function in HYX animals. Infusion of reconstituted freeze-dried uterine venous plasma (Caldwell \& Moor, 1971) and ether-soluble uterine endometrial extracts (Kiracobe et al., 1966) depressed luteal function in the HYX ewe, while porcine uterine flushings were shown to have a cytolytic action upon cultured granulosa ce1ls (Shomberg, 1967).

Crude cell suspensions and aqueous extracts of bovine endometria collected on Days 10 to 13 of the estrous cycle were shown to reduce the luteal weight and progesterone content of hamster CL (Lukaszewska \& Hanse1, 1970). Most of the luteolytic activity of the extract was precipitated in a $55 \%$ ammonium sulfate fraction. Further fractionation of the precipitate on columns of Sephadex G-100 yielded an active fraction having a partition coefficient of 0.271 . At this time Lukaszewska and Hansel felt, "the results suggest 
that the active factor is a large molecular weight protein, or some smaller molecule bound to protein" (Lukaszewska \& Hanse1, 1970; p. 261). Hanse1, Concannon, and Lukaszewska (1973) later reported that the 55\% ammonium sulfate fraction contained some 1 ipids and that an ethanolic extract of the precipitate was as effective as the entire precipitate in reducing luteal weight and progesterone content of pseudopregnant hamster CL. However, further partitioning of the ethanolic extract with thin layer chromatography suggested that only the fraction containing free fatty acids was luteolytic. The authors indicated that "the bovine endometrium might exert its Iuteolytic effect by providing the CL with one (arachidonic acid) or more precursors which are converted into prostaglandins, or other luteolysin in situ by the luteal tissue" (Hansel et a1., 1973; p. 239). This was further supported by the finding that arachidonic acid given to cattle on Day 12 and 13 of the estrous cycle was luteolytic (Shemesh et a1., 1974).

The uterus has been shown to contain large amounts of prostaglandins (Pickles, 1959) and in 1969 Pharriss and Wyngarden (1969) were the first to report that exogenous PGF lowered the progesterone content of pseudopregnant rat ovaries. Exogenous PGF was luteolytic in the rabbit (Gutknecht et a1., 1966), guinea-pig (B1atchley \& Donovan, 1972), mouse (Saksena \& Lau, 1973), gerbil (Chaichareon et a1., 1974), hamster (Johnson \& Hunter, 1970), cow (Lauderdale, 1972), pig (Moeljono et a1., 1977), sheep (McCracken et a1., 1970), mare 
(Douglas \& Ginther, 1972), and monkey (Kirton et al., 1970) but not in the human (Wiqvist et al., 1970).

The luteolytic effect of exogenous PGF in the mare was first demonstrated by Douglas and Ginther in 1972. A11 mares that were subcutaneously injected with PGF returned to estrus 3 to 4 days after treatment (Douglas \& Ginther, 1972). Since 1972, PGF was found to be luteolytic in the mare when administered intravenously (Douglas et al., 1976), intramuscularly (Spincemaille et al., 1975), intrauterine or intraluteal (Douglas \& Ginther, 1975). Furthermore, PGF was luteolytic if given to cycling (Douglas \& Ginther, 1972), pregnant or pseudopregnant mares (Kooistra \& Ginther, 1976). However, the early CL (< Day 5) of the non-pregnant mare was refractory to exogenous PGF (Douglas \& Ginther, 1972; Ginther \& Meckley, 1972; Oxender et a1., 1975). The lowest effective dose for a luteolytic effect in the non-pregnant mare was determined to be $1.25 \mathrm{mg}$ or $8.8 \mu \mathrm{g} / \mathrm{kg}$. This was not expected, since on a body weight basis, considerably higher subcutaneous doses are required to induce luteolysis in other species (144 $\mathrm{\mu g} / \mathrm{kg}$ for sheep, Douglas if Ginther, 1973; $30 \mathrm{mg}$ for cattle, Lauderdale, 1972). This high sensitivity is further perplexed by the apparent lack of a local transfer (counter-current) of PGF between the equine uterus and ovary (Ginther \& First, 1971).

If uterine PGF is the luteolytic agent, its secretory patterns should be temporally associated with luteal regression. The concentration of $\mathrm{PGF}$ in the uterine venous 
drainage of the non-pregnant sheep (Bland et al., 1971), sow (Gleeson et al., 1974), cow (Shemesh \& Hanse1, 1975), rat (Saksena \& Harper, 1972a), guinea-pig (Blatchley et a1., 1972), and mare (Douglas \& Ginther, 1976) are maximal at the expected time of luteolysis.

In the mare, luteal regression occurs approximately 14 days after ovulation. At this time, peripheral progesterone levels drop (Sharp \& Black, 1973; Douglas \& Ginther, 1976) and the histological degeneration of the luteal cell is pronounced (van Niekerk et $\underline{\text { al. }}$, 1975). Douglas $\xi_{\text {G }}$ Ginther (1976) demonstrated that uterine venous concentration of PGF in the anesthetized non-pregnant mare rose from $1.4 \mathrm{ng} / \mathrm{m} 1$ at the time of ovulation to a maximal concentration of $14.9 \mathrm{ng} / \mathrm{m} 1$ on Day 14 post-ovulation and declined to $6.4 \mathrm{ng} / \mathrm{m} 1$ on Day 18 . In a similar fashion, Zavy and co-workers (1978) indicated that the total amount of PGF within the uterine lumen of the unanesthetized mare rose from $52.19 \mathrm{ng}$ on Day 4 to a maximal concentration on Day 14 of $1,133.81 \mathrm{ng}$ and declined to 24.4.06 ng by Day 20. In the early pregnant (anesthetized) mare, the uterine venous concentration of PGF was lower than that found in the non-pregnant animal (Day $10=4.3$, Day $14=9.3$, and Day $18=7.3 \mathrm{ng} / \mathrm{ml}$; Douglas \& Ginther, 1976). Thus at a time of luteal maintenance the uterine output of PGF appears to be 1ow. This has also been observed in the ewe (Barcikowski et a1., 1974) and pig (Noeljono et a1., 1977).

The PGF content of the uterine endometrium has also been shown to be temporally related to the time of luteolysis 
in the non-pregnant cow (Shemesh \& Hanse1, 1975), ewe (Wilson et $\underline{\text { al }} .$, 1972), mouse (Saksena et a1., 1974), rat (Saksena \& Harper, 1972a), monkey (Demers et $\underline{\text { a1. }}$, 1974), and woman (Singh et al., 1975); while, the endometrial PGF content in the ewe (Lewis et a1., 1977) and rat (Carminati. et al., 1975) increased during the early stages of pregnancy. Since luteostasis is required for maintenance of pregnancy, these latter findings appear to be contrary to in vivo physiology. In contrast, Walker and Poyser (1974) incubated homogenized Day 15 pregnant and non-pregnant guinea-pig uteri and demonstrated that the production of PGF in the pregnant animal was lower than the non-pregnant (15 ng vs $110 \mathrm{ng} / \mathrm{mg}$ homogenate, pregnant vs non-pregnant). In Chapter III, experiments are described which were performed to determine the PGF content and production capabilities of the equine endometrium during the estrous cycle and early pregnancy.

A possible explanation for the high PGF levels within the pregnant uterus has been set forth by Bazer \& Thatcher (1977). Based on the secretory patterns of PGF (Moeljono et al., 1977; Frank et al., 1978) and purple protein (Chen et $\underline{a} 1 ., 1975)$ by porcine endometrium, they have suggested that the embryo influences the direction of movement of uterine secretions. In pregnancy, uterine secretory products, e.g., PGF, move toward the uterine lumen (exocrine secretion); while, in the absence of embryonic influence, uterine secretions proceed toward the endometrial stroma and associated vascular system (endocrine secretion) (Bazer \& Thatcher, 
1977). In this fashion, uterine PGF production may be sequestered within the uterus during pregnancy and may never reach the CL. The experimental evidence for this hypothesis was derived primarily from the following three observations: 1) The uterine venous concentrations of PGF in the pregnant and the estrogen induced pseudopregnant gilt were lower than those of the non-pregnant animal; while, the uterine luminal concentration of PGF and porcine purple glycoprotein was higher in the pregnant and pseudopregnant sow than in the non-pregnant animal (Moeljono et al., 1976; Moeljono et al., 1977; Frank et a1., 1978); 2) the porcine embryo secretes estrogen (Perry et al., 1973; Perry et a1., 1976); and 3) immunofluorescent studies have indicated that the porcine purple glycoprotein of the endometrium (Chen et al., 1975) and the PGF of the primate oviduct (Ogra et a1., 1974) were secreted in a luminal direction when under the in vivo influence of pregnancy and in a vascular direction in its absence.

\section{Steroid Modulation of PGF Production}

The possibility of steroids controlling endometrial PGF was first suggested in 1972 when injections (10 $\mu \mathrm{g}$, S.C.) of estradiol benzoate into the guinea-pig (Day 4 to 6 of the estrous cycle) dramatically increased the concentration of PGF in the utero-ovarian vein (Blatchley et al., 1972). These findings immediately prompted studies in the ewe 
(Caldwell et al., 1972), hamster (Saksena \& Harper, 1972b), and rat (Castracane \& Jordan, 1975) demonstrating that exogenous estrogen and progesterone were both stimulatory to PGF production and also that estrogen was a more potent stimulator than progesterone. Caldwell postulated the possibility that in the case of the ewe, "each estrous cycle is terminated due to the rise in estradiol (on Day 13) which causes a release of $\mathrm{PGF}_{2 \alpha}$ from the uterus which in turn causes luteal regression and the loss of progesterone" (Caldwell et al., 1972; p. 226). In the case of the ovariectomized rat, Castracane and Jordan (1975) have shown a positive synergism between estrogen and progesterone. Optimal conditions for PGF biosynthesis occurred when $1.0 \mathrm{\mu g}$ of estradiol was given to animals that had been pretreated for two days with progesterone ( $2 \mathrm{mg} /$ day). Similarly, estrogen has been shown to increase the concentration of PGF within the uterine flushings of the luteal phase pig (Frank et al., 1978) and cow (W. Thatcher, G. Lewis, \& F. Bartol, personal communication). No research data are available on the interrelationships between ovarian steroids and PGF production by equine endometrium. This lack of information was the stimulus for a portion of this dissertation (Chapter IV).

\section{The Membrane Receptor for Prostaglandins}

kuchl and co-workers (1970) at the Merck Institute for Therapeutic Research demonstrated a distinct dose-dependent 
relationship between prostaglandins (PG) and cyclic adenosine monophosphate (AMP) formation in isolated mouse ovary. This finding propagated a series of experiments that they had hoped would be the basis for a PG radio-1igand assay. These binding studies with the mouse ovary were unsuccessful (Kueh1 \& Humes, 1972); therefore, the Merck group initiated experiments on the rat lipocyte. In 1972, competition studies with $\mathrm{PGE}_{1}-{ }^{3} \mathrm{H}$ demonstrated the presence of a PG receptor on the rat adipocyte $(1000$ G) membrane (Kueh1 \& Humes, 1972). The affinity of PGE for the adipocyte receptor was greater than that of PGF and PGA; an observation consistent with their relative potencies in stimulating cyclic AMP. The dissociation constants $(\mathrm{Kd})$ for $\mathrm{PGE}_{1}$ and $\mathrm{PGE}_{2}$ were determined by Lineweaver-Burk plots to be $3 \times 10^{-9}$ [M].

At this same time, Marsh at the University of Miami demonstrated that, in the case of the bovine CL, PGs also stimulated the adenyl cyclase system. Prostaglandins $E_{1}$ and $\mathrm{E}_{2}$ elicited a $130 \%$ increase in cyclic AMP formation (relative to controls) and $\mathrm{PGF}_{2 \alpha}$ a $40 \%$ increase (Marsh, 1971). With the inference that PG interacted with the membrane-associated adenyl cyclase system, a search was initiated to characterize a luteal membrane receptor for PG. In 1974, Rao, of the University of Louisville, isolated and characterized a PGE receptor in the cow (Rao, 1974) and powe11 and co-workers from Sweden presented evidence for the existence of an ovine PGF luteal receptor (Powell et al., 1974). Since that time, a PGF receptor has been found on luteal membranes from the 
Cow (Kimball \& Lauderdale, 1975; Rao, 1976), woman (Rao, 1977), and mare (Kimball \& Wyngarden, 1977).

Scatchard analysis (Scatchard, 1949) of the PGF bovine CL receptor indicated a heterogenic population of receptors having Kds of $1.3 \times 10^{-9}[\mathrm{M}]$ and $1.0 \times 10^{-8}[\mathrm{M}]$ (Rao, 1974). However, a single homogenous receptor population was shown to exist in the cow $\left(\mathrm{Kd}=2.1 \times 10^{-8}[\mathrm{M}]\right.$; Kimball \& Lauderdale, 1975), sheep (Kd $=1 \times 10^{-7}[\mathrm{M}]$; Powell et a1., 1974), and mare (Kd $=3.2 \times 10^{-9}[\mathrm{M}]$; Kimball \& Wyngarden, 1977).

The equine membrane receptor preparation described by Kimball and Wyngarden (1977) required 1.5 to 2 hrs to reach equilibrium with PGF at $37 \mathrm{C}$ and was displaceable, in a dosedependent fashion with radioinert PGF. Competition studies with several natural PGs for the PGF receptor indicated specificity for the $9 \alpha$-hydroxyl moiety and the 5,6-cis double bond. However, the specific binding of PGF in luteal tissue collected on Days (n), $7(2), 8(2), 10(1), 11(1)$, and $15(1)$ of the estrous cycle was determined to be devoid of any physiological patterns (51258\&52252, $23629 \& 38159,25548$, 15317, \& $30585 \mathrm{DPM} / \mathrm{mg}$ membrane protein for the above days, respectively). As a part of this dissertation, a study was conducted to further characterize the equine luteal PGF receptor and to assess its possible physiological role in the cycling and early pregnant mare (Chapter VII).

In addition to binding to plasma membranes, PGF has recently been demonstrated to bind to several cytoplasmic inclusions. Utilizing differential and discontinuous sucrose 
gradient centrifugation, PGF was found to bind specifically to the nuclear, mitochondrial, microsomal, cytosol, and membrane fractions $(4.4,32.4,18.9,5.1$, and $192.5 \mathrm{fmol} / \mathrm{mg}$ protein, respectively) (Rao \& Mitra, 1977). Since the total mitochondrial fraction contained both mitochondria and lysosomes, it was subfractionated and only the lysosomal enriched fraction bound PGF (Rao \& Mitra, 1978). Lysosomal PGF binding may be interpreted as further evidence for the role of the lysosome in hormone action (Szego, 1974) or internalization and catabolism of the membrane receptor within the lysosome (Chen et a1., 1978).

\section{Mechanism of Action of PGF}

Although the mechanism of action of the luteolytic effect of PGF is not well understood, the presence of a membrane receptor and the involvement of the adenyl cyclase system suggests that the primary site of action of PGF is at the luteal cell level. However, some evidence is available to indicate that PGF may exert its luteolytic effect via vasoconstriction (Pharriss, 1970) or hypophyseal interaction (Labsetwar, 1970$)$.

The possibility that PGF may induce luteolys is by restricting the oxygen and nutritive supply to the rat and rabbit ovary was demonstrated by Pharriss (1970) when a single intravenous injection of PGF elicited a rapid drop in ovarian vein drainage. Luteolysis, through anoxia, was 
also indirectly supported by the initial observation that in vitro PGF stimulated luteal progesterone production (Behrman et al., 1971; Speroff \& Ramwe11, 1970). But contrary results indicating in vitro PGF inhibition of progesterone production (O'Grady et a1., 1972; Henderson \& McNatty, 1975 ) and no vascular effect (McCracken et a1., 1971) have severely weakened the argument. Furthermore, Janson et al. (1975) has indicated that the vascular effect may be an artifact of low systemic arterial pressure. Thus the lower venous blood pressure observed by some may just be a result of a hormonal lowering of the systemic pressure.

Another appealing theory was the possibility of an interrelationship between $\mathrm{PGF}$ and the anterior pituitary. A potential role for the equine pituitary was implicated when Pineda and co-workers (1972) induced CL regression with an antisera against the equine pituitary. However, the role of the equine pituitary appears to be permissive since Garcia and Ginther (personal communication) have indicated that the luteotropic action of human chorionic gonadotropin (HCG) cannot override the luteolytic action of PGF. The daily injection of 1500 IU of HCG from Day 9 to Day 17 lengthened the lifespan of the CL by four days. This luteotropic response to HCG was ineffective in altering $P G F$ induced $C L$ regression. In the rat, PGF has been shown to increase the content of pituitary LH (Labsetwar, 1970) and LH has been demonstrated to be luteolytic in rats (Leavitt \& Acheson, 1972), rabbits 
(Stormshak \& Casida, 1965), and hamsters (Greenwald, 1967). However, this positive feedback system has not been observed in any of the domestic animals (Cerini et al., 1972).

Therefore, PGF induced luteal regression probably involves a direct biochemical reaction with the luteal cell. As previously stated, this is supported by the presence of the PGF receptor and the involvement of the membraneassociated adenyl cyclase system. Furthermore, the addition of cyclic AMP to cultures of porcine (Channing \& Seymour, 1970) and monkey (Channing, 1970) luteinized granulosa cells stimulated progesterone production. Henderson and McNatty (1975) have suggested a biochemical mechanism of action for the luteolytic process. Using the membrane model of Garren et al. (1971), they viewed the membrane as a dynamic mosaic (Singer \& Nicholson, 1972), containing regulatory, coupling, and catalytic units. They postulate that binding of $\mathrm{LH}$ to the regulatory unit enhances production of cyclic AMP, which in turn stimulates the protein kinase activity of the catalytic unit. The kinase then phosphorylates and activates cholesterol esterase to stimulate progesterone production. During luteolysis, PGF would bind to the membrane (coupling unit) and prevent the LH regulatory unit from activating the catalytic unit and thus halt the biochemical cascade leading to progesterone production (Henderson \& McNatty, 1975). The theory, however, is not compatible with the findings of Marsh (1971) that PGF stimulates in vitro cyclic AMP production by the CL. Henderson and MCNatty (1975) also offer an 
explanation for the inability of the early CL to respond to PGF (Douglas \& Ginther, 1972). After the ovulatory LH surge, the luteal membrane may be saturated with $L H$ and this high saturation may induce conformational change in the membrane that interferes with luteal PGF uptake. Due to the dynamic equilibrium of a receptor, LH could slowly dissociate from the membrane and facilitate subsequent PGF uptake and regression (Henderson \& McNatty, 1975). The authors support this second hypothesis with the findings of Hichens and coworkers (1974) where PGF was demonstrated to decrease the HCG binding capacity of luteal tissue, "possibly by inducing conformational changes" (Henderson \& McNatty, 1975; p. 791). However, final proof of this hypothesis awaits experimental evidence indicating that LH interferes with PGF binding. Rao (1974) indicated that neither $\mathrm{HCG}$ and $\mathrm{PGE}_{1}$, nor PGE and PGF compete with each other for their respective receptors. 


\section{CHAPTER I I}

THE ENDOMETRIAL PGF IN THE

INTACT PREGNANT AND CYCLING MARE

Prostaglandin $F_{2 \alpha}$ (PGF) has been proposed as the uterine luteolytic substance in the mare (Chapter II). Maximal levels of PGF occur in the uterine Iumen (Zavy et a1., 1978) and uterine venous drainage (Douglas \& Ginther, 1976) at the expected time of luteolysis. Since 1ittle is known about the endogenous levels of PGF in the equine endometrium, this study was conducted to evaluate PGF content and production capabilities during the estrous cycle and early pregnancy.

\section{Materials and Methods}

Test Anima1s

Tissues for this experiment were obtained from 41 reproductively sound pony mares of mixed breeding, having a mean weight at the time of experimentation, of $175.6 \pm 38.7$ $(\bar{X} \pm$ S.D.) $\mathrm{kg}$ (range $86-306 \mathrm{~kg})$. During the course of the experiment, the animals were maintained ad libitum on pasture and supplemental hay at the Horse Research Center in Lowe11, F1orida. 
The animals used in the non-pregnancy study were derived from a herd of 68 mares in the summer of 1977 and, in addition to the following endometrial study, were also involved in a luteal PGF $2 \alpha$ binding study (Chapter VII). The day of ovulation (Day 0) was determined by daily teasing and palpation per rectum and on the day of ovulation the mares were assigned randomly for surgery on either Day 4, 8, 12, 16, or 20 postovulation. A total of 20 non-pregnant mares, four per day, was used.

The animals used in the pregnancy study were derived from a herd of 42 mares in the summer of 1976 which, in addition to being in this study and the luteal PGF binding study (Chapter VII), were also involved in studies concerned with uterine secretions by Michael T. Zavy and studies of embryonic steroidogenic capabilities by Richard E. Mayer. Animals were bred once daily if their ovaries contained a follicle of ovulatory size (35-60 $\mathrm{mm}$ diameter). When possible, mating was natural; however, artificial insemination was utilized if there was a shortage of available stallions. On the day of ovulation (Day 0 ), mares were randomly assigned for surgery on either Day 4, 8, 12, 14, 16, 18, or 20 post-ovulation with pregnancy confirmed by the presence of an embryo at surgery. Conception rate at the termination of the study was $76 \%$. As determined at surgery, three mares were assigned to Days 8, 12, and 14, and four mares to Days 14, 18, and 20 of gestation. No embryos were discovered in the oviducts or uteri of Day 4 bred mares 
and therefore this day was not included in the pregnancy study.

\section{Surgery}

To reduce bowel contents and motility during surgery, solid food was restricted $24 \mathrm{hr}$ prior to surgery. On the day of surgery, the animals were weighed and tranquilized with Acepromazine (see Appendix I for 1 isting of commercial suppliers) ( $4 \mathrm{mg} / 45 \mathrm{~kg}$ body weight). General anesthesia was induced with a fast-acting barbiturate (1 g Pentotha1/150 kg body weight) and 5\% fluothane gas at a flow rate of 4 to 5 $1 / \mathrm{min}$. After the proper plane of anesthesia was attained (2-10 min), general anesthesia was maintained for the remainder of the surgery at 1 to $2 \%$ halothane gas, at a flow rate of $1-31 / m i n$. The animals were then placed in dorsal recumbency and the surgical area was shaved and scrubbed with an iodine solution (Betadine). In the pregnancy study a complete ovario-hysterectomy was performed via a mid-saggital incision ( $~ 150 \mathrm{~mm}$ ) in the abdomen; while, in the nonpregnancy study entry was via a para-lumbar incision and only the ovulatory ovary and a segment of the adjacent uterine horn were ablated. The removed tissue was placed on ice and brought immediately to the laboratory for subsequent processing. After the incision area was closed, the wound was sprayed with a topical sulfa drug and protected temporarily with surgical tape. Each animal then received 1,000,000 IU of 
penicillin and, after recovery, was placed in a post-operative stall for observation.

\section{Incubation Procedure}

In the pregnancy study, $60 \mathrm{ml}$ of hypertonic saline $(0.33$ M) were injected into the extirpated uterus at the uterotubal junction and the embryo and uterine secretions were flushed through an incision made in the uterine horn. As explained before, the embryos, uterine secretions, and ovaries were used in separate studies.

The uterus was cut along its longitudinal axis and the endometrium was dissected bluntly from the myometrium and placed into a flask containing chilled (4 C) phosphate buffered saline (PBS) $(\mathrm{pH}=7.4)$. The endometrium was then cut into strips, weighed ( $300 \mathrm{mg} / \mathrm{strip}$ ), placed into $25 \mathrm{ml}$ Erlenmeyer flasks containing PBS and kept on ice until incubation. Endometrial strips from pregnant animals were derived from the body of the uterus, while the strips from non-pregnant animals were derived from the medial portion of the uterine horn, ipsilateral to the ovulatory ovary.

After endometrial strips were collected, two strips each were transferred to glass test tubes containing $5.0 \mathrm{ml}$ of Krebs-Ringer Carbonate-Bicarbonate buffer (KRB) and frozen immediately. The buffer system was constructed according to the procedure outlined by Umbreit and co-workers (1957). Unincubated samples were assayed by radioimmonoasay at the 
termination of the experiment for PGF concentration in the endometrium prior to incubation, i.e., endogenous PGF content. Two additional strips each were transferred to $25 \mathrm{ml}$ Erlenmeyer flasks containing $5.0 \mathrm{ml}$ KRB. Serum bottle caps were placed on the flasks containing endometrium and KRB and the flasks were flushed for $30 \mathrm{sec}$ with $95 \%$ oxygen5\% carbon dioxide. The flushing step was accomplished by piercing the serum cap with two 18 gauge hypodermic needles, using one needle as a gas inlet and the second as a vent. After flushing, the needles were removed and the flasks were placed in an incubator-shaker ( $\& 37 \mathrm{C} \& 1$ stroke/sec). The endometrium was incubated for $2 \mathrm{hr}$ and then placed into glass test tubes and frozen until it was radioimmunoassayed for PGF. The concentration of endometrial PGF within these samples represents the total amount of PGF present after the two hour incubation (i.e., total production \& endogenous content). In addition to the two treatments just described, endometrial strips from non-pregnant animals were also incubated, in duplicate, in media containing $1.0 \mathrm{\mu g}$ estradiol178 or $1.0 \mu \mathrm{g}$ progesterone. To construct the steroid treatments, steroids in a $95 \%$ ethanolic solution were added directly to the $25 \mathrm{ml}$ incubation flasks, dried, and resuspended in $5.0 \mathrm{~m} 1 \mathrm{KRB}$.

\section{Radioimmunoassay for PGF}

The concentration of PGF in the endometrial incubation was measured with a double antibody radioimmunoassay. The 
first antibody was donated by Dr. Kenneth T. Kirton of the Upjohn Company, Kalamazoo, Michigan, and was generated in rabbits by subcutaneous injections of $\mathrm{PGF}_{2 \alpha}$ conjugated to bovine serum albumin at the $\mathrm{C}_{1}$ carbon. The second antibody, purchased from Cappe1 Laboratories, Inc., was generated in goats against 1 ight and heavy IgG chains purified from rabbit serum. Radioactive $\mathrm{PGF}_{2 \alpha}$ (NET-345, Lot 932-121) was purchased from New England Nuclear. The PGF $2 \alpha$ molecule was labelled at the $\mathrm{C}_{9}$ position with tritium and had a specific activity of $10.9 \mathrm{Ci} / \mathrm{mmol}$. The radioinert $\mathrm{PGF}_{2 \alpha}$ was a $\mathrm{gift}$ from Dr. John E. Pike of the Upjohn Company.

Measurement of PGF in the endometrial incubation was performed after tissues from both pregnant and non-pregnant animals were collected. Samples were thawed at ambient temperature $(23 \mathrm{C})$ and homogenized in a Potter-type hand homogenizer. The homogenizations and al1 subsequent procedures were conducted at $4 \mathrm{C}$ with ice baths and mechanical refrigeration. The homogenate $(100 \mu 1)$ was transferred to a test tube containing $900 \mu 1$ of absolute ethanol and vortexed for $5 \mathrm{sec}$. The mixture was then centrifuged at $1086 \mathrm{G}$ for $10 \mathrm{~min}$. A portion $(100 \mu 1)$ of the resulting supernatant was transferred into $10 \mathrm{~mm} \times 75 \mathrm{~mm}$ culture tubes, dried, and resuspended in $100 \mu 1$ of Tris-HCL buffer $(\mathrm{pH}=8.0)$. Usually 32 endometrial extracts (unknowns) were run in duplicate, between two standard curves which were composed of ten reference points ranging from $10 \mathrm{pg}$ to $10 \mathrm{ng}$ of authentic 
$\mathrm{PGF}_{2 \alpha}$. The radioimmunoassay procedure, described elsewhere (Moeljono, 1975), required an incubation period of $48 \mathrm{hr}$ at $4 \mathrm{C}$. At the end of the incubation, the test tubes were centrifuged at $1086 \mathrm{G}$ for $20 \mathrm{~min}$ and $500 \mu 1$ of the resulting supernatant were counted for $5 \mathrm{~min}$ in $4.0 \mathrm{ml}$ cocktail $(3.9 \mathrm{~g}$ PPO, $0.1 \mathrm{~g}$ POPOP/1 toluene-20\% triton $\mathrm{X}$ ) in a Beckman LS-300 liquid scintillation spectrophotometer.

The concentration of PGF in the unknowns was calculated from the equation of the line derived from a logit transformation of the standard curve values. The equation for the line of the standard curve was calculated by a least squares regression program on a Monroe 1860 calculator. The concentration of PGF in the ethanolic extract was corrected for procedural dilutions and endometrial mass, and expressed as ng PGF/mg endometrium.

The radioimmunoassay has been previously validated for the measurement of PGF in porcine plasma (Moeljono, 1975; Moeljono et a1., 1977) and equine uterine secretions (Zavy et a1., 1978). For the purpose of validating the assay for the endometrial extract, increasing concentrations of authentic $\mathrm{PGF}_{2 \alpha}$ were added to an endometrial homogenate (range 1 to $50 \mathrm{ng}$ ) and processed as described previously. The amount of PGF recovered in the assay (after subtraction of the 0 tube) was graphed against the amount of PGF added to the homogenate (Fig. III-1) and the resulting line verified the accuracy of the extraction procedure and also indicated the possible absence of any extraneous endometrial competitors. During the course of the 
Fig. III-1. Recovery of PGF $2 \alpha$ added to endometrial homogenates prior to extraction. 


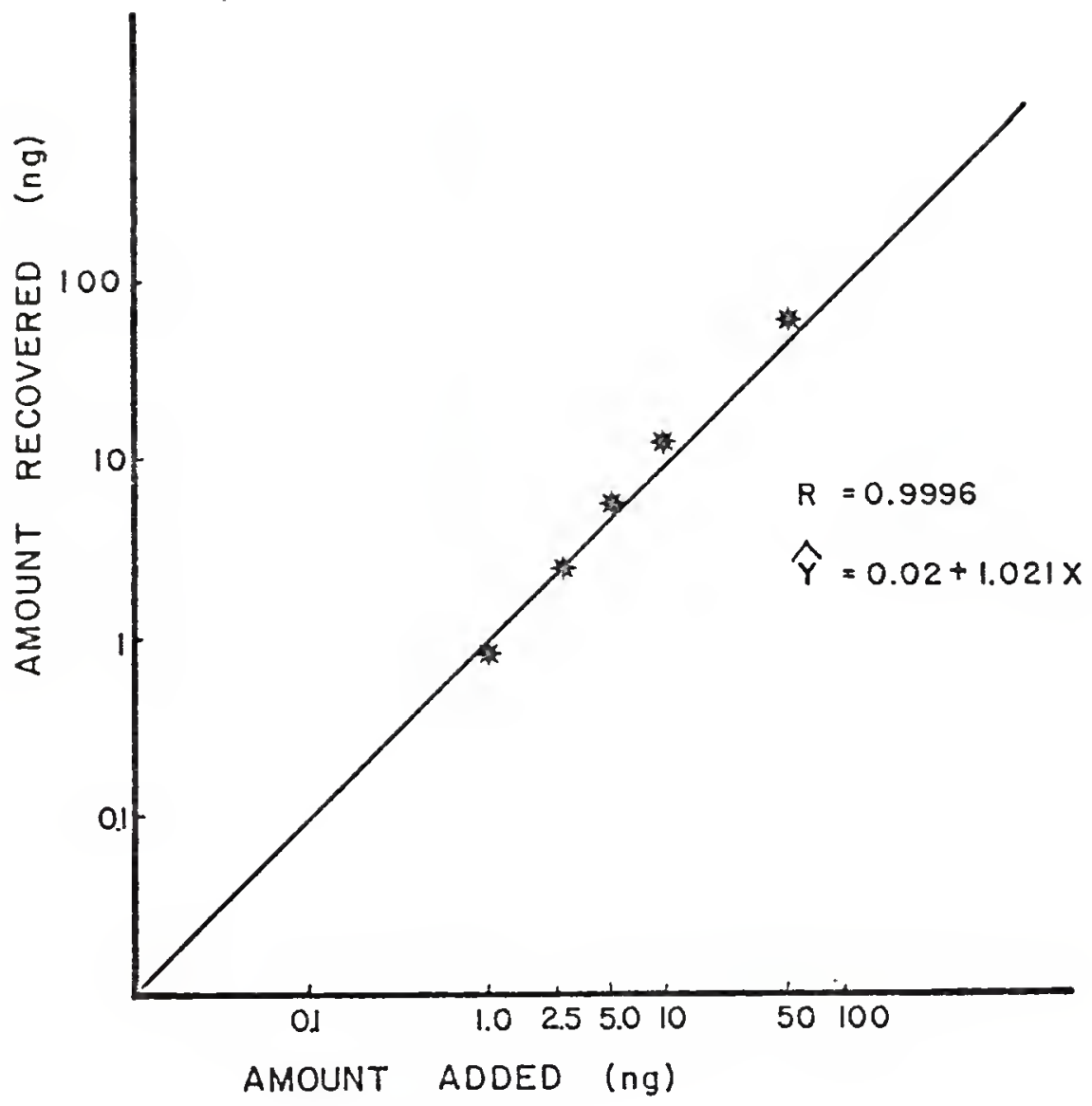


assay, the interassay coefficient of variability was $11.63 \%$ $(n=7$ e $500 \mathrm{pg})$ and the intrassay coefficient of variability was $5.89 \%(\mathrm{n}=6$ e $500 \mathrm{pg})$. Since the recovery of radioactive $\mathrm{PGF}_{2 \alpha}$ in this extraction system was found to be $102.99 \pm 1.2 \%(\bar{X} \pm$ S.D. $)$, no corrections were made for procedural losses. The specificity of the assay (Cornette et $\underline{\text { al. }}$, 1972), as shown by cross reactivity studies, indicated that the only major competitor for the first antibody was PGF $1 \alpha(\sim 8 \%)$. Additional1y, Fenwick and co-workers (1977) reported the presence of large amounts of 6 keto PGF $1 \alpha$ within the rat uterus, and Kimball of the Upjohn Company suggests that 6 keto $\mathrm{PGF}_{1 \alpha}$ cross reacts $(\sim 1 \%)$ with the $\mathrm{PGF}_{2 \alpha}$ antibody (Kimba11, personal communication). For this reason the results of the assay are interpreted as a measure of a PGF-1ike molecule and not specifically $\mathrm{PGF}_{2 \alpha}$.

\section{Statistical Design}

Analysis of data for Treatment and Day effects was by analysis of the variance. Treatments were $\mathrm{T} 1=$ content (no incubation), $\mathrm{T} 2=2 \mathrm{hr}$ incubation, $\mathrm{T} 3=\mathrm{T} 2+1.0 \mu \mathrm{g}$ progesterone, and $\mathrm{T} 4=\mathrm{T} 2+1.0 \mu \mathrm{g}$ estradiol. Since variability due to animal was random and since there was an unequal distribution of animals within treatments, the data were representative of a mixed model with unequal subclass numbers (Steel \& Torrie, 1960). With this in mind, the data were analyzed with the LSML76 computer program developed by 
Dr. Walter R. Harvey of Ohio State University. The statistical models submitted to the computer are shown in Tables III- 1 and III-2. Since the tissue collection was completely confounded by year and locus of sampling, statistical inferences between these two studies were impossible and the data were thus analyzed separately.

\section{Results and Discussion}

The content and production capabilities of endometrial PGF in the intact pregnant and non-pregnant mare are shown (Tables III- 3 \& III-4; Figs. III-2-7). In the non-pregnant mare a significant Day $(\mathrm{P}<.0001)$ and in vitro Treatment effect $(\mathrm{P}<.0001)$ as well as a Treatment $\mathrm{x}$ Day interaction $(\mathrm{P}<.0077)$ were detected (Table III-1). For the non-pregnant study, the Treatments were $\mathrm{T} 1$ = content, $\mathrm{T} 2$ = incubation, $\mathrm{T} 3=\mathrm{T} 2$ with progesterone, $\mathrm{T} 4=\mathrm{T} 2 \mathrm{with}$ estradiol. Due to the Treatment $x$ Day interaction, the in vitro Treatments within each Day were compared by orthogonal contrasts. Additional1y, the time trends within each Treatment (reduced statistical model) were analyzed with polynomial regression. These subsequent analyses were performed with the Statistical Analysis System (SAS) computer program (procedure GLM) and least squares means and SEM from this reduced statistical model are shown in Tables III-3 and III-4. The production capacity of the non-pregnant endometrium increased $(P<.0001)$ from estrus until Day 16 post-ovulation and 


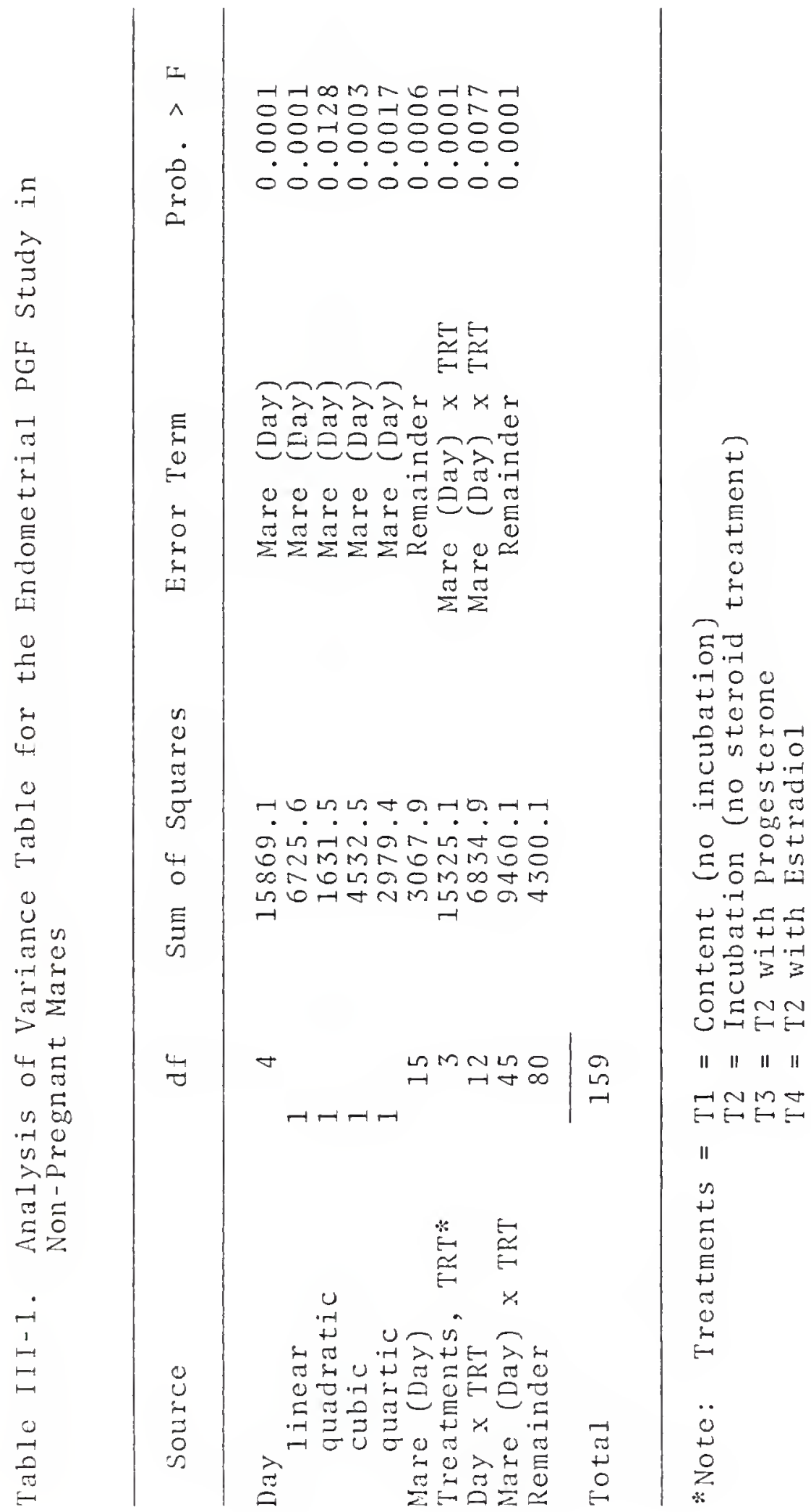




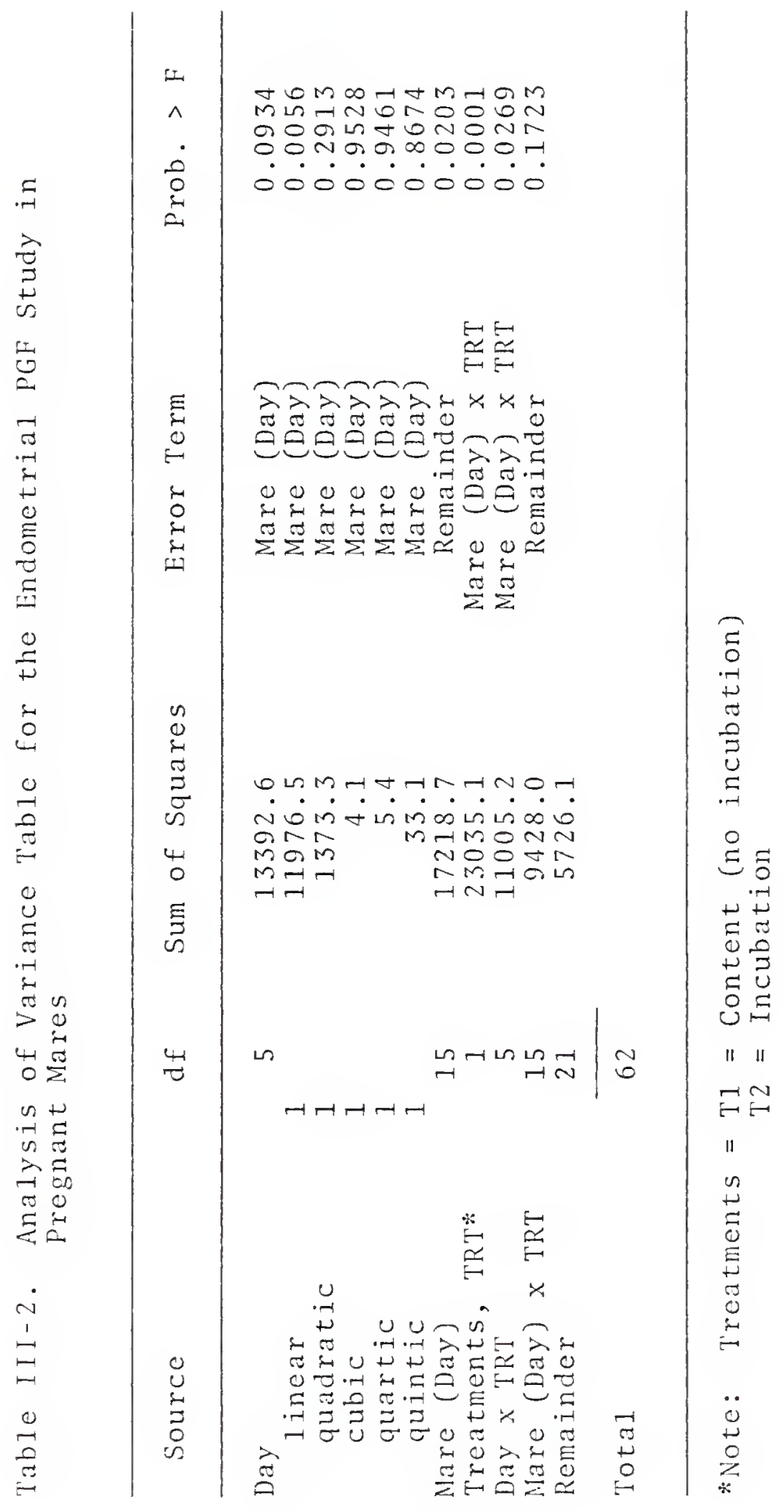




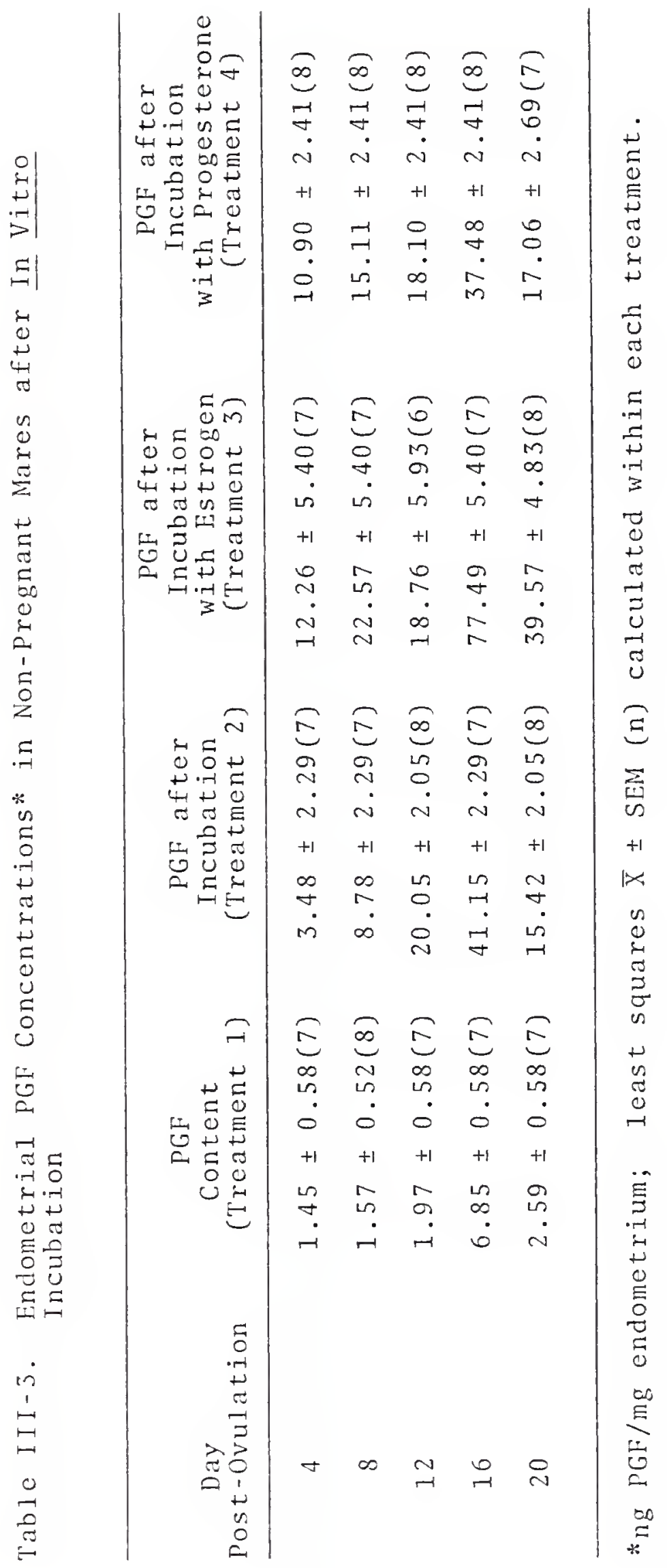


Table III-4. Endometrial PGF Concentration* in Pregnant Mares after In Vitro Incubation

\begin{tabular}{ccc}
$\begin{array}{c}\text { Day } \\
\text { Post-0vulation }\end{array}$ & $\begin{array}{c}\text { PGF } \\
\text { Content } \\
\text { (Treatment 1) }\end{array}$ & $\begin{array}{c}\text { PGF after } \\
\text { Incubation } \\
\text { (Treatment 2) }\end{array}$ \\
\hline 8 & $1.12 \pm 1.72(3)$ & $10.05 \pm 14.66(5)$ \\
12 & $1.31 \pm 1.72(3)$ & $16.75 \pm 13.38(6)$ \\
14 & $2.09 \pm 1.72(3)$ & $26.87 \pm 14.66(5)$ \\
16 & $2.38 \pm 1.49(4)$ & $49.77 \pm 12.39(7)$ \\
20 & $3.07 \pm 1.49(4)$ & $67.60 \pm 13.38(6)$ \\
\hline
\end{tabular}

*ng PGF/mg endometrium; 1east squares $\bar{X} \pm \operatorname{SEM}(n)$ calculated within each treatment. 


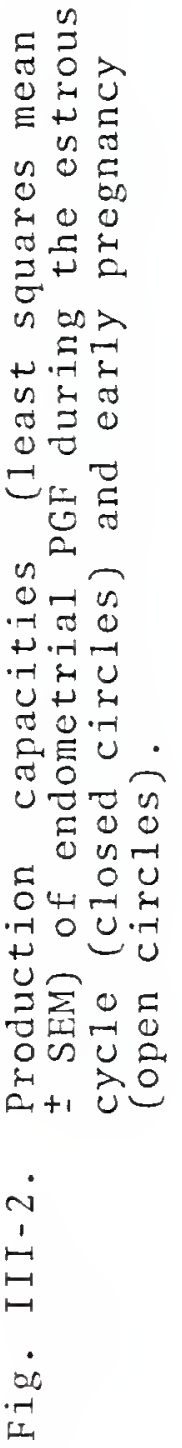




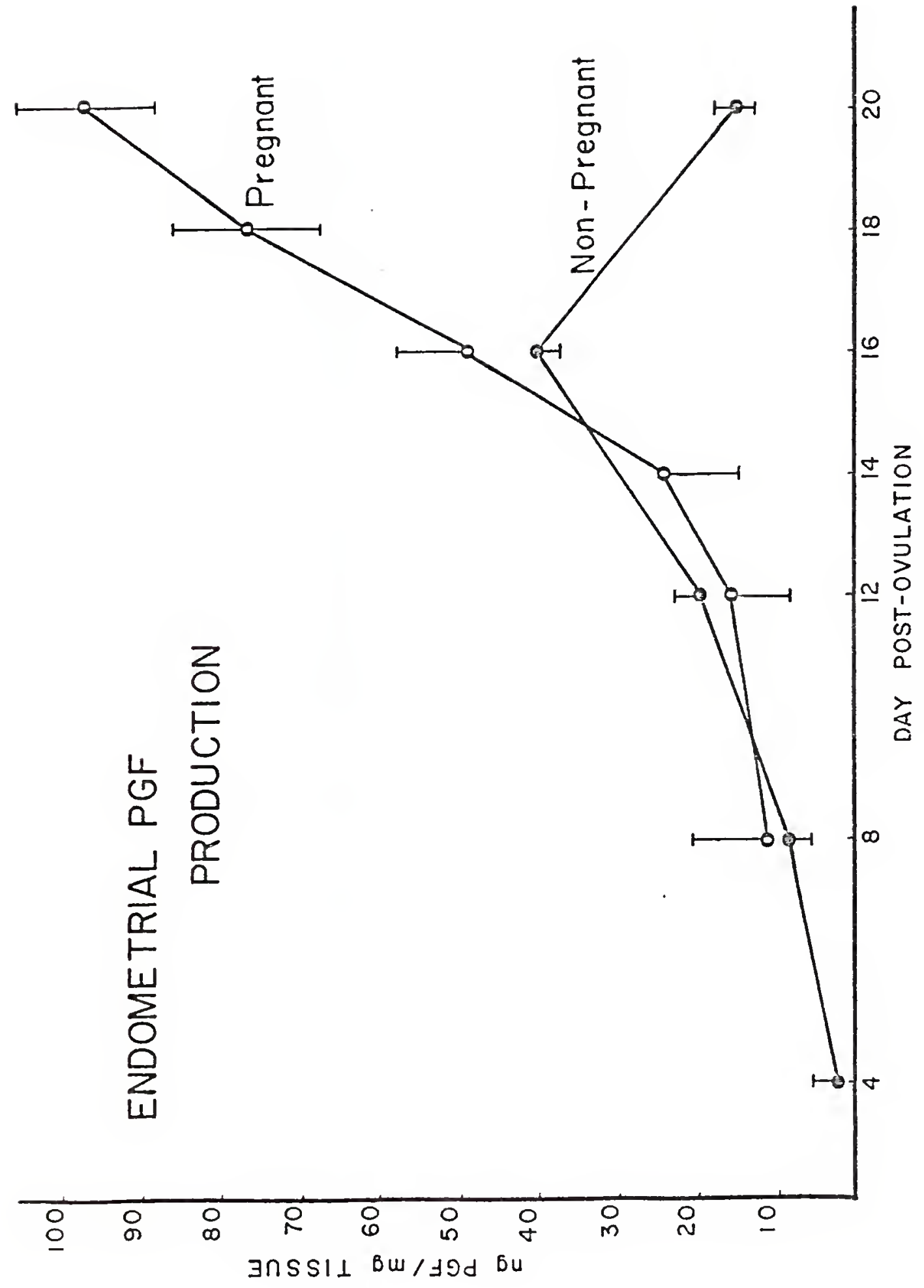




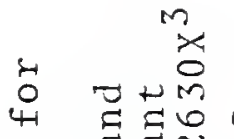

สี สิ

ข 10500

जु की 0

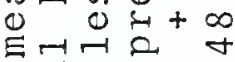

त U in

क्त है हो।

0 म.

स

워

$\exists$ हण

- $00 \cdot m$.

ज包舟,

$+0 \begin{gathered}0 \\ +0\end{gathered}$

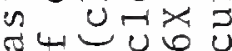

00 .

$\begin{array}{lll}0.0 & 0.4\end{array}$

- $u$ uี

ॠ

$\geq .-10$

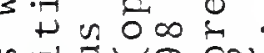

n. $3 \operatorname{con}^{\infty}$

0 U 이수

द्र UM E

उ

I $=000000$

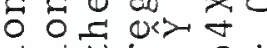

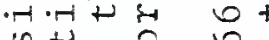

is un ...

क

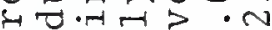

bo क्ष स \& 00

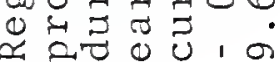

$\dot{2}$
$\dot{G}$
$\square$
$\dot{\sigma}$
$\dot{a}$ 


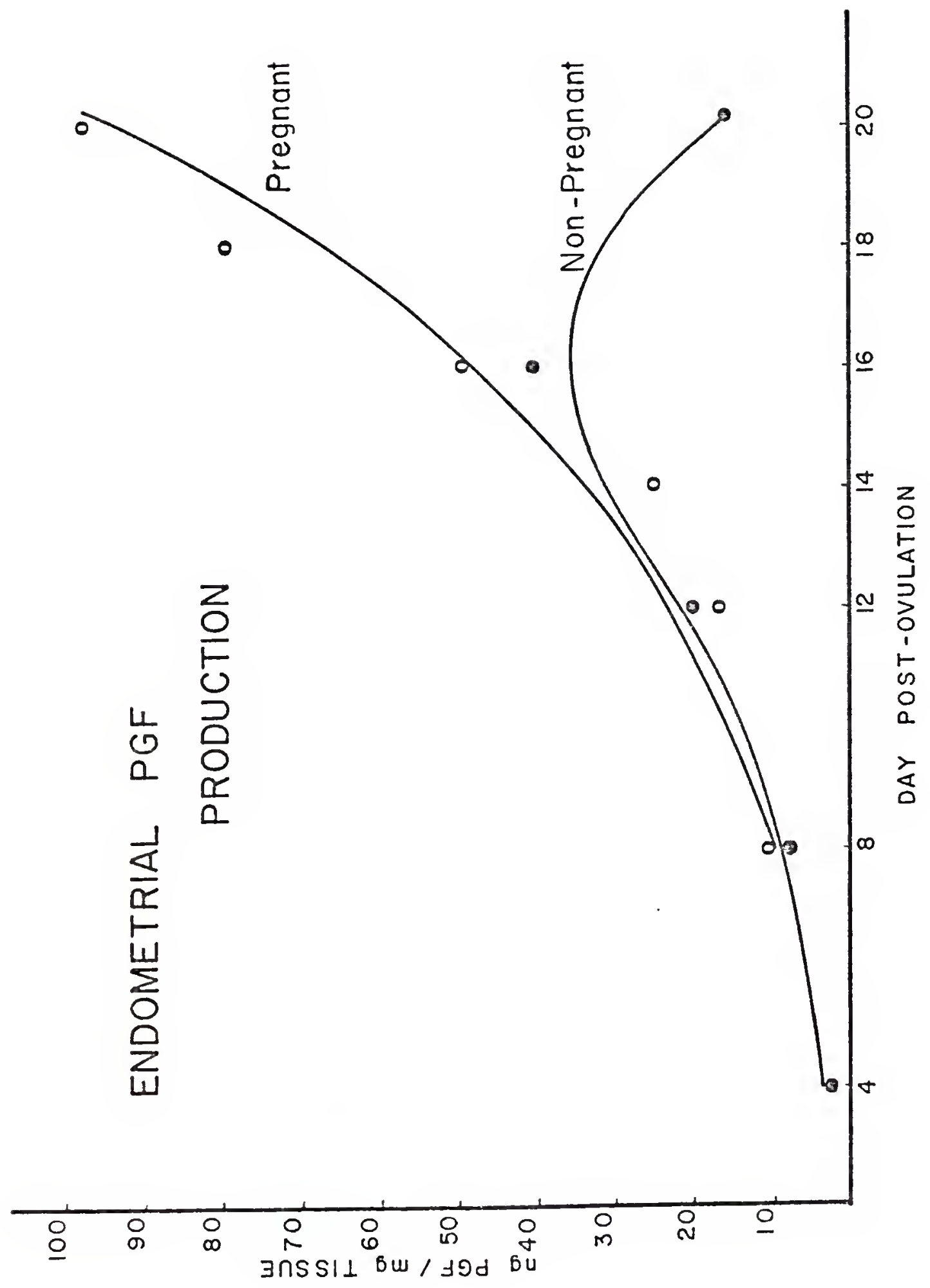




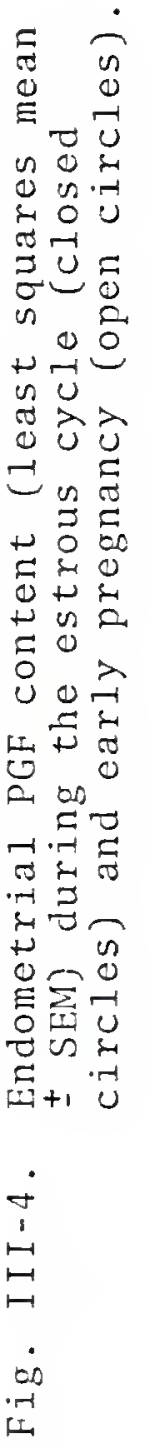




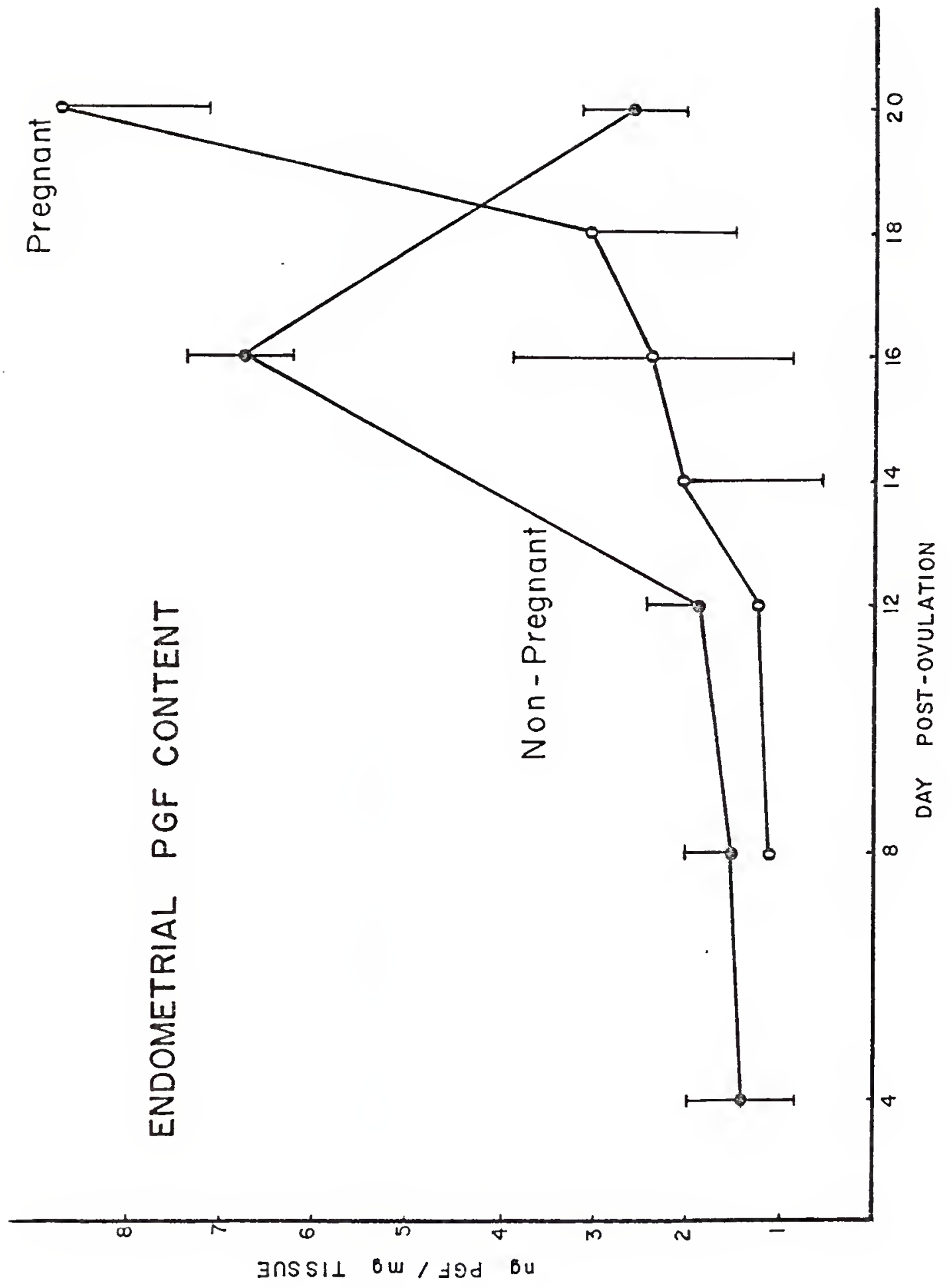




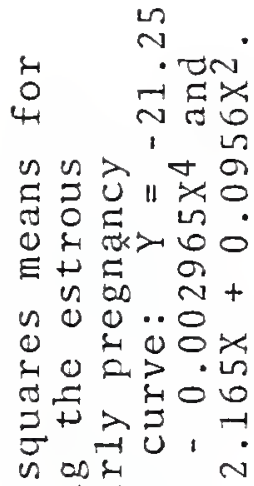

ज若 w

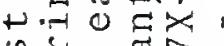

उ

U च

-1 ब 0 r.

द I

$\rightarrow+\infty \dot{E}+11$

3 푸워

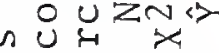

0 .

约 U N

勾

उ $00-\xi$

त 2010

‥-단

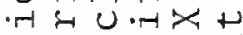

蛏U的

क 0 ०

$\rightarrow$ -

bo U एव

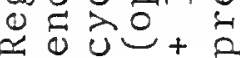

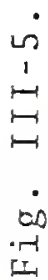




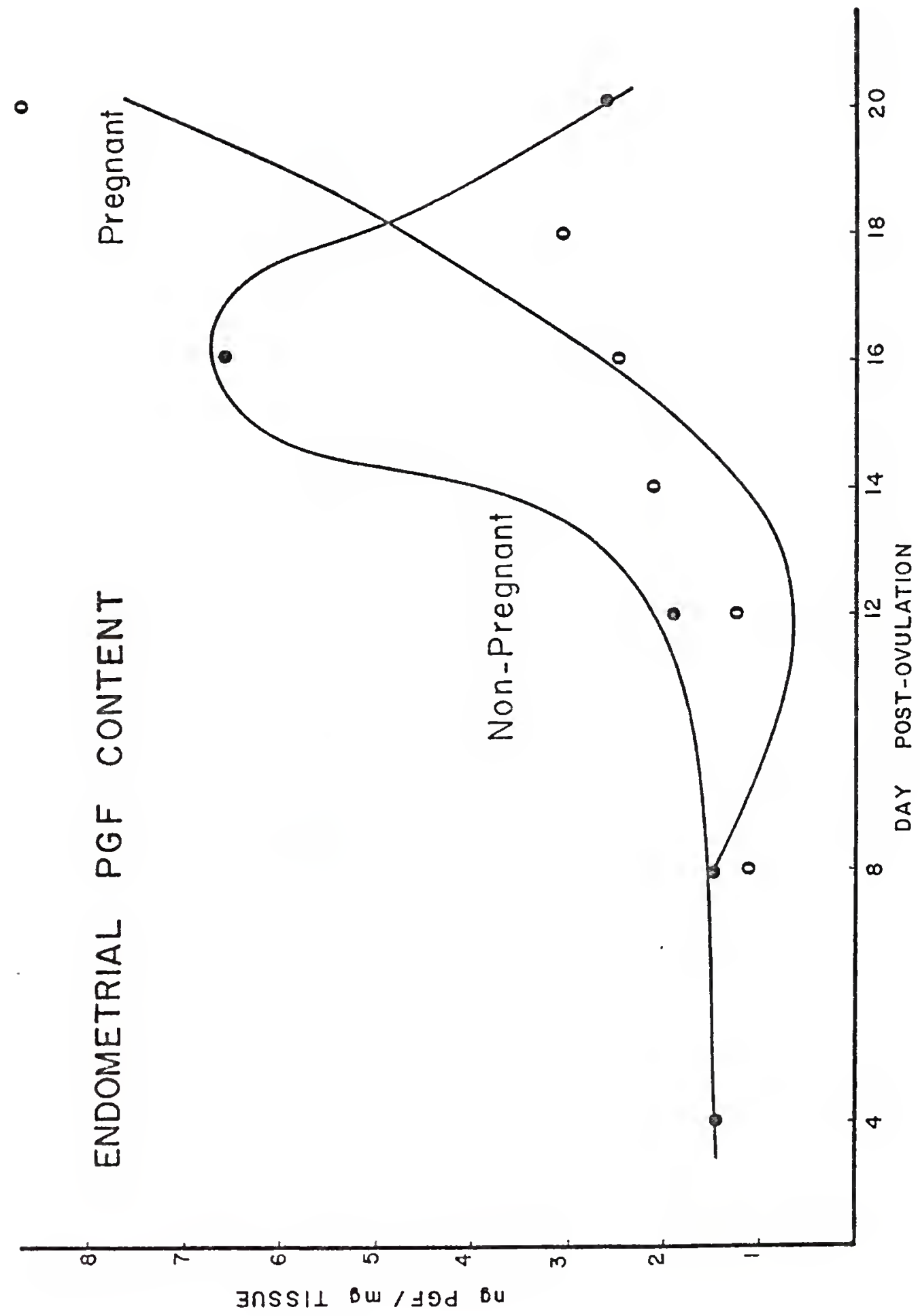




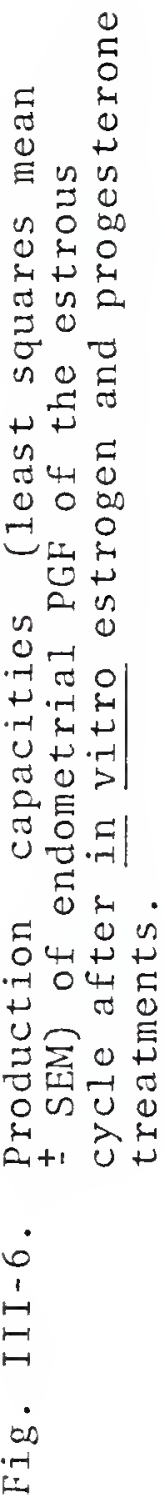




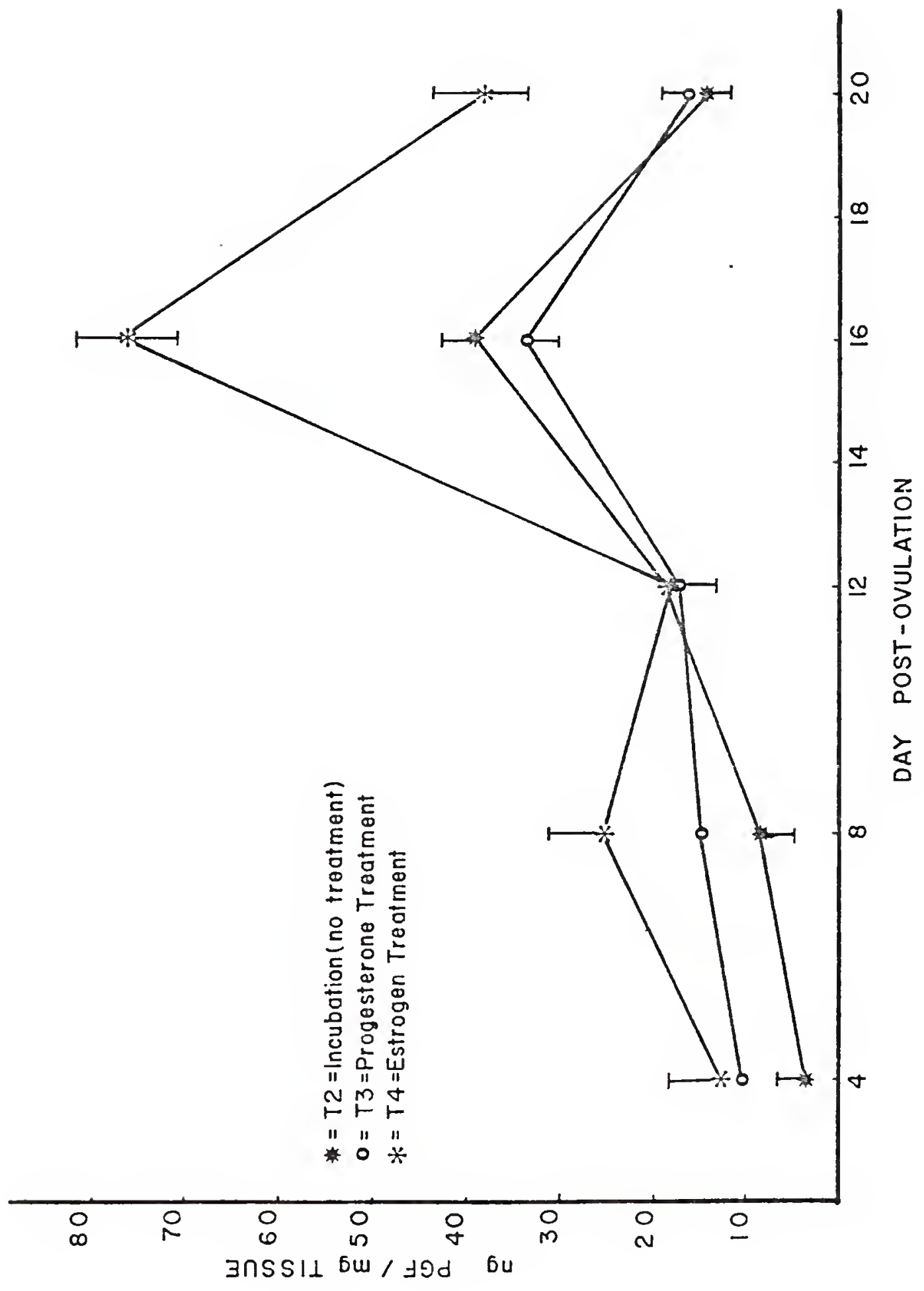




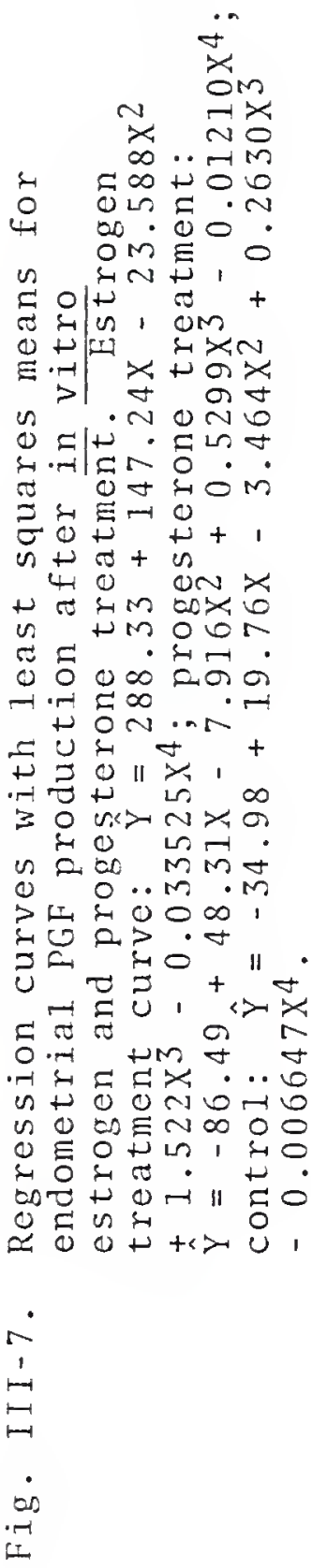




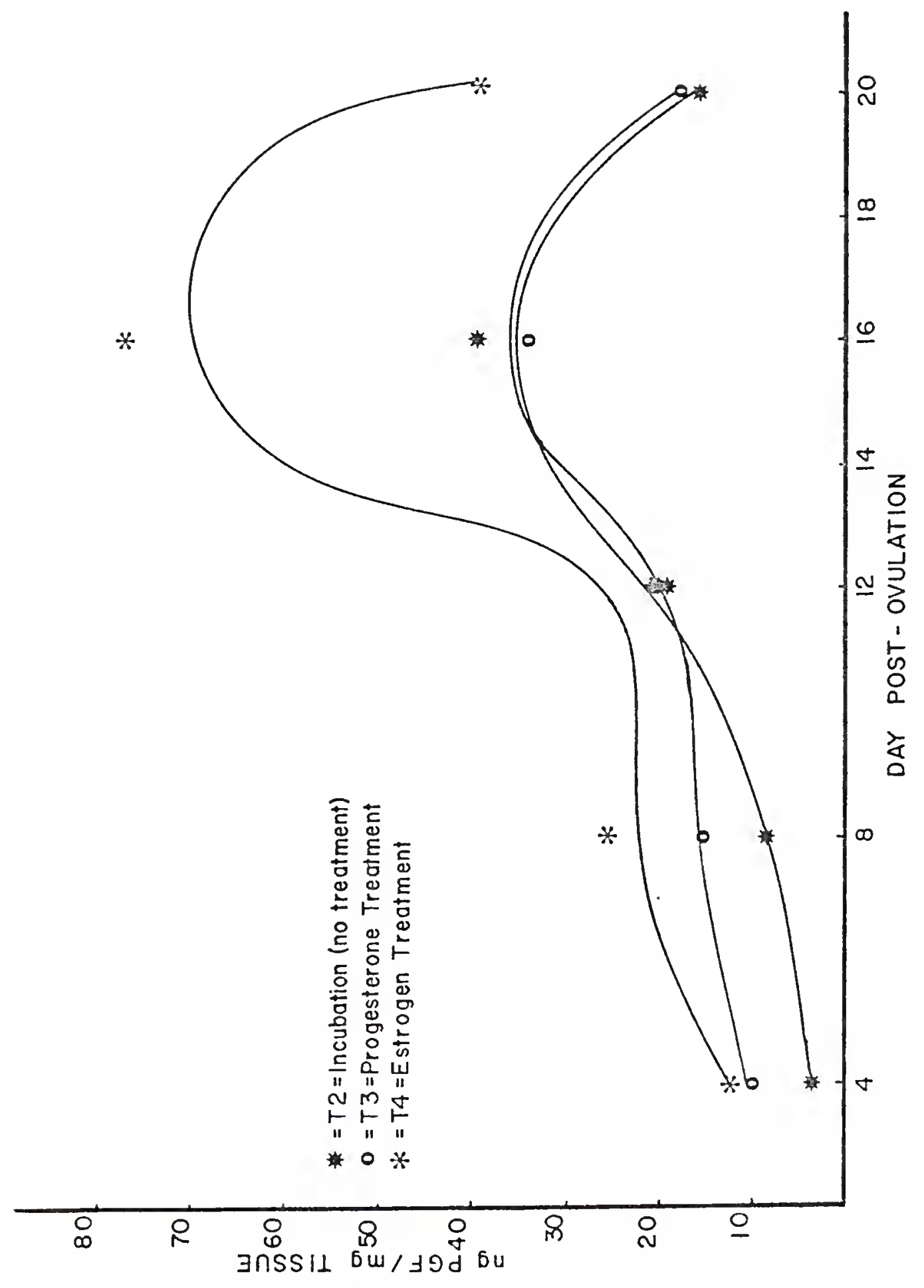


decreased on Day 20 (Fig. III-2). This time trend was best described by the cubic equation $\left(P<.0046 ; R^{2}=0.4708\right)$, $Y=38.96-15.00 X+1.815 X^{2}-0.561 X^{3}$; however, visual1y the data were described best by the quartic equation $(\mathrm{P}<.2692$; $\left.R^{2}=0.4909\right), Y=-34.98+19.76 X-3.464 X^{2}+0.2630 X^{3}-$ $0.006647 \mathrm{X}^{4}$ (Fig. III-3). Orthogonal contrasts between Treatments in non-pregnant mares indicated that, on a11 days, content was lower than production (Table III-3) but mimicked PGF production trends (Fig. III-4) and was best described ( $<<$ $\left..0007 ; \mathrm{R}^{2}=0.6732\right)$ by the quartic equation, $\mathrm{Y}=-21.25+$ $11.45 X-1.921 X^{2}+0.1297 X^{3}-0.02965 X^{4}$ (Fig. III-5). Therefore, in the non-pregnant animal, maximal endometrial production and content occurred at a time corresponding to the expected time of luteolysis (Chapter II) and support the hypothesis that PGF is the luteolytic substance of the mare. Orthogonal contrasts between in vitro Treatments within each Day (Fig. III-6) indicated that progesterone treatment was without effect, but that estrogen was stimulatory on Days 8 $(\mathrm{P}<.0032), 16(\mathrm{P}<.0037)$, and $20(\mathrm{P}<.0023)$. The time trends of the estrogen treatment were best described $(P<$ $.0018 ; \mathrm{R}^{2}=0.5943$ ) by the quartic equation, $Y=288.33+$ $147.24 X-23.588 X^{2}+1.522 X^{3}-0.033525 X^{4}$ and the progesterone treatment $\left(\mathrm{P}<.0035 ; \mathrm{R}^{2}=0.6098\right)$ by, $\mathrm{Y}=-86.49+48.31 \mathrm{X}-$ $7.916 x^{2}+0.5299 X^{3}-0.012101 x^{4}$. These data suggest that estrogen has an in vitro stimulatory effect on the luteal phase endometria. The question of steroid modulation is addressed 
further in Chapters IV and $V$. In the pregnant mare, a highly significant Treatment $(\mathrm{T} 1=$ content $\& \mathrm{~T} 2=$ incubation $)$ $(\mathrm{P}<.0001)$ and Day $\mathrm{x}$ Treatment $(\mathrm{P}<.0269)$ and a less significant Day effect $(\mathrm{P}<.0934)$ were detected (Table III-2). Due to the interaction, the Day effect of each Treatment (reduced statistical model) was, as before, analyzed with polynomial regression. The production capabilities of the endometrium varied with Day $(P<.0001)$ and increased continually from Day 0 to Day 20 post-ovulation (Fig. III-3). The time trend for production due to incubation was best described $\left(P<.1018 ; R^{2}=0.4906\right)$ by the quadratic equation, $\hat{Y}=48.04-9.623 X+0.5945 X^{2}$ (Fig. III-3). Prostaglandin $F$ content mimicked the production time trends and was also best described $\left(\mathrm{P}<.0417 ; \mathrm{R}^{2}=0.4611\right)$ by a quadratic equation, $\hat{Y}=12.78-2.165 X+0.0956 X^{2}$ (Fig. III-5). Therefore, in the pregnant mare maximal potential PGF production occurred at a time of expected luteal maintenance. Since the CL is capable of binding PGF at this time (see Chapter VII and Kimball \& Wyngarden, 1977) and undergoing regression, it is possible that endometrial PGF fails to reach the ovary. Indeed, uterine venous PGF levels are lower in the pregnant mare than in the non-pregnant mare (Douglas \& Ginther, 1976). Based on the secretory patterns of the porcine endometrium, Bazer and Thatcher (1977) suggested that the embryo influences the direction of movement of uterine secretions. In pregnancy, uterine secretory products, such as PGF, move toward 
the uterine lumen (exocrine secretion); while, in the absence of embryonic influence, uterine secretions proceed toward the endometrial stroma and associated vascular system (endocrine secretion) (Bazer \& Thatcher, 1977). Alternately, the absence of luteolysis in pregnancy may also be a result of sequestering and/or metabolizing endometrial PGF by the embryo itself. Supportive of this hypothesis are the observations that the yolk sac fluid of the equine embryo contains PGF (zavy et al., 1979), the porcine conceptus metabolizes PGF (Walker et a1., 1977), and the murine conceptus requires PGF for implantation (Saksena et al., 1976).

Even though the reproductive status (pregnant vs nonpregnant) was confounded by year and direct quantitative comparisons were inappropriate, it is interesting to note that the time trends between status were different. The time trends for pregnant animals were best described by an upward directed quadratic equation while the time trends for nonpregnant animals were best described by a fourth order equation with a declining slope.

It must be mentioned that in vitro incubations of this nature may only indicate the endometrium's potential capacity for producing PGF. It presents no proof of in situ synthesis and production. Also, the membranes of the Day 18 and 20 embryos ruptured as they were removed from the uterus and some of the yolk sac fluid may have come in contact with the endometrium. Therefore, the possibility exists that the 
PGF production capability of the Day 18 and 20 endometrium may be influenced by fetal fluids. However, the exposure was short-term and the endometrium was washed in PBS prior to incubation. 
CHAPTER IV

STEROID MODULATION OF EQUINE ENDOMETRIAL PGF

Exogenous estrogen increased endometrial or uterine luminal concentrations of prostaglandin $F_{2 \alpha}$ (PGF) in the progesterone-primed uterus of the ewe (Lewis et al., 1977), cow (W.W. Thatcher, G. Lewis, \& F. Barto1, personal communication), hamster (Saksena ¿ Harper, 1972b), guinea-pig (Blatchley et a1., 1972), mouse (Saksena \& Lau, 1973), and pig (Frank et al., 1978). In Chapter III in vitro incubation of late luteal phase equine endometria in the presence of estrogen led to enhanced production of PGF. To assess the steroid modulation of endometrial PGF further, the effects of $\underline{\text { in }}$ vivo and in vitro steroid treatments on ovariectomized mares were investigated.

\section{Materials and Methods}

Except for the following modifications, the Materials and Methods described in Chapter III were utilized in this experiment. Endometrial tissue for this study was collected in the summer of 1978 from 16 pony mares, having a mean weight at the time of experimentation of $199.31 \pm 53.24$ $(\bar{X} \pm$ S.D.) $\mathrm{kg}$ (range 170.1-289.3 kg). These animals were 
derived from a pool of mares that had been previously uniIaterally ovariectomized.

The remaining ovary was extirpated and after a two week recovery period, the bilaterally ovariectomized animals were randomly assigned to one of four hormone treatments. One milliliter, each, of the following steroids was administered intramuscularly in sesame oil vechile, for the indicated time periods:

Treatment $(\mathrm{CN})=$ Sesame oil for 3 weeks (control)

Treatment $(\mathrm{XE})=50 \mu \mathrm{g} / \mathrm{ml}$ Estradiol Valerate for 3 weeks

Treatment $(X P)=50 \mathrm{mg} / \mathrm{ml}$ Progesterone for 3 weeks

Treatment $(X S)=50 \mu \mathrm{g} / \mathrm{ml}$ Estradiol Valerate for 7 days followed by 14 days of $50 \mathrm{mg} / \mathrm{ml}$ Progesterone

In this manner, the effects of long term exogenous estrogen and progesterone $(E X T=X E$ \& $X P)$ upon the equine endometrial PGF synthetase system could be evaluated. The effects of exogenous estrogen followed by progesterone $(E X T=X S)$ was studied in an attempt to mimic the temporal sequence of ovarian steroid secretion during early pregnancy.

At the end of the exogenous hormone Treatment (EXT) period, uteri were surgically removed and endometrial strips were incubated, in duplicate, to determine the effect of the following in vitro treatments (IVT) on PGF production.

Treatment $(\mathrm{CON})=$ no incubation, i.e., endogenous PGF content

Treatment $(P R D)=$ total production, i.e., endogenous PGF content +2 hr in vitro production

Treatment $(\mathrm{P} 4)=\mathrm{PRD}$ in the presence of $1.0 \mathrm{\mu g}$ Progesterone 
Treatment $(\mathrm{E} 2 \mathrm{~A})=\mathrm{PRD}$ in the presence of $1.0 \mu \mathrm{g} 173-$ Estradiol

Treatment $(E 2 B)=P R D$ in the presence of $10.0 \mathrm{ng} 17 \mathrm{~B}-$ Estradio1

Treatment $(\mathrm{E} 2 \mathrm{C})=\mathrm{PRD}$ in the presence of $1.0 \mathrm{ng} 17 \mathrm{~B}-$ Estradio 1

As previously described (Chapter III), incubation was for $2 \mathrm{hr}$ in $\mathrm{KRB}$ at $37 \mathrm{C}$. Endometrial tissue was frozen at the end of the incubation period and saved for subsequent PGF radioimmunoassay. The concentration of PGF was corrected for procedural dilutions and endometrial mass, and expressed as $\mathrm{ng}$ PGF/mg endometrium.

The statistical test for significance between treatments was through analysis of variance. Since exogenous treatments were cross-classified with in vitro treatments, the data were analyzed in a balanced $4 \times 6$ split plot design. The analysis of the data was accomplished with the SASTEST (Statistical Analysis System) computer program (Procedure GLM; Barr Goodnight, SAS Institute, Inc.) and the statistical model is 1isted in Table IV-1.

\section{Results and Discussion}

Significant in vitro treatment (IVT) $(\mathrm{P}<.0001)$ and exogenous treatment (EXT) effects $(\mathrm{P}<.0397)$, as well as an IVT $x$ EXT interaction $(P<.0438)$ were detected (Table IV-1). Due to the interaction, orthogonal contrasts among EXT were done with each IVT group (Table IV-3) and, likewise, orthogonal contrasts among the IVT were done with each EXT group (Table IV-4). 


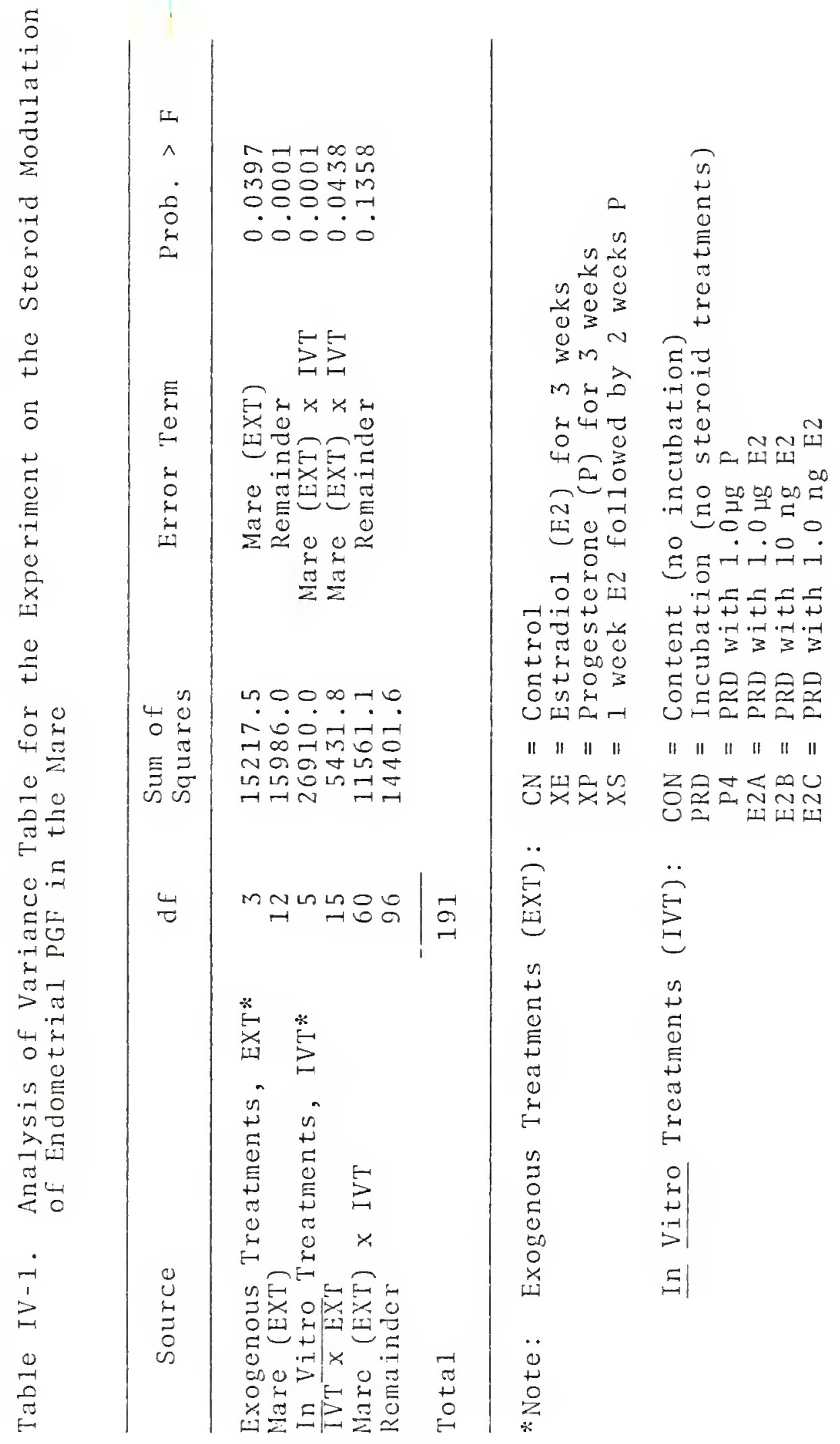




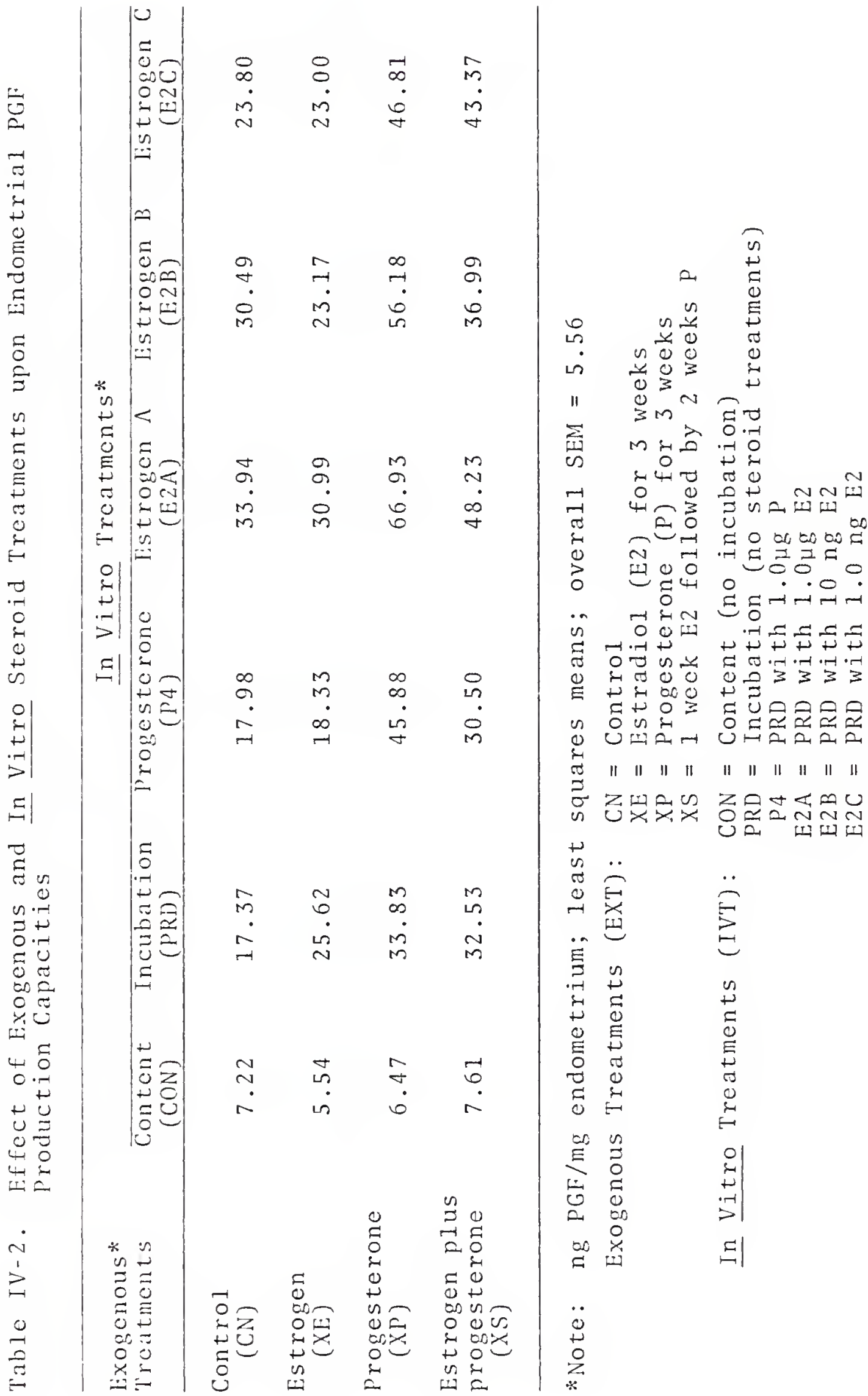




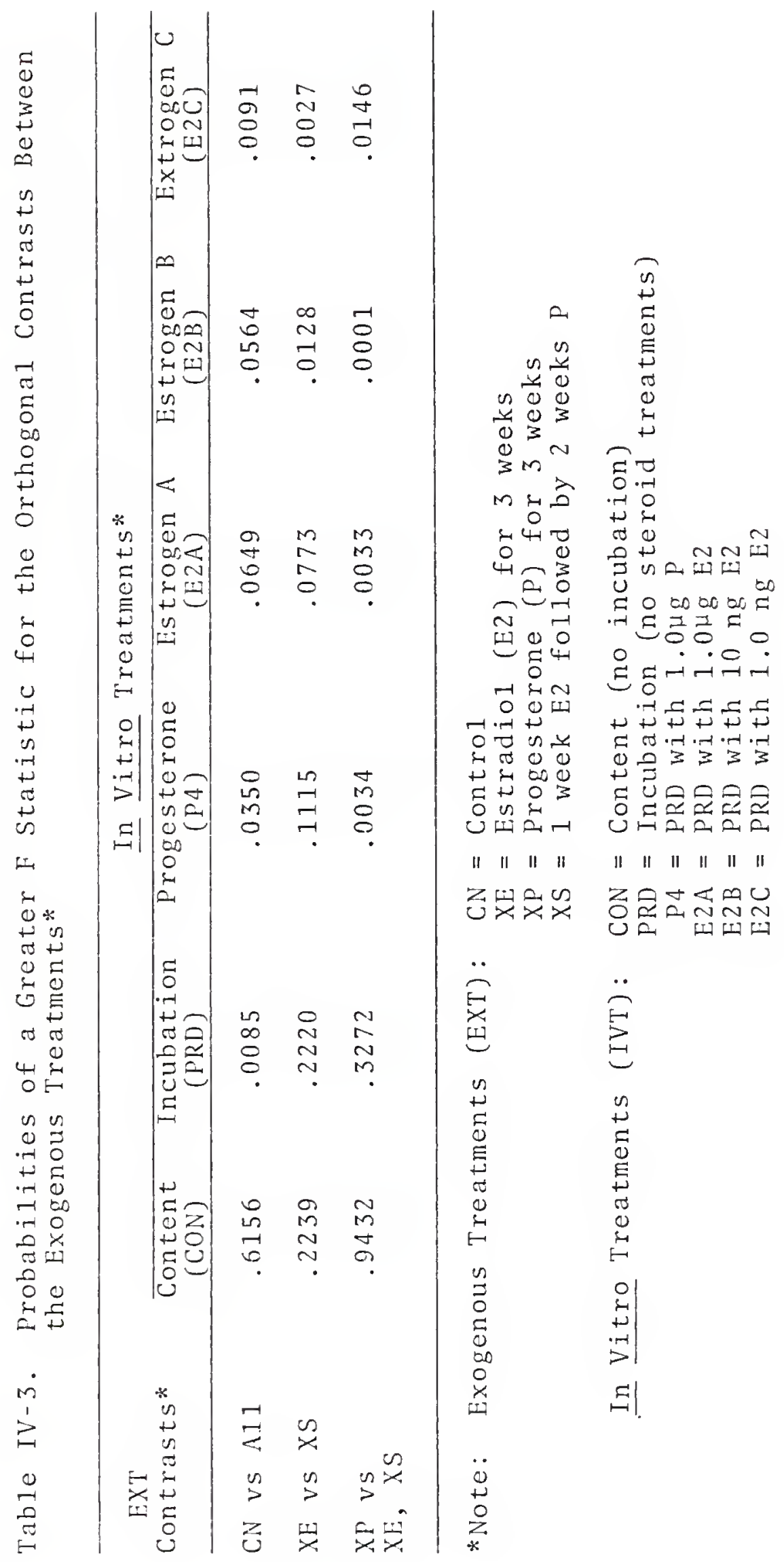




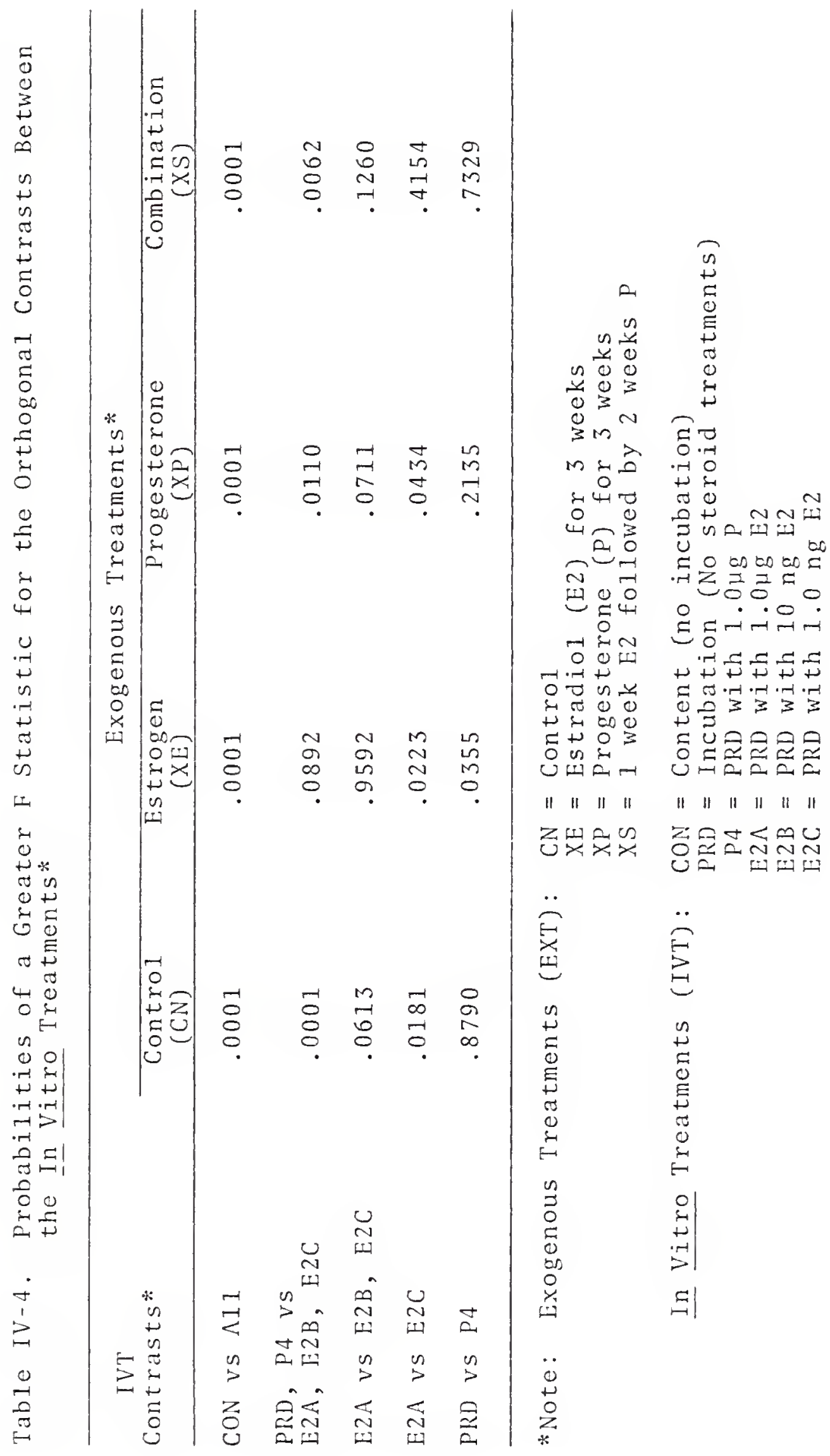


The PGF content $($ IVT $=$ CON) did not differ with EXT; however, PGF basal production (IVT = PRD) was stimulated $(\mathrm{P}<.0085)$ by the exogenous steroid treatments $(\mathrm{CN}<\mathrm{XS}$, XP, \& XE) (Table IV-2 \& Fig. IV-1). In addition, content was lower $(\mathrm{P}<.0001)$ than all production treatments (CON < PRD, P4, E2A, E2B, \& E2C), thus verifying that PGF production occurred during incubation.

Orthogonal contrasts among the four EXT (Table IV-3) indicated that the capacity of the endometrium to produce PGF in animals treated with estrogen plus progesterone was elevated above the estrogen treated animals $(P<.2220$ for PRD; $\mathrm{P}<.0773$ for E2A; $\mathrm{P}<.0128$ for E2B; $\mathrm{P}<.0027$ for E2C; $\mathrm{P}<.1115$ for $\mathrm{P} 4)(\mathrm{XP} \& \mathrm{XS}>\mathrm{XE})$ and that the progesterone treatment was more stimulatory than the estrogen and estrogen plus progesterone treatments $(X P>X E \& X S)(P<.3272$ for PRD; $\mathrm{P}<.0033$ for E2A; $\mathrm{P}<.0001$ for E2B; $\mathrm{P}<.0146$ for E2C; $\mathrm{P}<.0034$ for $\mathrm{P} 4$ ).

Contrasts of the IVT (Table IV-4) indicated that PGF production in the incubations containing the three levels of estrogen was elevated above the progesterone treatment $($ IVT $=\mathrm{P} 4)$ and no treatment $($ IVT $=\mathrm{PRD})(\mathrm{P}<.0001$ for $\mathrm{CN}$; $\mathrm{P}<.0892$ for XE; $\mathrm{P}<.0110$ for XP; $\mathrm{P}<.0062$ for XS); while progesterone treatment was ineffective in stimulating PGF production above the no treatment groups. An estrogen response existed among the three levels of estrogen, in that, the $1.0 \mathrm{ng}$ level of estrogen was lower than the $1.0 \mathrm{\mu g}$ level in all cases except the estrogen plus progesterone treatment 


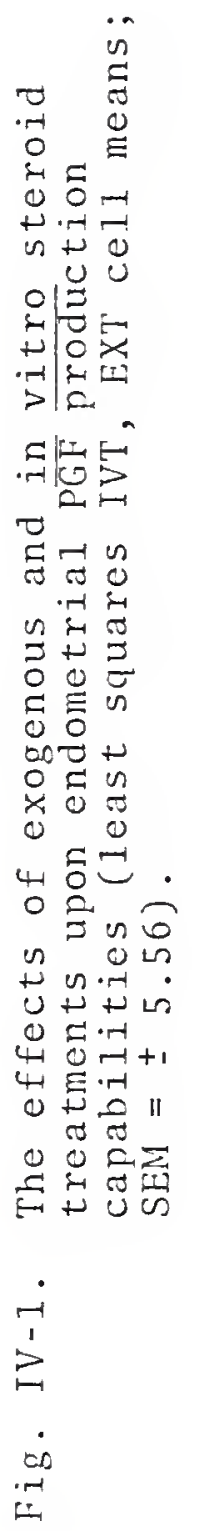




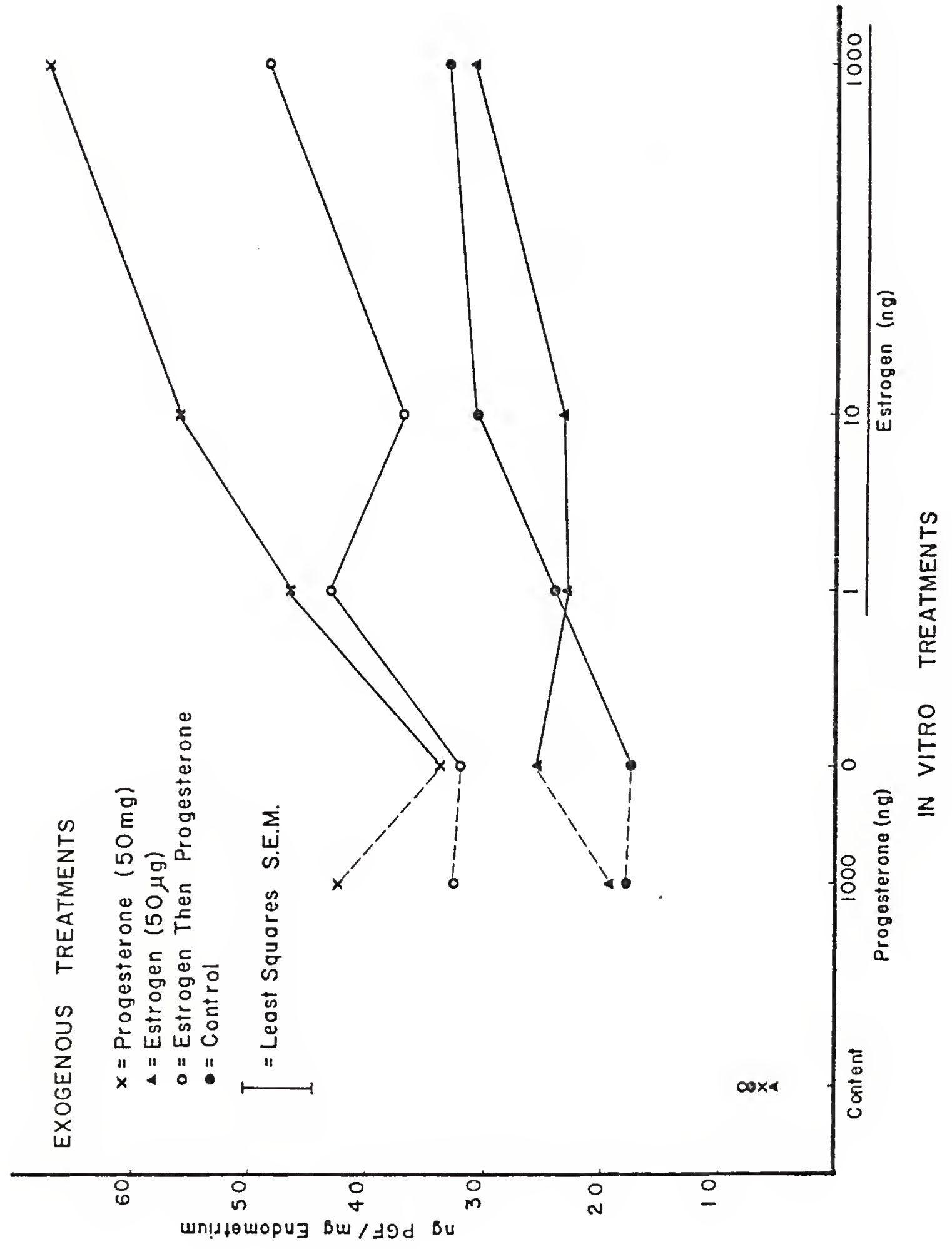


$(\mathrm{P}<.0181$ for $\mathrm{CN} ; \mathrm{P}<.0223$ for $\mathrm{XE} ; \mathrm{P}<.0434$ for XP; $\mathrm{P}<.4154$ for $X S$ ) (therefore $E 2 A>E 2 B>E 2 C>P R D=P 4$ ).

Thus maximal stimulation of endometria1 PGF production occurred in a (systemic) progesterone-primed uterus treated in vitro with estrogen; however, this effect was absent in endometria collected from animals treated systemically with estrogen and in vitro with progesterone. Therefore effects of steroids upon the endometrial PGF synthetase system may vary in a manner dependent upon route of administration, length of exposure, or dosage. Systemically administered steroids, as the EXT or in vivo ovarian steroids, circulate in the entire cardiovascular system and may interact with non-reproductive tissue or organs, as adrenals, kidney, and liver, and initiate secondary effects that may, in turn, have a unique effect upon the endometrial PGF synthetase system. This systemic effect would be absent in IVT where the endometria may interact directly with the steroids during incubation. Additionally, the incubated endometrium was physically isolated from any potential inhibitory or stimulatory (bodily) influences that may or may not be related to steroid action. Finally, steroids of EXT were diluted by the fluids of the entire circulatory system and were administered for a longer time period ( 3 weeks versus $2 \mathrm{hr}$ ) than IVT.

However, the observation that maximal stimulation of endometrial PGF production occurred in a systemically progesterone-primed uterus treated in vitro with estrogen is 
consistent with the findings of the endometrial production studies conducted on the pregnant and non-pregnant mare (Chapter III). In the pregnant mare, the capacity of the endometrium to produce $P G F$ increased $(P<.0001)$ from the beginning of pregnancy to Day 20 (Fig. III-2). This rise in PGF was observed to occur in a uterus that had been under the continual influence of systemic progesterone (Allen \& Hadley, 1974) and the influence of embryonic and/or endometrial estrogens locally. The equine conceptus was first shown to be a potential source of estrogens with the histochemical localization of several hydroxysteroid dehydrogenase (HSD) enzymes within the membranes of the trophoblast (Flood \& Marrable, 1975). However, intense 17B-HSD activity was found only in the endometrium, and specifically in the endometrium in intimate contact with the conceptus (Flood et al., 1979). Additionally, the equine embryo has been shown to contain (Zavy et a1., 1979) and produce (Mayer et al., 1977) estradiol and preliminary studies suggest that the blastocyst may convert ${ }^{3} \mathrm{H}$-progesterone into ${ }^{3} \mathrm{H}$-estrone (Seamens et al., 1979). Likewise, maximal PGF production in the non-pregnant mare (Fig. III-2) appeared at a time (Day 16) that corresponds to increased systemic progesterone production (Sharp \& Black, 1973; Douglas \& Ginther, 1976) and also at a time when intrauterine (local) estrogens are high (zavy et al., 1979; Fig. VIII-2 \& Fig. VIII-3).

When the endometrium of the estrous cycle (Chapter III) was incubated in the presence of steroids, progesterone was 
ineffective in altering PGF production, whereas estrogen had 1ittle or no effect on Days 4 to 12 but was stimulatory on Days 16 and 20 (Fig. III-6). The in vitro stimulatory effect of estrogen may be effective only in a uterus that has had prior (prolonged systemic) progesterone exposure. In this manner, the $\mathrm{CL}$, through the secretion of its primary product, progesterone, may ultimately orchestrate its own destruction, via PGF stimulation. 
CHAPTER V

THE LOCAL EFFECT OF THE EMBRYO ON ENDOMETRIAL PGF

The early pregnant equine endometrium has a high capacity for producing prostaglandin $F_{2 \alpha}$ (PGF) (Chapter III) and endometrial PGF production has been shown to be modulated by steroids (Chapter IV). Maximal PGF production occurred in a progesterone-primed uterus stimulated in vitro with estrogen. The high endometrial levels of PGF in pregnancy may reflect endogenous steroid enhancement, since this is a time when both systemic luteal progesterone (A1len \& Hadley, 1974) and local fetal and endometrial estrogens are high. The equine conceptus contained (Zavy et $\underline{\text { al }}$, 1979) and produced estradiol (Mayer et al., 1977) and may convert ${ }^{3}$ H-progesterone into ${ }^{3}$ H-estrone (Seamens et a1., 1979). Flood and co-workers (1979) have observed histochemically, the presence of high levels of $17 \beta$-hydroxysteroid dehydrogenase on those parts of the uterine endometrium directly apposed to the trophoblast. This is suggestive of a local conceptus influence on the endometrium. Since the local production of PGF by the equine endometrium may be enhanced by fetal estrogens, the PGF production by the endometrium associated with the embryo was compared with PGF production of the endometrium contralateral to the embryo. 


\section{Materials and Methods}

Endometrial strips were collected from ten pony mares during the summer of 1978 and incubated according to the procedures outlined in the Materials and Methods of Chapter III. Mean weight of the animals at the time of experimentation was $188.8 \pm 28.9$ ( $\bar{X} \pm$ S.D.) $\mathrm{kg}$ (range $154.2-231.3 \mathrm{~kg}$ ).

As before, production and content of PGF were measured in endometrial strips. Duplicate strips were obtained from the medial portion of the right and left uterine horns of three Day 12 non-pregnant mares, three Day 18 non-pregnant mares, and four Day 18 pregnant mares. In this manner a comparison could be made of the PGF synthetase system between the uterine horns of non-pregnant mares, i.e., horn versus horn variability, as well as a comparison between the uterine horns of pregnant mares, i.e., local influence of embryo.

The statistical test for significance between Treatments and Hornsides was by analysis of variance. The Treatments were $\mathrm{T} 1=$ content (no incubation) and $\mathrm{T} 2=2 \mathrm{hr}$ in vitro incubation; and the hornsides were $H 1=$ right horn in nonpregnancy and gravid horn in pregnancy, and $H 2=$ left horn in non-pregnancy and non-gravid horn in pregnancy. Since variation due to animal was considered to be random and since there was an unequal distribution of animals within treatments, the data were representative of a mixed model with unequal subclass numbers (Steel \& Torrie, 1960). As such the data were analyzed with a SAS (Statistical Analysis 
System) computer program (Procedure GLM; Barr \& Goodnight, SAS Institute, Inc.). The statistical model is 1 isted in Table $V-1$.

\section{Results and Discussion}

The PGF production and content in opposite uterine horns are shown in Fig. $V-1$ and Table $V-2$. As in previous experiments, endometrial PGF content was significantly lower $(\mathrm{P}<.0003)$ than production (Table V-1) (Treatments: $\mathrm{T} 1=$ content, $\mathrm{T} 2$ = incubation). The lack of a Day $x$ Hornside interaction $(P<.8313)$ demonstrated a lack of horn versus horn variability in the non-pregnant mare while a significant Status $x$ Hornside interaction $(P<.0032)$ indicated that, in pregnancy, the gravid horn had a higher capacity for producing PGF than the non-gravid horn (Status: $P=$ pregnant, $\mathrm{NP}=$ non-pregnant; Hornside: $H 1=$ right horn in $\mathrm{NP}$ \& gravid horn in $\mathrm{P}, \mathrm{H} 2=1$ eft horn in $\mathrm{P} \&$ non-gravid horn in NP). Thus it appears that the embryo has a $10 \mathrm{cal}$ influence on the uterus to stimulate PGF production. Endometrial PGF of pregnancy may not be involved in ovarian function, since uterine vein concentrations of PGF were lower in pregnant than in non-pregnant mares (Douglas $\&$ Ginther, 1976); instead, the PGF may be involved in fetal-placental physiology. Enhanced production of PGF in only those areas of the equine endometrium that are in intimate contact with the embryo suggests that PGF may be utilized by the embryo. Indeed, 
PGF has been demonstrated to be present within equine yolk sac fluids (Zavy et al., 1979) and required for implantation in mice (Saksena et a1., 1976). 


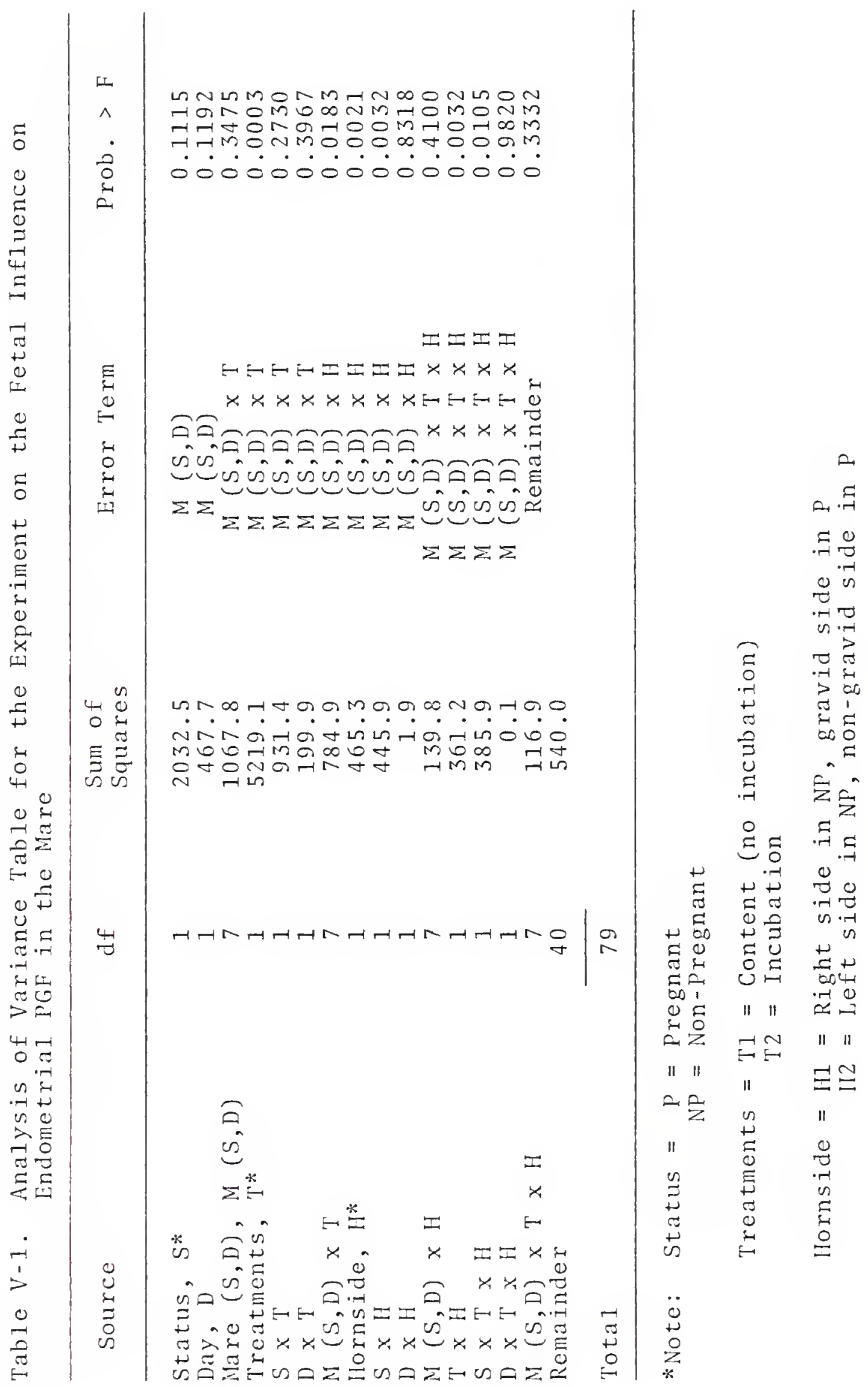


Table V-2. Local Influence of Embryo upon Endometrial PGF Production Capacities

\begin{tabular}{lcccc}
\hline Status* & Day & Hornside* & $(\mathrm{n})$ & $\mathrm{X}$ ng $\begin{array}{c}\text { PGF } \\
( \pm \text { SEM }) *\end{array}$ \\
\hline $\mathrm{NP}$ & 12 & 1 & 3 & $19.85 \pm 2.008$ \\
$\mathrm{NP}$ & 12 & 2 & 3 & $20.30 \pm 2.008$ \\
$\mathrm{NP}$ & 18 & 1 & 3 & $9.82 \pm 2.008$ \\
$\mathrm{NP}$ & 18 & 2 & 3 & $9.67 \pm 2.008$ \\
$\mathrm{P}$ & 18 & 1 & 4 & $41.24 \pm 2.373$ \\
$\mathrm{P}$ & 18 & 2 & 4 & $19.08 \pm 2.373$ \\
\hline
\end{tabular}

*Note: Status $=\begin{aligned} P & =\text { Pregnant } \\ N P & =\text { Non-Pregnant }\end{aligned}$

Hornside $=H 1=$ Right side in NP, gravid side in $P$ $\mathrm{H} 2$ = Left side in $\mathrm{NP}$, non-gravid side in $\mathrm{P}$

The estimate of SEM included $\sigma_{M}^{2}(S, D) \times T \times H$. 
Fig. V-1. Local influence of embryo upon endometrial PGF production capacities (least squares mean \pm SEM) . 


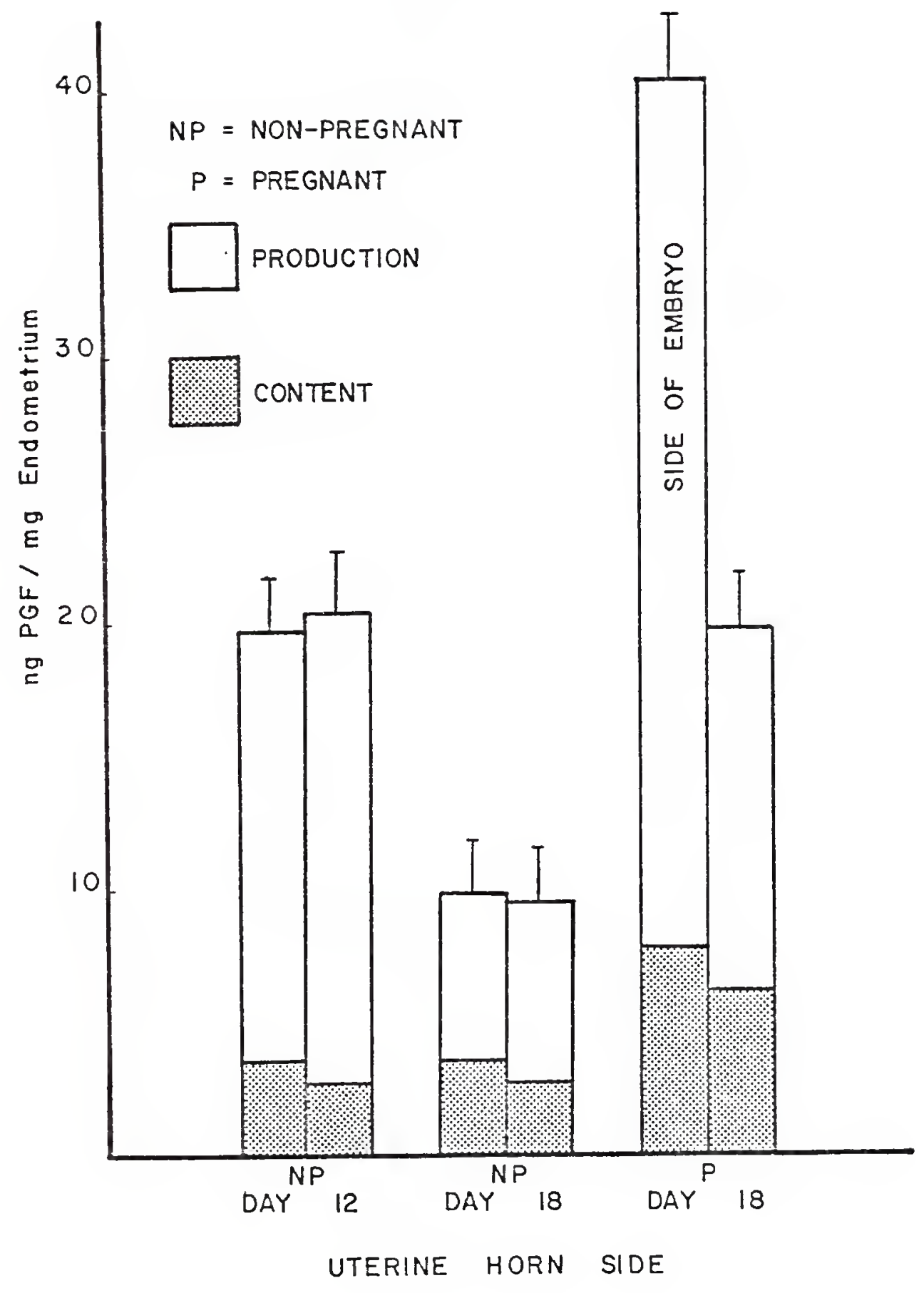


CHAPTER VI

THE LOCALIZATION OF PGF IN THE PERFUSED EQUINE OVARY

Observations that exogenous prostaglandin $F_{2 \alpha}$ (PGF) induced luteal regression in mares (Douglas \& Ginther, 1972; Allen \& Rowson, 1973), and that an increase in endogenous uterine luminal PGF (Zavy et a1., 1978), endometrial PGF (Chapter III), and uterine venous PGF (Douglas \& Ginther, 1976) occurred at the time of natural luteolysis, strongly suggests that uterine PGF is the luteolytic factor in the mare. Since the corpus luteum (CL) appears to be a target tissue for PGF, it would follow that exogenous PGF may localize in the CL. To this end, luteal phase ovaries were removed from mares and perfused with radioactive PGF. The localization of high levels of PGF within the CL would be supportive of the hypothesis that PGF is involved in luteal endocrinology.

\section{Materials and Methods}

Ovaries were collected from four, Day 14 non-pregnant pony mares during the summer of 1973 according to the procedure outlined in the Materials and Methods of Chapter III. The only deviation in the surgical technique was the placement 
of a loose tie of $2 / 0$ silk suture around the ovarian artery as an aid in locating the artery for cannulation after surgery.

After ovariectomy, the ovary was immersed immediately in a heparinized $0.9 \%$ saline bath maintained at $37 \mathrm{C}$. A cannula (PE 190) was inserted and sutured into the ovarian artery and attached to a 3-way valve with a 22 gauge needle (Fig. VI-1). The 3-way valve was attached to a 1 cc syringe containing $\mathrm{PGF}_{2 \alpha} \alpha^{-3} \mathrm{H}(\mathrm{NET} 345$, 1ot 932-121) in $0.9 \%$ saline and a $20 \mathrm{cc}$ syringe containing heparinized autologous blood that was collected at surgery. The $20 \mathrm{cc}$ syringe was removed temporarily and the ovarian vasculature was flushed with 2.0 mI of heparinized $0.9 \%$ saline to retard coagulation of endogenous blood. The ovary, with cannula, was suspended over a petri dish and perfused with the tritiated PGF $2 \alpha$ (Specific Activity $=10.9 \mathrm{Ci} / \mathrm{mmol}$ ) and heparinized plasma. The scheme of perfusion was comprised of injections of $100 \mu 1$ of $\mathrm{PGF}_{2 \alpha}{ }^{-}$ ${ }^{3} \mathrm{H}$ (11.46 ng) followed by $2.0 \mathrm{ml}$ of heparinized plasma. This scheme was repeated five times at a flow rate of approximately $2.0 \mathrm{~m} 1 / \mathrm{min}$. Thus, a total of $57.30 \mathrm{ng}(0.5$ m1) of labeled $\mathrm{PGF}_{2 \alpha}$ was injected. The ovary was then fiusized with $10.0 \mathrm{mI}$ of heparinized $0.9 \%$ saline. All fluids injected into the ovary were maintained at a temperature of 37 C.

At completion of the perfusion, the ovary was wiped dry and stored frozen for subsequent analysis. In 


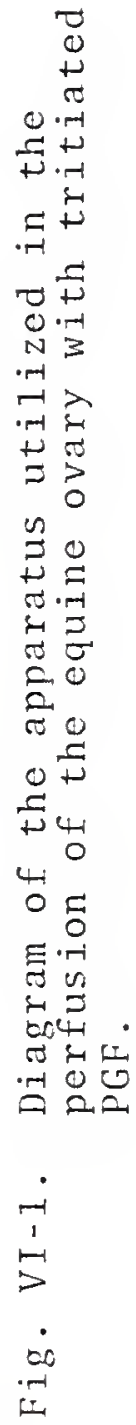




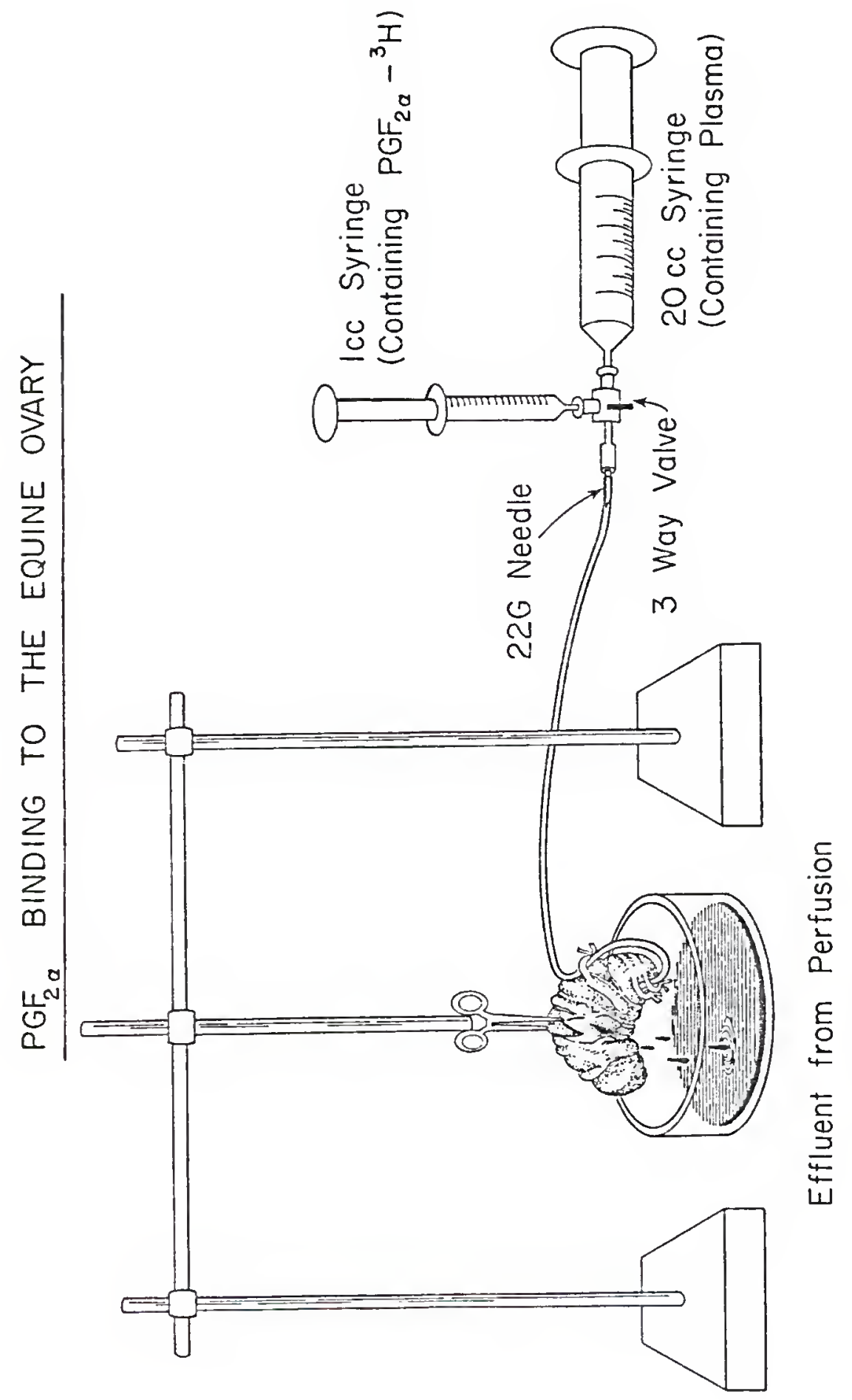


addition, $5.0 \mathrm{ml}$ of effluent and $500 \mu 1$ of the original PGF $2 \alpha^{-{ }^{3}}$ H stock solution were saved to determine total uptake and total amount injected.

The frozen ovaries were thawed at room temperature and weighed. The corpus luteum was ablated carefully, so as not to disrupt any follicles, then weighed. Each follicle was exposed by dissection and the follicular fluid was aspirated into syringes and the total volume of fluid noted. One hundred microliters of the follicular fluid from each ovary were added to liquid scintillation vials containing cocktail and counted in a Beckman LS-300 1iquid scintillation spectrophotometer. The percentage of $\mathrm{PGF}_{2 \alpha^{-}}{ }^{3} \mathrm{H}$ injected that localized within the follicular fluid was calculated.

The ovary, now minus the $\mathrm{CL}$ and follicular fluid, was weighed. This weight served as an estimate of stromal weight. In addition to the connective tissue and interstitial cells of the ovarian stroma, this estimate of stromal weight also includes the weight of the ovarian vasculature and follicular structural elements. Physical separation of these ovarian components was found to be impossible. Approximately $100 \mathrm{mg}$, each, of the CL and ovarian stroma were homogenized in $2.0 \mathrm{ml}$ of absolute ethanol in a Potter-type hand homogenizer. Ovarian stroma samples were collected from areas of the ovary that were devoid of large blood vessels and follicles. Thus, although the "stromal weight" includes follicle structures, the stroma used for estimation of 
radioactive label was devoid of any follicle structures. The homogenate was centrifuged at $1086 \mathrm{G}$ for $10 \mathrm{~min}$ and $100 \mathrm{\mu l}$ of the supernatant were added directly to liquid scintillation vials containing cocktail and counted as before. The percentage of the total (perfused) $\mathrm{PGF}_{2 \alpha^{-}}{ }^{3} \mathrm{H}$ injected that localized within the entire CL and ovarian stroma was calculated. Finally, $100 \mu 1$ of the effluent and original $\mathrm{PGF}_{2 \alpha}{ }^{-3} \mathrm{H}$ stock solution were added to liquid scintillation vials and counted.

The amount of radioactivity (CPM) within al1 components was corrected for quench with a water quench curve and expressed as DPM. Quench corrections were determined with the aid of an external standard $\left({ }^{137} \mathrm{Ce}\right)$ supplied with the Beckman LS-300 1iquid scintillation spectrophotometer. The water quench curve was constructed by adding a known amount of radioactivity to liquid scintillation vials containing increasing concentrations of water $(250 \mu 1$ to $1500 \mu 1)$. Efficiency $\left(\frac{\%}{0}\right)$ of counting was graphed against the external standard ratio computed by the liquid scintillation spectrophotometer. Corrections for quench within sampleswere then calculated by extrapolation of the external standard ratio from each sample on the water quench curve. Statistical tests were performed on the amount of radioactivity, expressed as DPM.

The test of significance between Treatments was by one-way analysis of variance (Treatments: $\mathrm{T} 1=\% 3_{\mathrm{H}}$ in effluent, $\mathrm{T} 2=\% 3_{\mathrm{H}}$ in $\mathrm{CL}, \mathrm{T} 3=\% 3_{\mathrm{H}}$ in follicular fluid, $\mathrm{T} 4=\%{ }^{3} \mathrm{H}$ in 
ovarian stroma). The analysis was computed with the SASTEST (Statistical Analysis System) computer Procedure GLM (Barr \& Goodnight, SAS Institute, Inc.) and the statistical model with appropriate orthogonal contrasts is shown in Table VI-1.

\section{Results and Discussion}

In an attempt to mimic in vivo conditions, $\mathrm{PGF}_{2 \alpha^{-}}{ }^{3} \mathrm{H}$ was perfused through the equine ovarian artery at a rate $(2.0$ $\mathrm{ml} / \mathrm{min}$ ) comparable to that detected by electromagnetic flow probes (M. Simone11i, D. Caton, and D. Sharp, unpublished observations). Furthermore, since endogenous PGF may be secreted by the pig in a pulsatile fashion (Moeljono et a1., 1977) PGF was injected into the ovary in five pulses. Although not quantified, the amount of infused heparinized saline required to remove endogenous ovarian blood was approximately $2.0 \mathrm{~m} 1$.

The variances of the four treatments $\left(\mathrm{T} 1=\% 3_{\mathrm{H}}\right.$ in effluent, $\mathrm{T} 2=\%{ }^{3} \mathrm{H}$ in $\mathrm{CL}, \mathrm{T} 3=\%{ }^{3} \mathrm{H}$ in follicular fluid, $\mathrm{T} 4={ }_{0}^{3} \mathrm{H}$ in ovarian stroma) were heterogeneous as determined by the Bartlett's test for homogeneity of variances (Stee1 \& Torrie, 1960) and therefore a log transformation of the data was performed. Orthogonal contrasts (Table VI-1) of the data (Table VI-2) indicated that the percentage of radiation (DPM) localized in the ovarian tissues differed $(P<.0006)$ from the amount remaining in the effluent (42.2\%) (Fig. VI-I) $(\mathrm{T} 1>\mathrm{T} 2, \mathrm{~T} 5, \mathrm{~T} 4)$. Furthermore, of the three ovarian tissues 


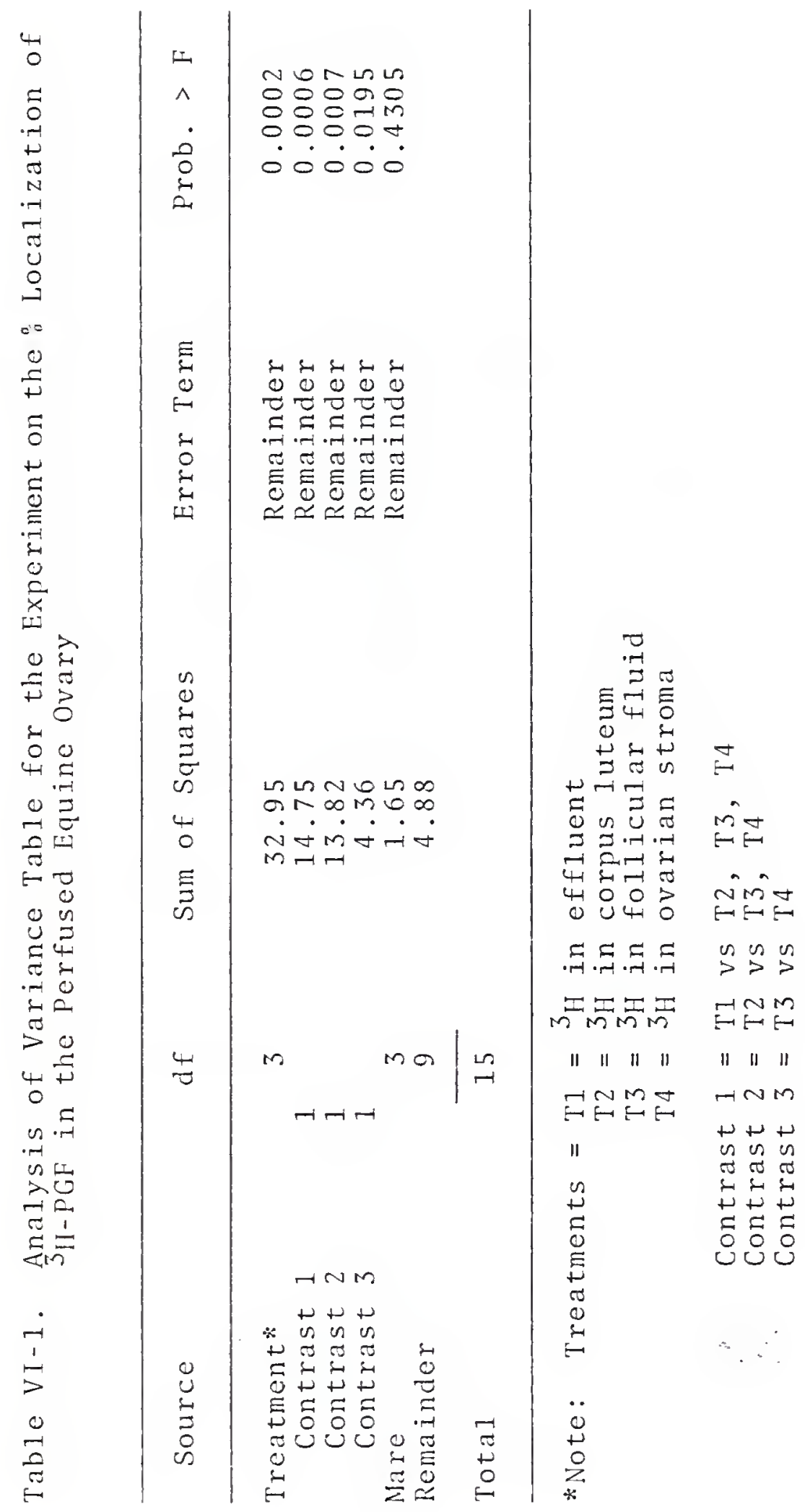




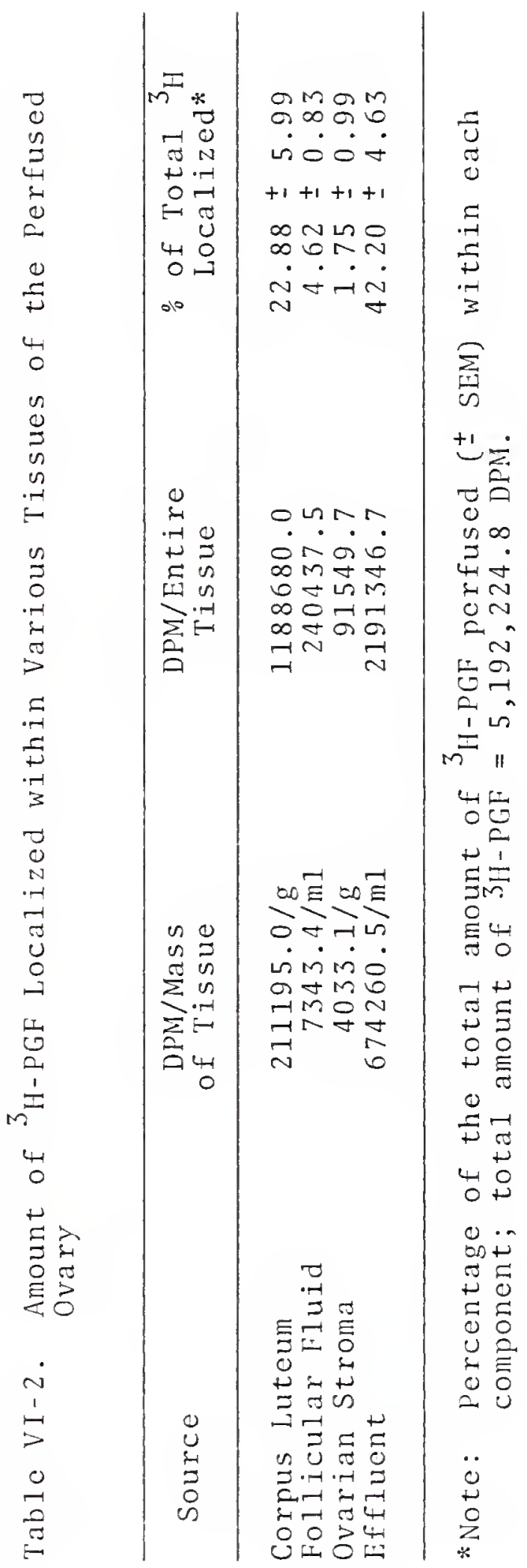


studied, the CL $(22.88 \%)$ sequestered the largest $(P<.0007)$ amount of radiation while the follicular fluid (4.62\%) contained more $(\mathrm{P}<.0195)$ than the stroma $(1.75 \%)(\mathrm{T} 2>\mathrm{T} 3>\mathrm{T} 4)$ (Fig. VI-1). The effluent, CL, ovarian stroma and follicular fluid represented $71.54 \%$ of the injected $\mathrm{PGF}_{2 \alpha} \alpha^{-{ }^{3} \mathrm{H}}$. Localization of the remaining $28.55 \%$ was unknown, but presumed to be in ovarian tissues not studied, i.e., granulosa cells and epithelial cells.

The high level of radioactivity within the CL is supportive of the hypothesis that PGF is involved in luteal physiology. However, interpretation of these results is mitigated by the possibilities of $\mathrm{PGF}^{3} \mathrm{H}$ being metabolized prior to binding or the high levels of radiation in the CL being a result of vascular pooling. 
Fig. VI-2. Localization of tritiated PGF within various tissues of the perfused equine ovary $(\bar{X} \pm \mathrm{SEM})$. 
$-84-$

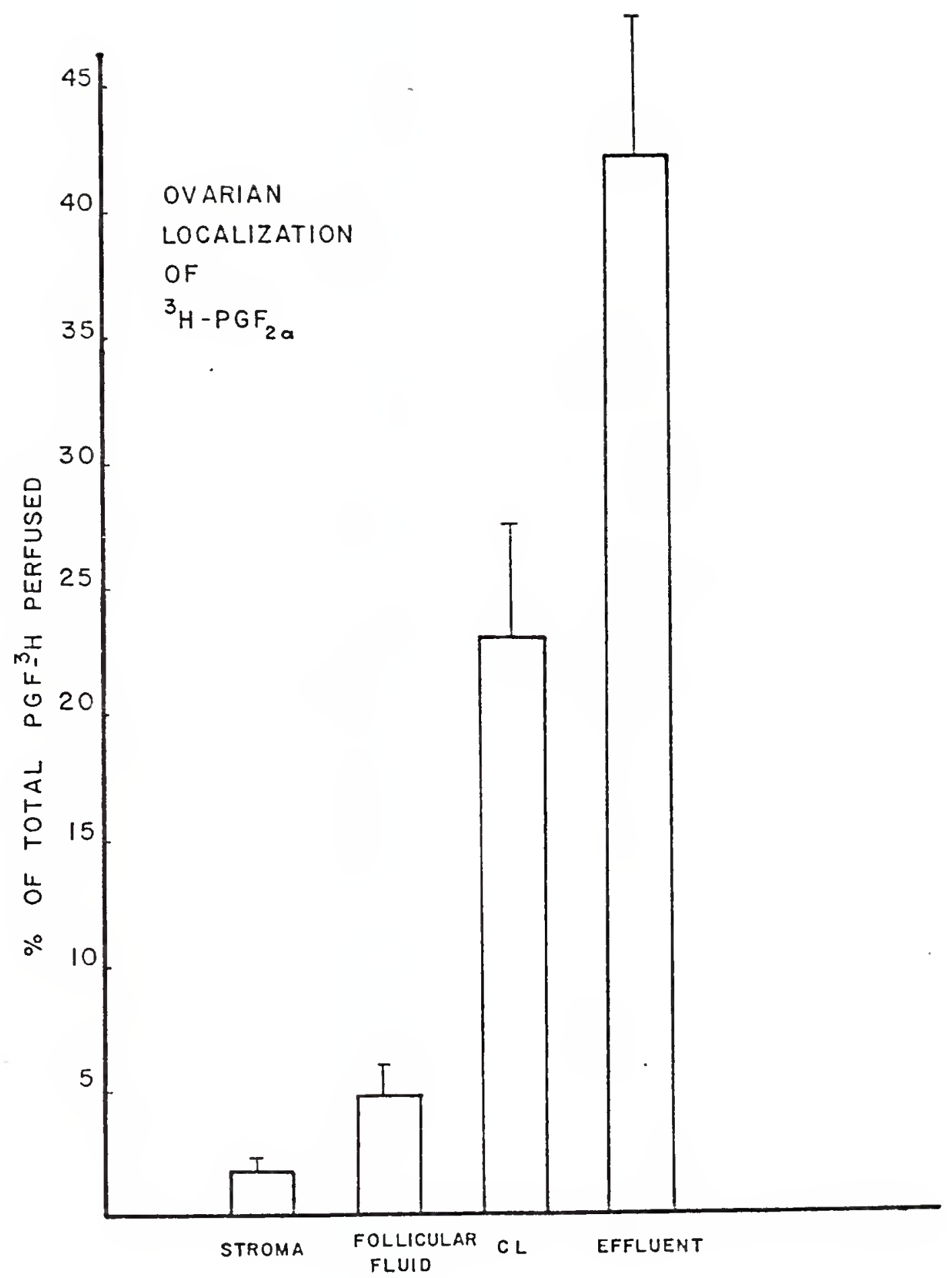


CHAPTER VII

SPECIFIC BINDING OF PGF TO THE

EQUINE CORPUS LUTEUM

Exogenous PGF will localize in the equine CL (Chapter VI) and induce luteal regression (Douglas \& Ginther, 1972; A11en \& Rowson, 1973). Although the mechanism of action of this effect of PGF is not well understood, involvement of the membrane-associated adenyl cyclase system in luteolysis (Marsh, 1971) suggests that the mode of action of PGF is through a membrane receptor. Luteal PGF membrane receptors have been isolated and characterized biochemically in the cow (Kimbal1 \& Lauderdale, 1975; Rao, 1976), sheep (Powell et al., 1974), mare (Kimbal1 \& Wyngarden, 1977), and woman (Rao, 1977). Therefore, the membrane receptor may play a role in luteal regression in the cycling mare, or in prevention of luteal demise in the pregnant mare. This study was designed to characterize the equine 1uteal PGF receptor and to assess its possible role in the cycling and early pregnant mare.

\section{Materials and Methods}

\section{PGF Binding to Luteal Tissue}

Ovaries containing luteal tissue were removed surgically from mares according to the procedure outlined in the Materials 
and Methods of Chapter III. After surgery, the ovary was immersed immediately in chilled (4 C) phosphate buffered saline (PBS) containing indomethacin $(10 \mu \mathrm{g} / \mathrm{ml})$ and the $\mathrm{CL}$ was dissected free, weighed, quick frozen in liquid nitrogen, and stored at $-60 \mathrm{C}$. Blood clots found within a corpus hemorrhagicum were removed prior to weighing.

Later, the frozen CL was sliced thinly with a scalpel and homogenized in a Potter-type hand homogenizer. To remove cellular debris, the homogenate was filtered through three layers of cheesecloth and centrifuged at $1086 \mathrm{G}$ for $10 \mathrm{~min}$ at $4 \mathrm{C}$. The supernatant was recentrifuged at $100,000 \mathrm{G}$ for $1 \mathrm{hr}$ at $4 \mathrm{C}$, and the resultant pellet was resuspended in $\mathrm{PBS}$ (2 ml PBS/g of original tissue). This (particulate) membrane fraction was then stored at $-60 \mathrm{C}$ until analysis.

In the equilibrium binding study, $100 \mu 1$ of membrane preparation (MP) containing approximately $0.8 \mathrm{mg}$ of protein were incubated with $0.38 \mathrm{ng} \mathrm{PGF}_{2 \alpha^{-}}{ }^{3} \mathrm{H}$ (specific activity = $9.2 \mathrm{Ci} / \mathrm{mMol} ; \mathrm{NET} 345$, Lot 787-250) in either the presence (non-specific binding) or absence (total binding) of $1.0 \mathrm{\mu g}$ PGF. Unless otherwise stated, incubations were conducted in a reaction volume of $300 \mathrm{\mu l}$, in triplicate, for $3 \mathrm{hr}$ at $22 \mathrm{C}$, pH 7.4. Following incubation, the free [F] and bound [B] ligands were separated by ultrafiltration as described by Kimball and Lauderdale (1975). Separation was accomplished by filtering $100 \mu 1$ of the incubation mixture through HAwP 0.45 Millipore filters. Filters were washed with $4 \times 3 \mathrm{ml}$ 
PBS and air dried. The filters were then added to liquid scintillation vials, solubilized with $15.0 \mathrm{~m} 1$ methyl cellusolve, and the tritium counted on a Beckman LS-300 liquid scintillation spectrophotometer as described previously. Specific binding was calculated by subtracting non-specific binding from total binding and was expressed as the percentage of the total PGF bound to the membrane preparation.

\section{Receptor Characterization}

The time required for PGF to equilibrate with its receptor was determined by measuring the amount of $\mathrm{PGF}_{2 \alpha^{-}}{ }^{3} \mathrm{H}$ specifically bound to the MP after incubation times of 15 , $30,120,180$, and $240 \mathrm{~min}$ at both $4 \mathrm{C}$ and $22 \mathrm{C}$. The reversibility of ligand-receptor binding was studied by measuring bound PGF at $0,15,30,60,120,180$, and 240 min after addition of $1.0 \mu \mathrm{g}$ of unlabelled PGF to a $180 \mathrm{~min}$ incubation. A dose-response study was conducted by performing competitive binding studies in the presence of $0,2.5,5,10,25$, 50, and $100 \mathrm{ng}$ unlabelled PGF.

To further assess receptor specificity and crossreactivity, incubations were conducted in the presence of $0.1,1.0$, and $10 \mu \mathrm{g}$ of the various PGF analogues shown in Fig. VII-1. The resulting dose-response curves were analyzed by least squares regression analysis on a Monroe 1860 calculator and the theoretical concentration required to displace $50 \%$ of the bound $\mathrm{PGF}_{2 \alpha}-{ }^{3} \mathrm{H}$ was calculated. The ratio of $\mathrm{PGF}_{2 \alpha}$ 
Fig. VII-1. Listing of the chemical structures of the PGF $2 \alpha$ analogues used in the cross-reactivity study. Arrows indicate those areas of the analogue that differ with $\mathrm{PGF}_{2} \alpha$ and the parentheses indicate the $\%$ cross-reactivity between the analogues and $\mathrm{PGF}_{2 \alpha}$. 
HO
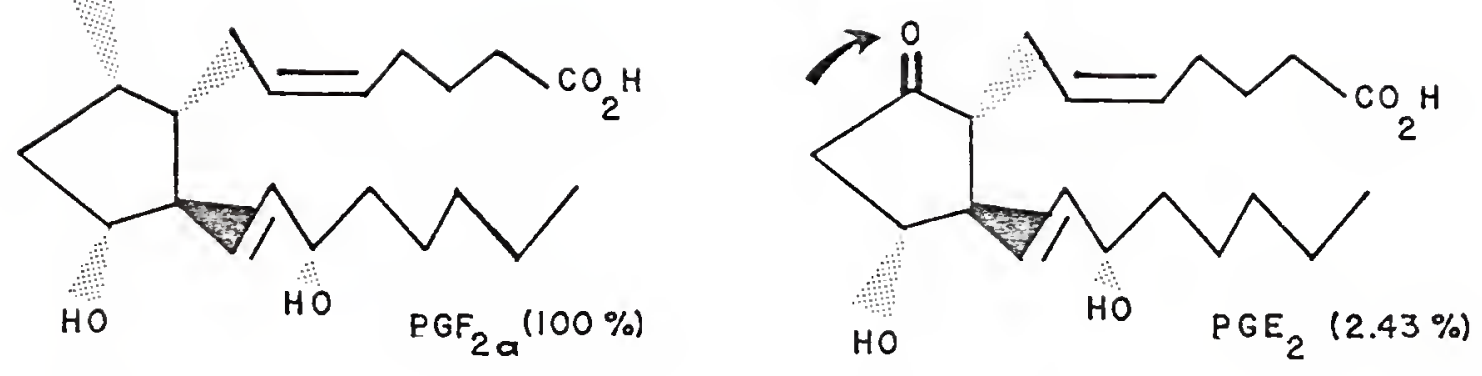

HO
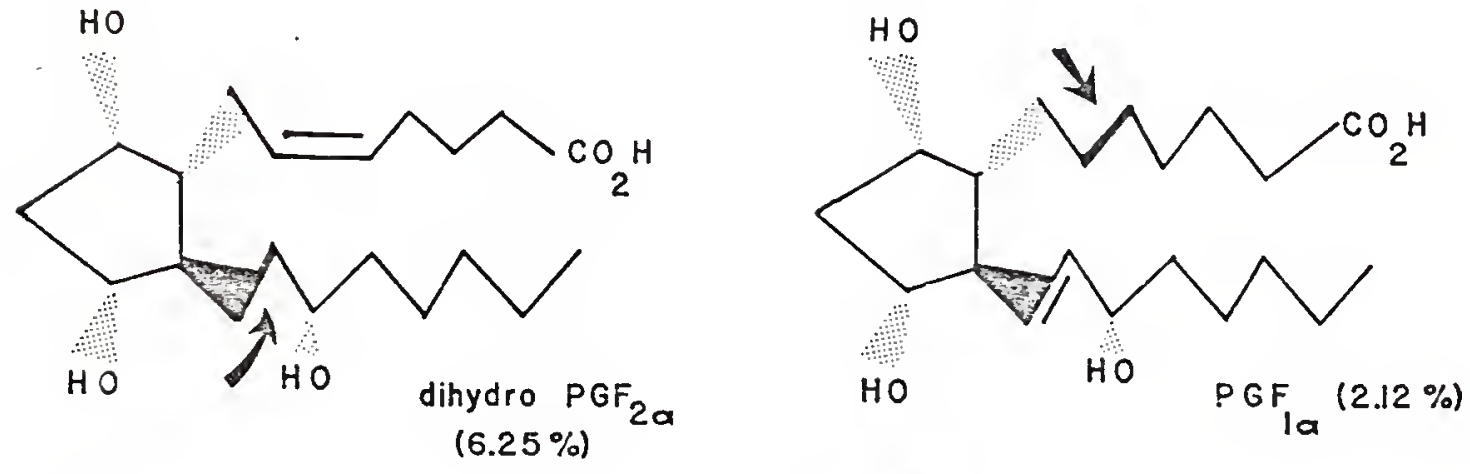

HO

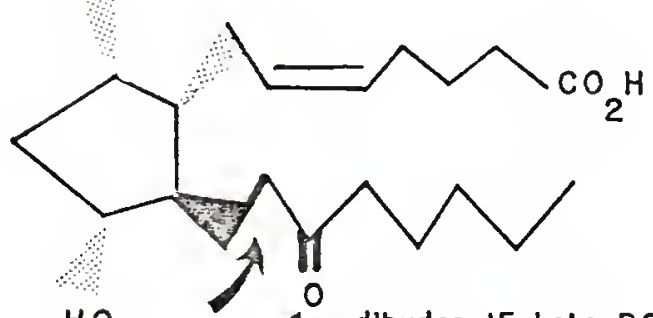

1 dihydro 15 keto $P G F_{2 a}$
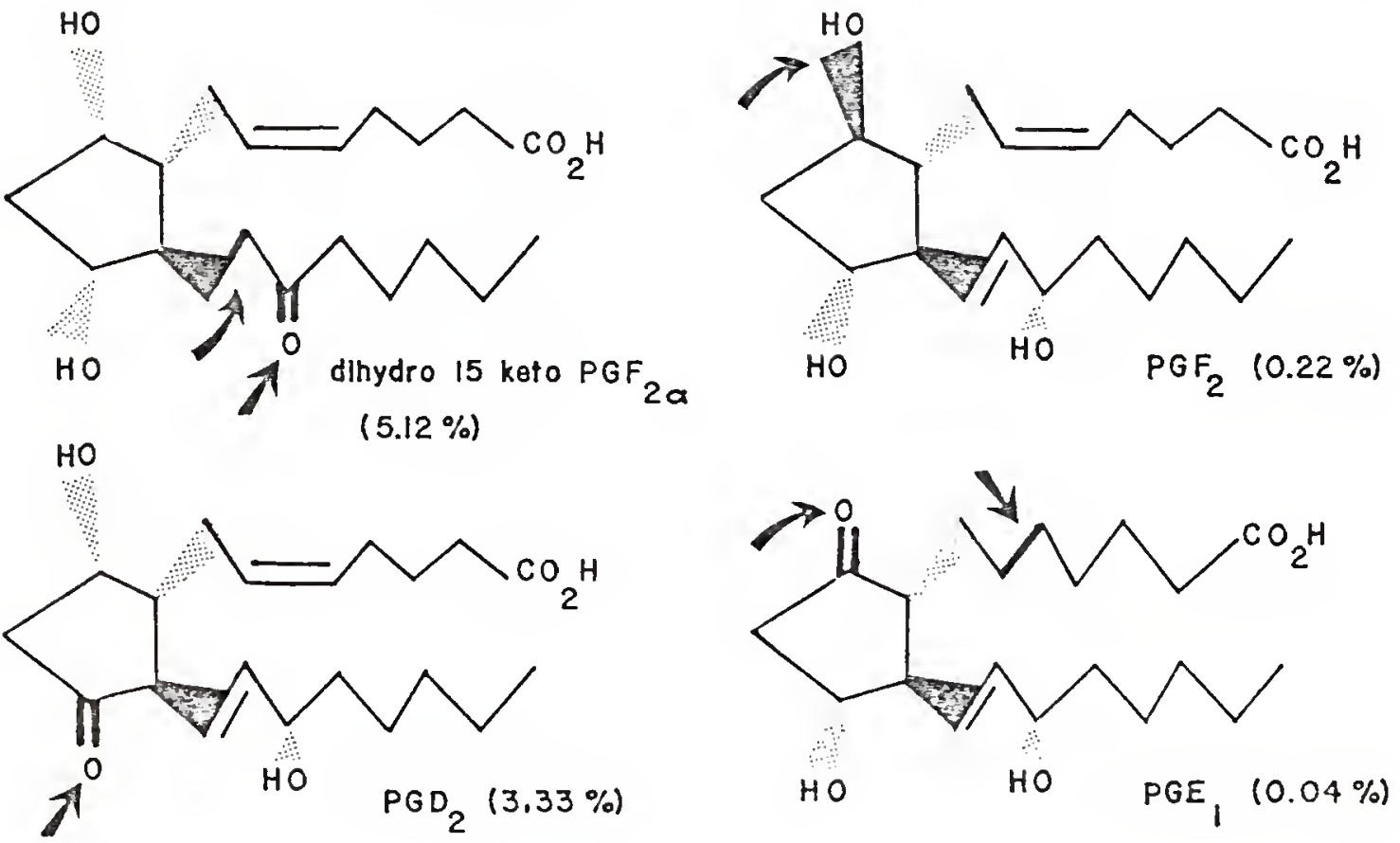
to PGF analogue at $50 \%$ displacement of bound $\mathrm{PGF}_{2} \alpha^{-{ }^{3} \mathrm{H} \text { was }}$ also calculated.

The dissociation constant and binding capacity of the PGF receptor were calculated by Scatchard analysis (Scatchard, 1949) by incubating the MP in the presence of increasing

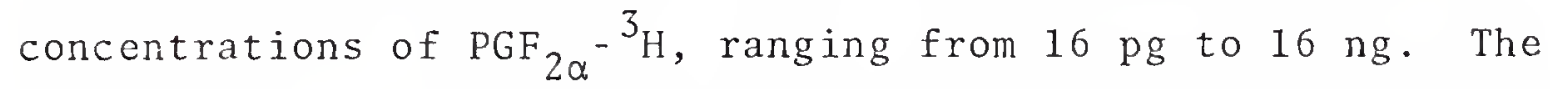
slope and $y$ intercept of [B] versus [B]/[F] were calculated by least squares analysis.

\section{PGF Binding in Pregnant and Non-Pregnant Mares}

Specific $\mathrm{PGF}_{2 \alpha}$ binding was determined in luteal tissue collected from the pony mares described in the Materials and Methods of Chapter III. Twenty non-pregnant mares during the summer of 1977 were assigned randomly to either Day 4 , 8, 12, 16, or 20 post-ovulation ( 4 mares/Day), and 20 pregnant mares during the summer of 1976 were assigned randomly to either Day $8,12,14,16,18$, or 20 post-ovulation (3 mares/Days 16 \& 20; 4 mares/Days 8, 12, 14, \& 18). Lutea1 tissue was processed as described previously, with binding expressed as pg PGF bound specifically/mg MP protein. The protein concentration of the MP was determined by the method of Lowry and co-workers (1951) using bovine serum albumin as the protein standard.

The statistical test for significance between Treatment and Day effects was by analysis of variance (Treatments: $\mathrm{T} 1=$ specific and $\mathrm{T} 2=$ non-specific binding). Since the experimental design represents a mixed model with unequal 
subclasses, the data were analyzed by Dr. Walter R. Harvey's (LSLM76) computer program. The statistical model submitted to the computer is shown in Tables VII-1 and VII-2. The results obtained from tissues used in the pregnancy and nonpregnancy study were confounded by year. Therefore, statistical inferences between these two studies were impossible and they were analyzed separately.

\section{$\underline{\text { Results and Discussion }}$}

Prostaglandin $\mathrm{F}_{2 \alpha}$ was found to bind specifically and reversibly to a $100,000 \mathrm{G}$ membrane preparation obtained from equine CL. The rate of association of PGF with its receptor indicated that an incubation time of $3 \mathrm{hr}$ was required before a dynamic equilibrium, i.e., maximum binding, was established at 22 C (Fig. VII-2a); however, no specific binding was observed at $4 \mathrm{C}$. With this finding, all subsequent binding studies were conducted for $3 \mathrm{hr}$ at $22 \mathrm{C}, \mathrm{pH} 7.4$. The time course of dissociation indicated that the addition of excess PGF to a preincubated, equilibrated, binding reaction could displace the bound PGF- ${ }^{3} \mathrm{H}$ within $60 \mathrm{~min}$ (Fig. VII-2b). The reversibility of the ligand-receptor binding was further confirmed by competitive displacement of bound PGF- ${ }^{3} \mathrm{H}$ with increasing levels of unlabelled PGF (Fig. VII-2C). The doseresponse curve was sensitive from 1 to $50 \mathrm{ng}$ PGF.

Scatchard analysis of a Day 12 non-pregnant CL (Fig. VII-5) suggested that the receptor population was heterogenous. 


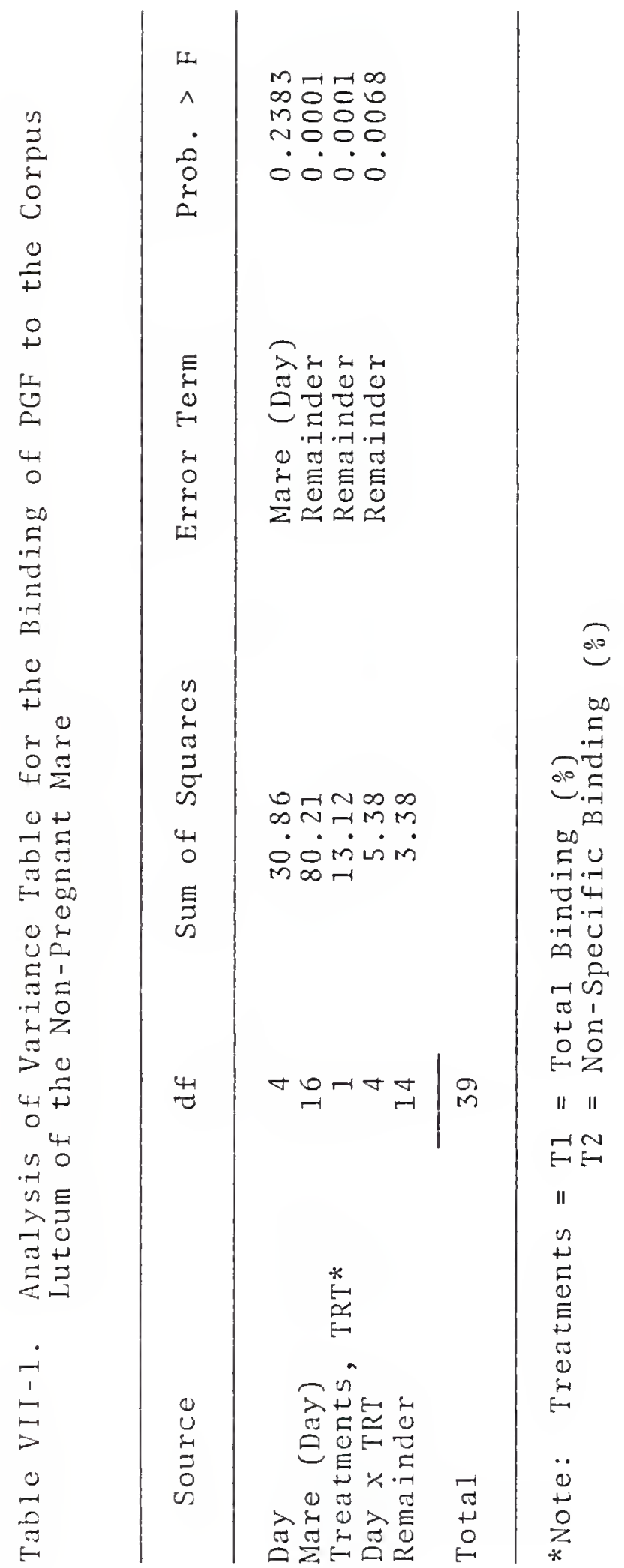




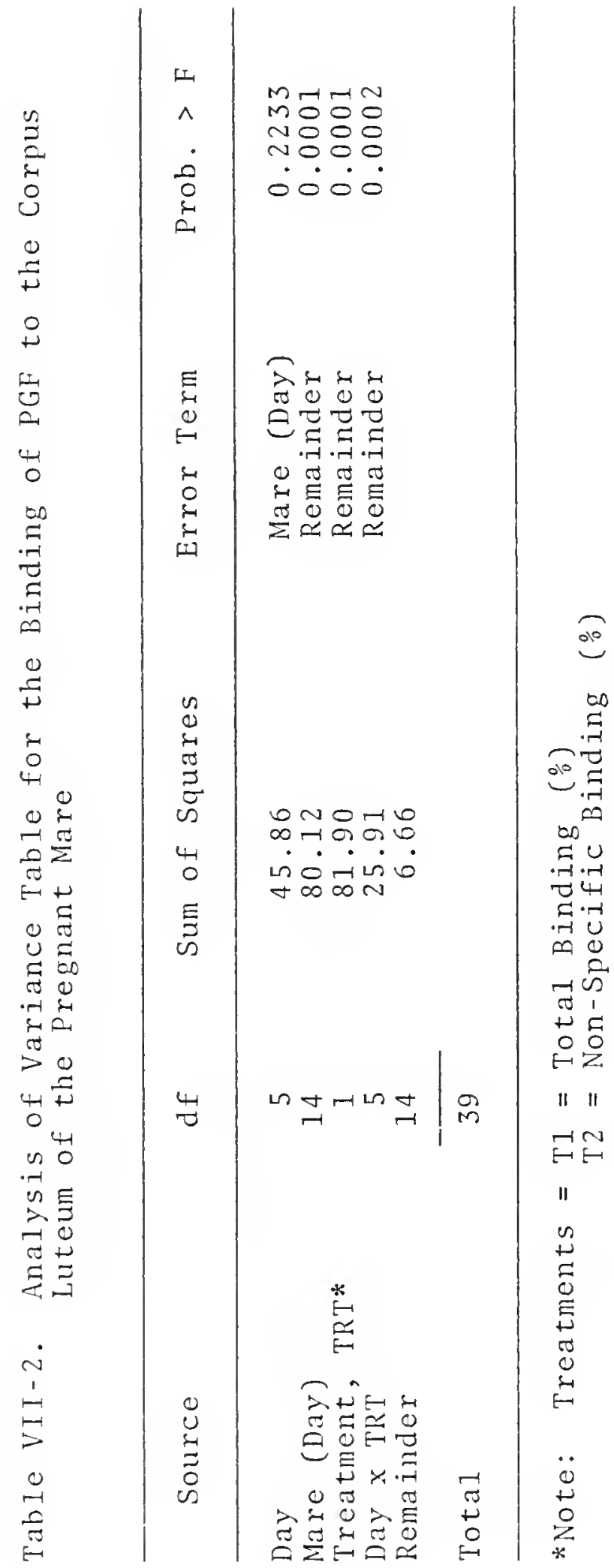


Fig. VII-2. (A) Rate of association of PGF to a Day 14 (open circles) and Day 8 (closed circles)

luteal membrane preparation;

(B) Rate of dissociation of PGF from the luteal membrane preparation;

(C) Dose-response relationship between the luteal membrane preparation, tritiated PGF, and various amounts of radioinert PGF. 


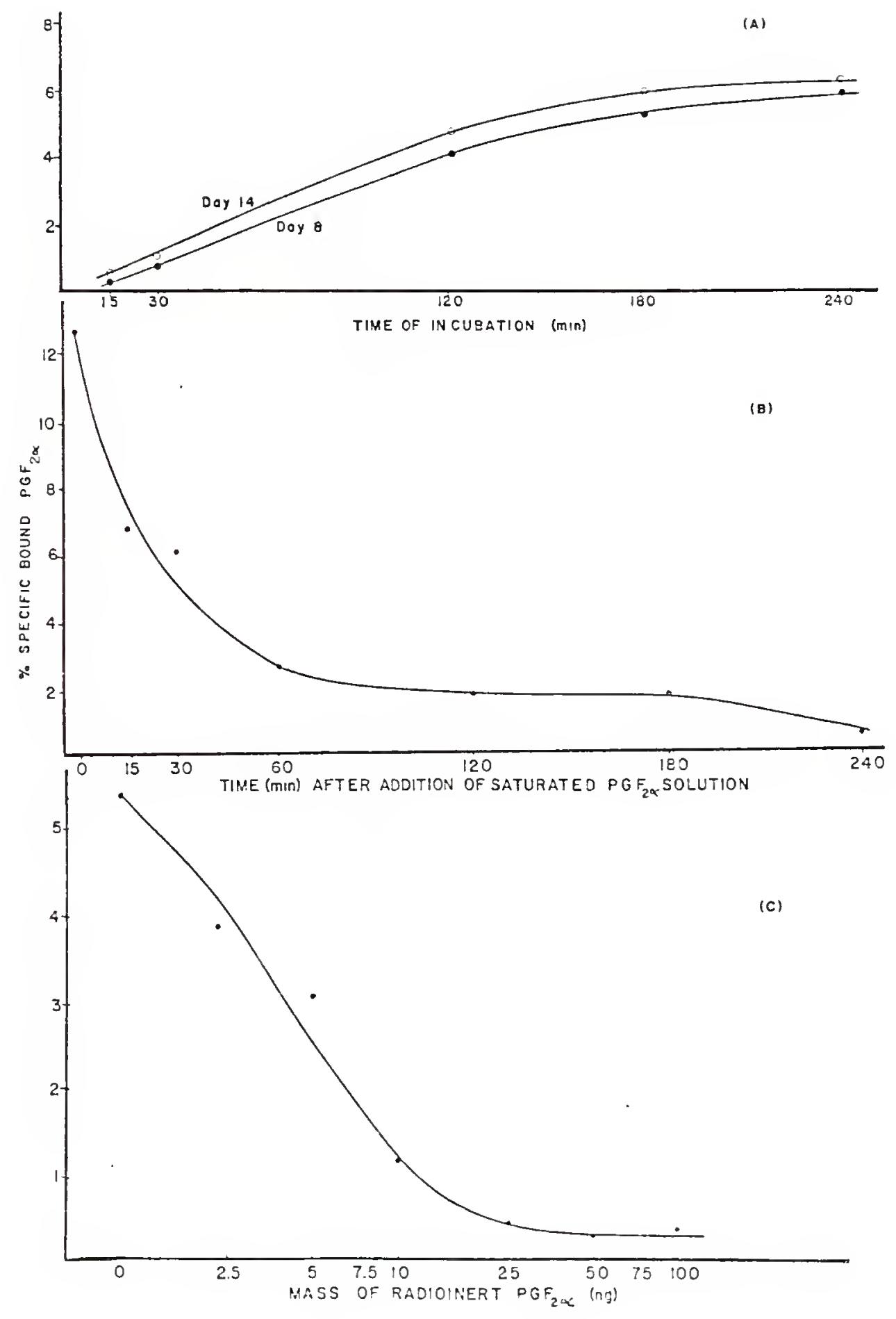




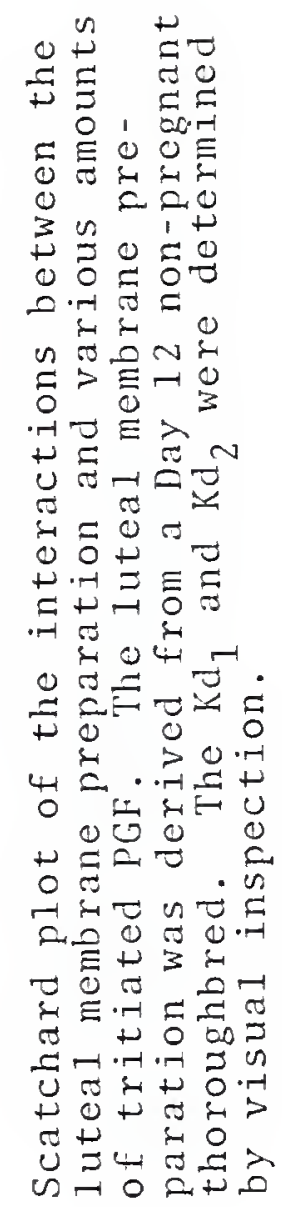

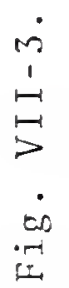




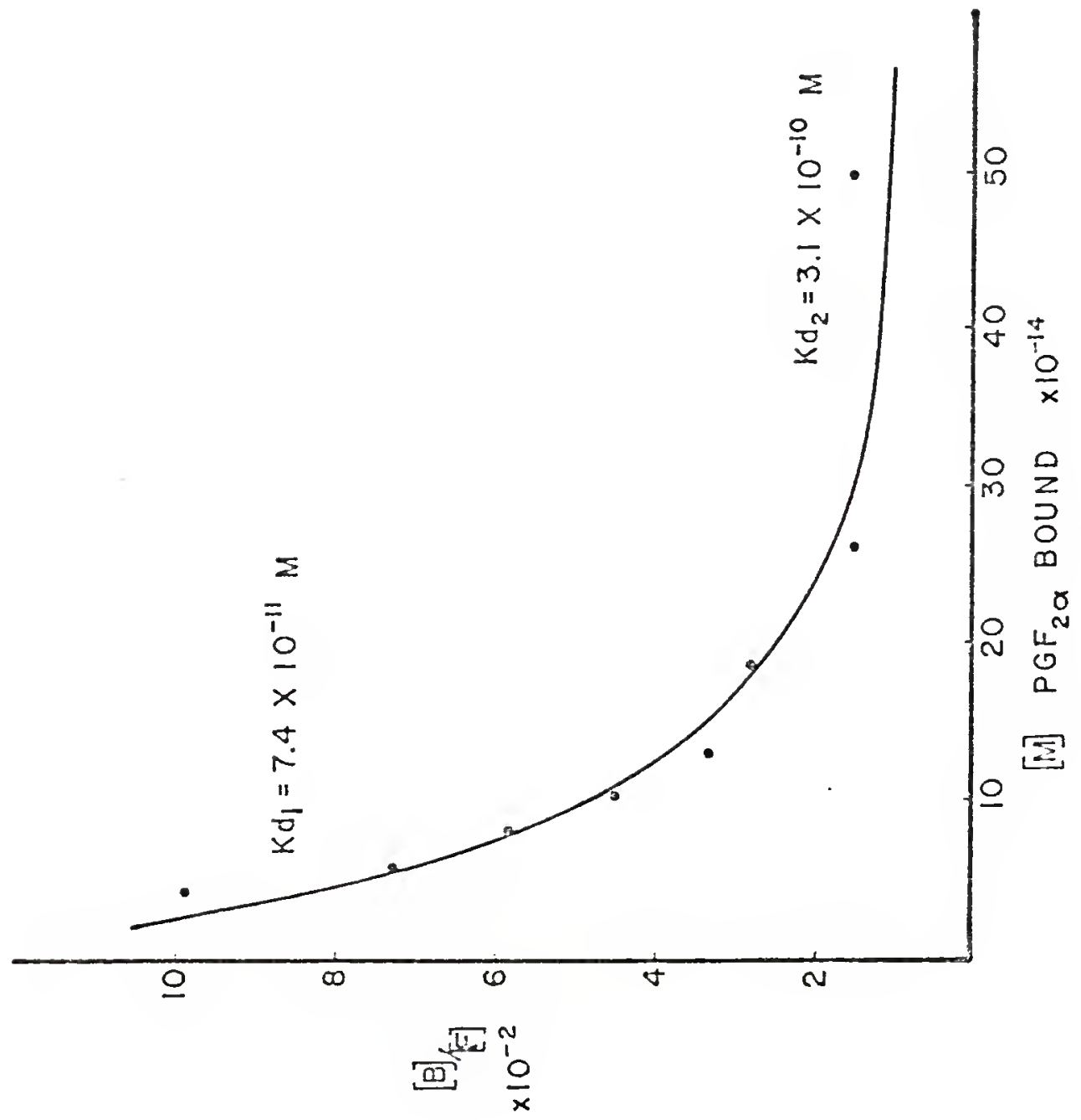


No apparent difference was observed in the binding parameters of CL from pregnant and non-pregnant mares or from different days after ovulation (Table VII-3). Thus, the mean dissociation constants of the membrane preparation derived from these mares were $\mathrm{Kd}_{1}=4.2 \times 10^{-11}[\mathrm{M}]$ and $\mathrm{Kd}_{2}=9.1 \times 10^{-10}[\mathrm{M}]$ with binding capacities of $\mathrm{BC}_{1}=1.4 \times 10^{-13}$ and $\mathrm{BC}_{2}=$ $7.5 \times 10^{-13}[\mathrm{M}] / \mathrm{mg}$ membrane preparation protein, respectively. Since the membrane preparation was derived potentially from more than one cell type, i.e., luteal cells, endothelial. celis, and plasma cel1s, and membrane type, i.e., plasma membrane, endoplasmic reticulum, and ribosomes, the apparent heterogeneity of receptors may be a reflection of this mixture. Alternatively, the heterogeneity may be a reflection of more than one population of receptors on the luteal ce11. Heterogeneity has been reported by Rao (1976) for cows $\left(\mathrm{Kd}_{1}=1.3 \times 10^{-9}[\mathrm{M}], \mathrm{Kd}_{2}=1.0 \times 10^{-8}[\mathrm{M}]\right)$, a1though others have reported a single homogeneous receptor population in the cow (Kd $=2.1 \times 10^{-8}$ [M]; Kimball G Lauderdale, 1975), mare $\left(\mathrm{Kd}=3.2 \times 10^{-9}[\mathrm{M}]\right.$; Kimbal1. E Wyngarden, 1977), and sheep $(\mathrm{Kd}=$ $1.0 \times 10^{-7}[\mathrm{M}]$; Powe11 et al., 1974). The affinity constants reported herein are higher than those cited above. This high affinity for PGF may explain partly the high sensitivity of mares to exogenous PGF relative to other species (Douglas $\&$ Ginther, 1975) and may also lend support to the concept of systemic delivery of endogenous PGF $2 \alpha$ to the CL (Ginther $\&$ First, 1971). The reasons for the dissimilarity in affinity 


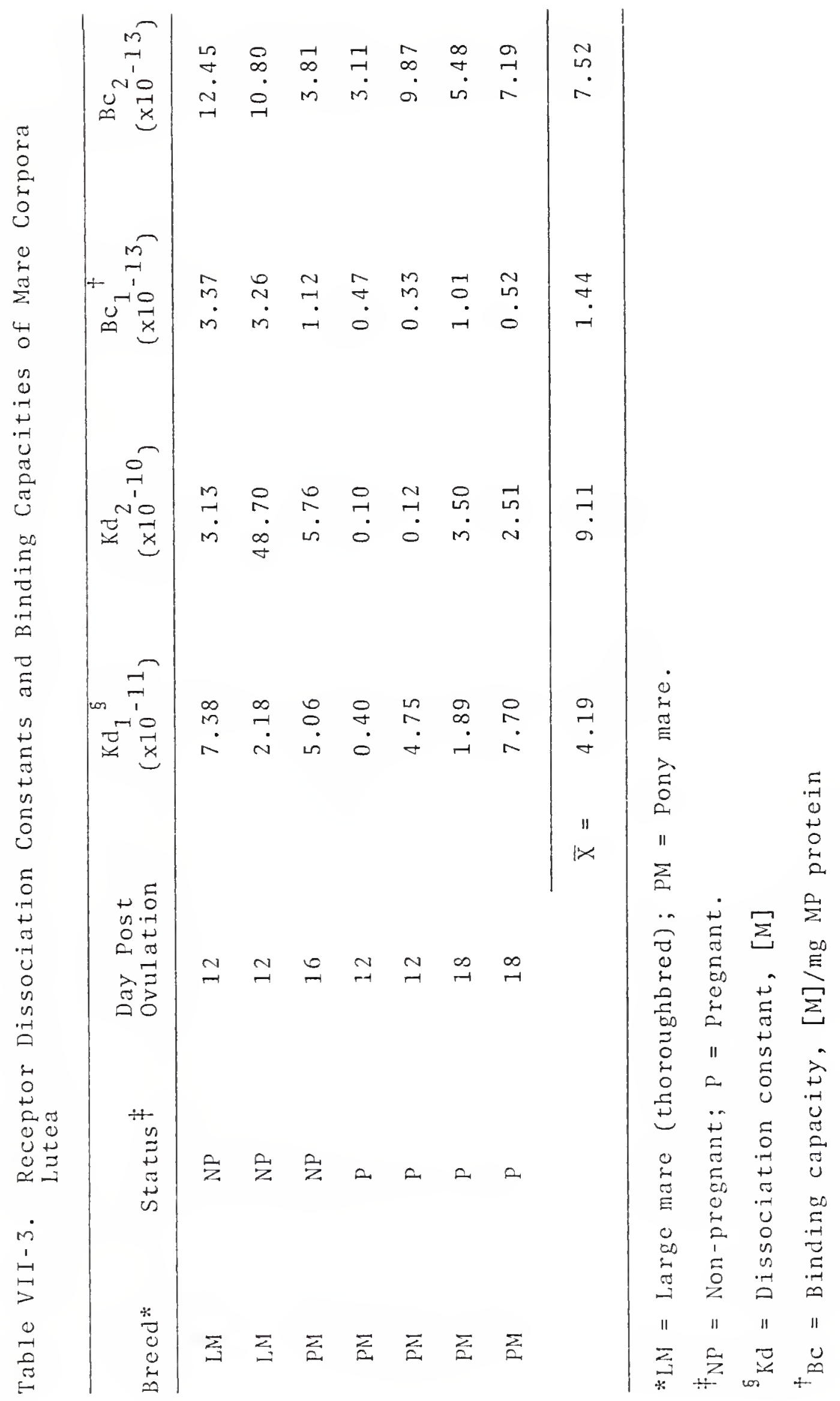


constants obtained in this study and that of Kimball (1977) are not known.

The relative affinities of various prostaglandins (Fig. VII-1) for the PGF receptor indicated that the metabo1ites, 13,14-dihydro-PGF and 13,14-dihydro-15-keto-PGF were the most competitive (Table VII-4). Since these metabolites have a low biological activity and a long half-life, their relatively high affinity for the PGF receptor suggests that they may function as endogenous competitive inhibitors of PGF action. A further decline in cross-reactivity was observed in compounds that differed from PGF $2 \alpha$ at the $\Delta^{5}$ double bond, i.e., $\mathrm{PGF}_{1 \alpha}$, or the $9 \alpha-\mathrm{OH}$ functional group, i.e., $P_{2} \& E_{2} P_{2 B}$. In addition, a marked decline in crossreactivity occurred when both the $\Delta^{5}$ double bond and $9 \alpha-\mathrm{OH}$ group differed, i.e., $\mathrm{PGE}_{1}$ thereby suggesting that these regions of the molecule play an important role in PGF membrane receptor recognition.

The weights of the CL in early pregnant mares did not change significantly, but CL weights from Day 16 and 20 non-pregnant mares were lower $(\mathrm{P}<.0080)$ than those from pregnant mares on Days 4, 8, and 12 (Fig. VII-4 \& Table VIII-5). Polynomial regression of the time (day) trends, with a SAS (Statistical Analysis System) computer program (procedure GLM), indicated that changes in weights of CL from non-pregnant mares were described best by the quadratic equation $\hat{Y}=2.62+1.09 X-1.96 X^{2}$ (Fig. VII-5). The decline 
Table VII-4. Relative Affinities of Various Prostaglandins for the $\mathrm{PGF}_{2 \alpha}$ Receptor

\begin{tabular}{|c|c|c|}
\hline Compound Name & $\begin{array}{c}\text { ng for } \\
50 \% \\
\text { displacement }\end{array}$ & $\begin{array}{l}\text { Relative } \\
\text { affinity }\end{array}$ \\
\hline $\mathrm{PGF}_{2 \alpha}$ & 4 & 1.0000 \\
\hline $15,14-$ dihydro-PGF $2 \alpha(-\Delta 13 \text { bond })^{1}$ & 64 & 0.0625 \\
\hline $\begin{array}{l}13,14 \text {-dihydro-15-keto-PGF } 2 \alpha \\
(+15-\text { keto \& }-\triangle 13 \text { bond })\end{array}$ & 78 & 0.0512 \\
\hline $\mathrm{PGD}_{2}(+11$ keto $)$ & 120 & 0.0333 \\
\hline $\mathrm{PGE}_{2}(+9$ keto $)$ & 164 & 0.0243 \\
\hline $\mathrm{PGF}_{1 \alpha}(-\Delta 5$ bond $)$ & 188 & 0.0212 \\
\hline $\mathrm{PGF}_{2 \beta}(+9 \mathrm{OHB})$ & 1800 & 0.0022 \\
\hline $\mathrm{PGE}_{1}(+9$ keto $\&-\Delta 5$ bond $)$ & 9200 & 0.0004 \\
\hline
\end{tabular}

${ }^{1}$ Structural difference from $\operatorname{PGF}_{2 \alpha}$. 


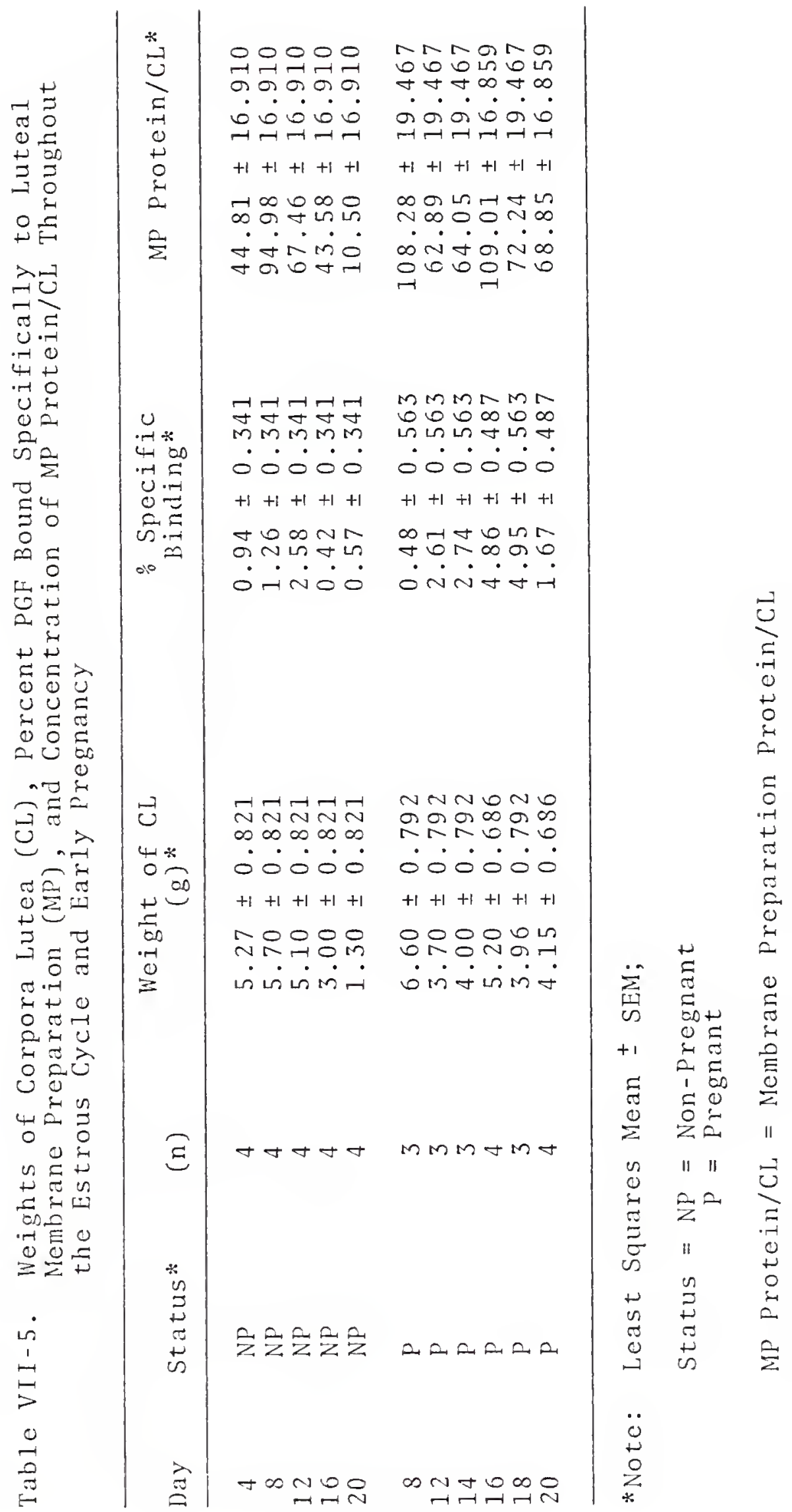




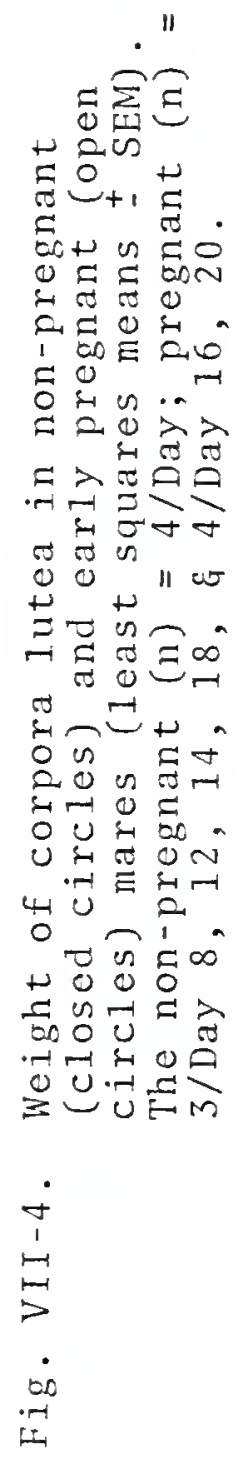




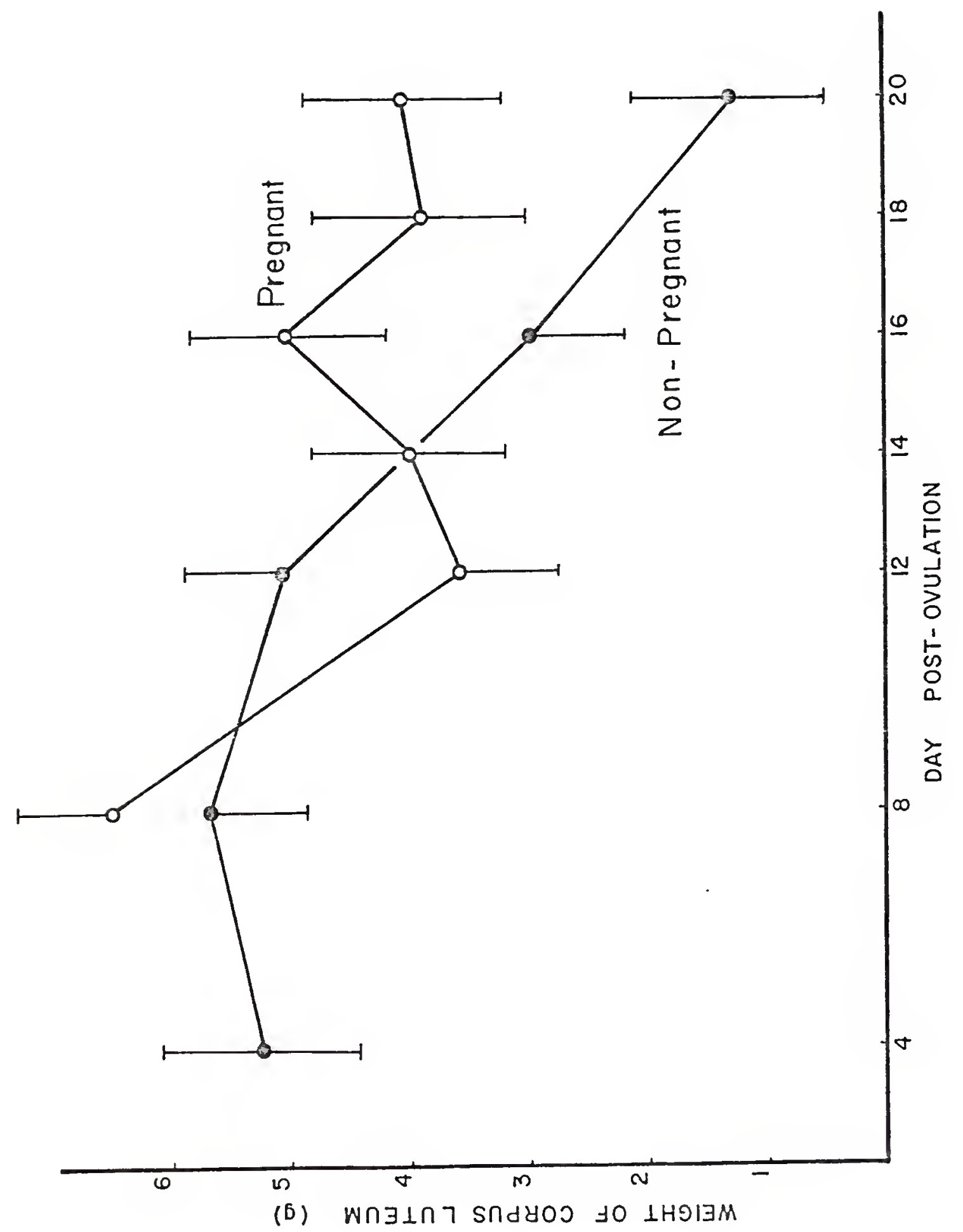




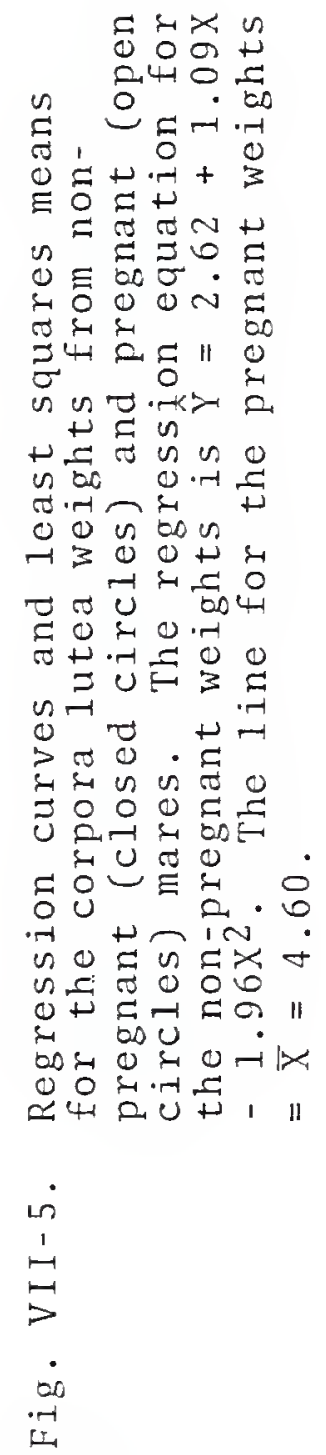


$-106-$

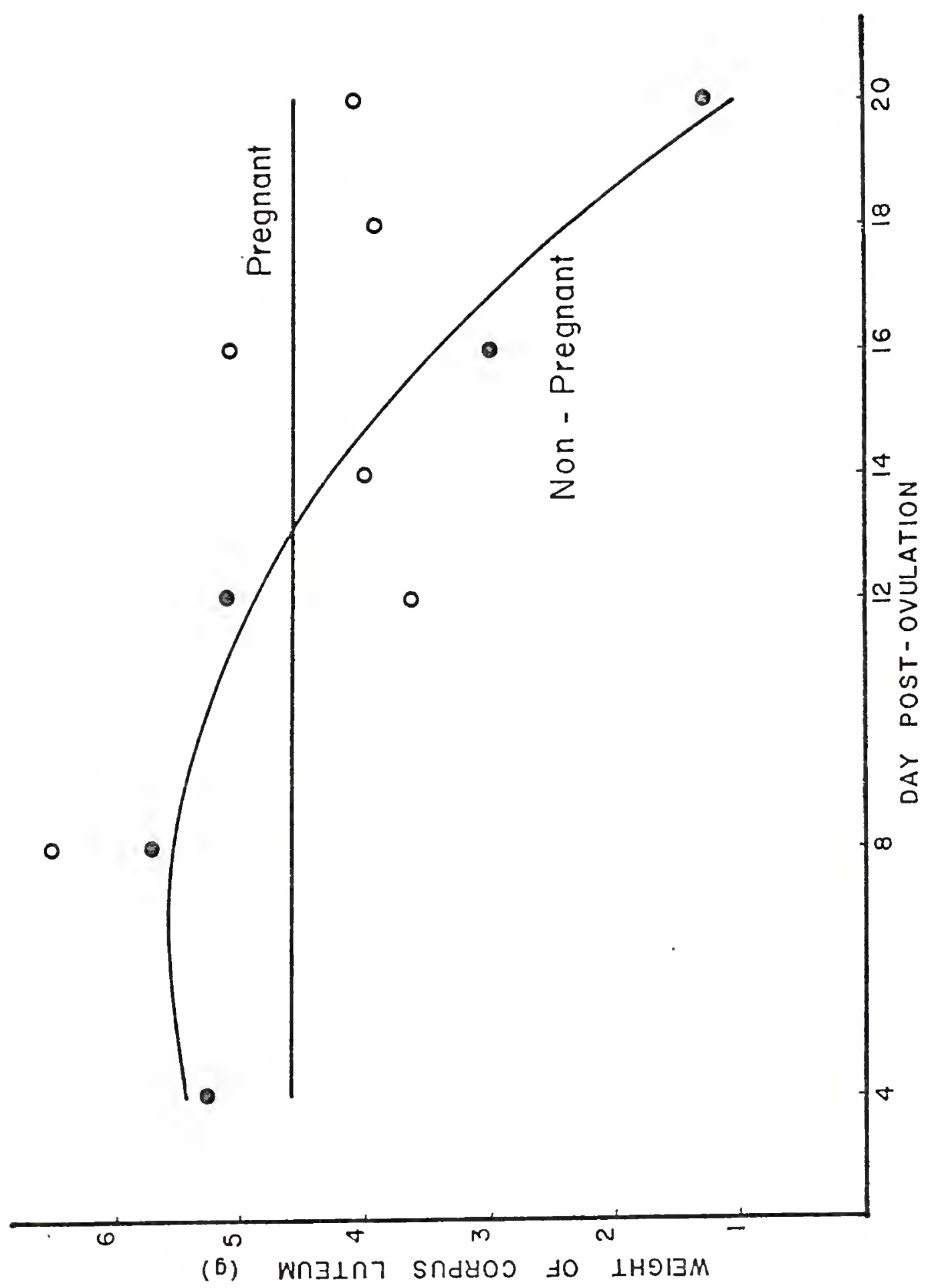


in luteal weight in the non-pregnant mare coincided with the time of maximal concentration of PGF in the uterine vein (Douglas \& Ginther, 1976), uterine lumen (Zavy et al., 1978), and endometrium (Chapter III) and also with the fall in peripheral progesterone concentrations (Sharp \& Black, 1973; Douglas $\&$ Ginther, 1976) and with histological degeneration of the luteal cells (van Niekerk et a1., 1975). Thus, the structural and functional demise of the CL is temporally associated with increased uterine production of PGF. In the pregnant mare, however, CL weights remained relatively constant, despite the fact that peripheral plasma progesterone concentrations declined between Days 12 and 24 (Squires et $\underline{\text { a1. }}$, 1974a; Squires et a1., 1974b; Holtan et a1. , 1975). Maintenance of luteal weight would perhaps suggest that progesterone production is maintained in early pregnancy and the decline in plasma concentrations between Days 12 and 24 could reflect increased uterine and/or conceptus metabolism of progesterone. The equine conceptus has been shown to produce estrogens by Day 14 (F1ood \& Marrab1e, 1975; Mayer et al., 1977; Seamens et a1., 1979) and it may well metabolize available progesterone for this purpose (Seamens et al., 1979). In the pregnant sow, which has the same type of diffuse epitheliochorial placentation as the mare, metabolism of progesterone by the uterus has been suggested (Knight et al., 1977) and conversion of tritium-labelled progesterone to estrone and estradiol by the Day 14 porcine embryo has been demonstrated by perry and co-workers (1973). 
The concentration of protein within the MP from the CL differed $(P<.0349)$ among Days in the non-pregnancy study but not $(\mathrm{P}<.2794)$ during the pregnancy study (Fig. VII-6 \& Table VII-5). The time trends of the non-pregnancy data were described best by the quadratic equation, $\hat{Y}=6.85+$ 14.44X-0.7269X (Fig. VII-7). In the non-pregnant animal, the concentration of MP protein declined at the expected time of luteal regression and was probably a result of luteolysis. To compensate for changes in the concentration of MP protein, PGF binding was corrected for protein concentration and expressed as pg PGF bound specifically/mg MP protein.

A significant $(P<.0001)$ Treatment effect (Treatments: $\mathrm{T} 1=$ specific binding, $\mathrm{T} 2$ = non-specific binding) was observed in both pregnant and non-pregnant mares (Tables VII-1 \& VII-2). However, no Day effects were observed. This may have resulted from a significant Day $x$ Treatment interaction in the non-pregnant $(\mathrm{P}<.0068)$ and pregnant mare studies $(P<.0002)$. Therefore, specific and non-specific binding were analyzed separately. Non-specific binding did not vary by Day in either study while the specific binding of PGF to the luteal receptor of the non-pregnant mare increased $(\mathrm{P}<.0085$; Table VIII-5) to Day 12 and declined abruptly on Days 16 and 18 (Fig. VII-8). This increase in PGF binding coincided with the expected time of lutcolysis and presumably reflected the readiness of the mid-diestrus $C L$ to bind PGF. Conversely, the paucity of PGF receptors on the early CL membrane may account for the refractoriness of the Day $3 \mathrm{CL}$ 


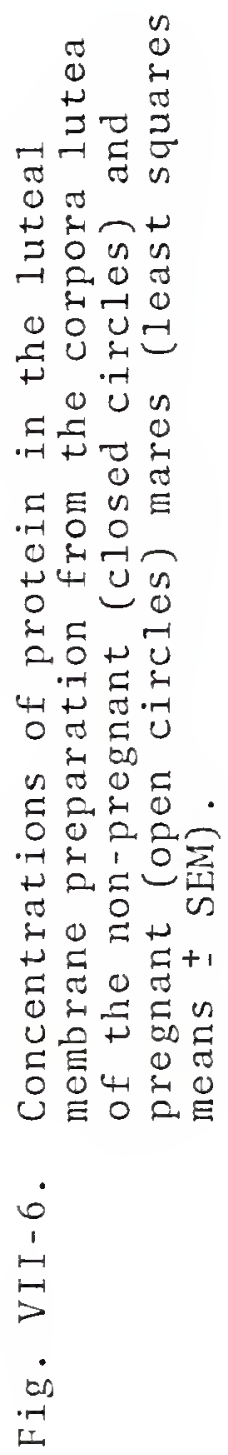




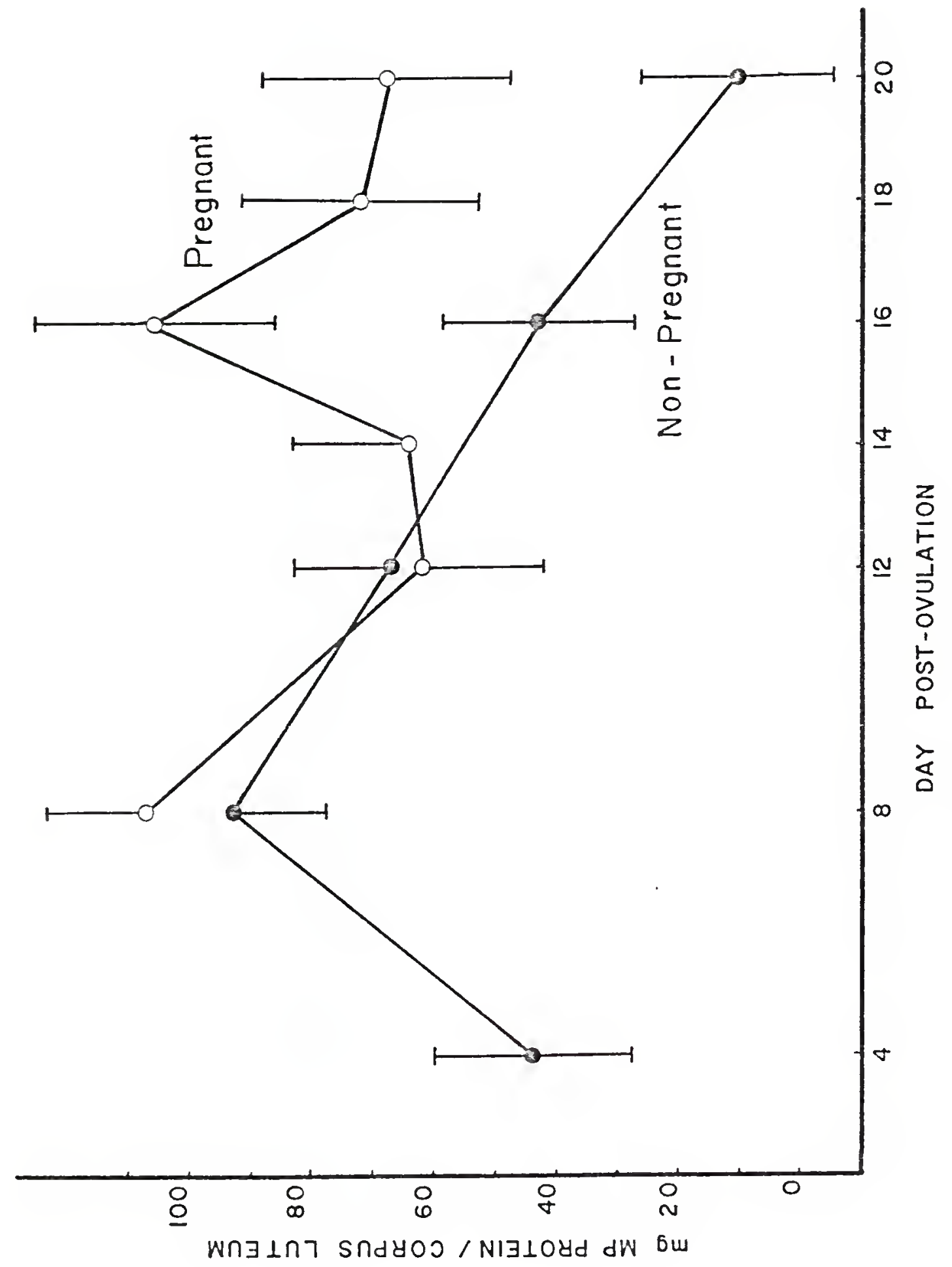




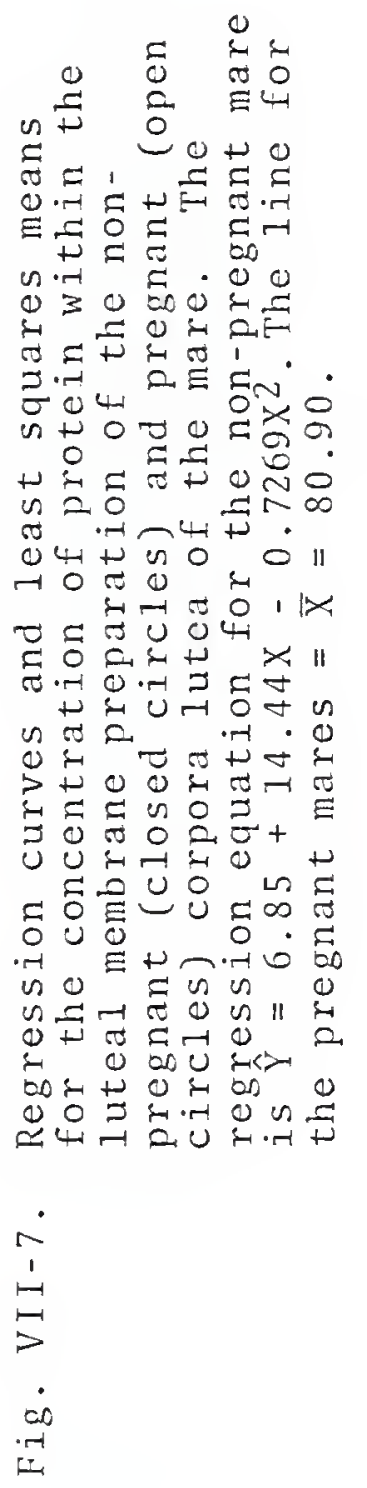




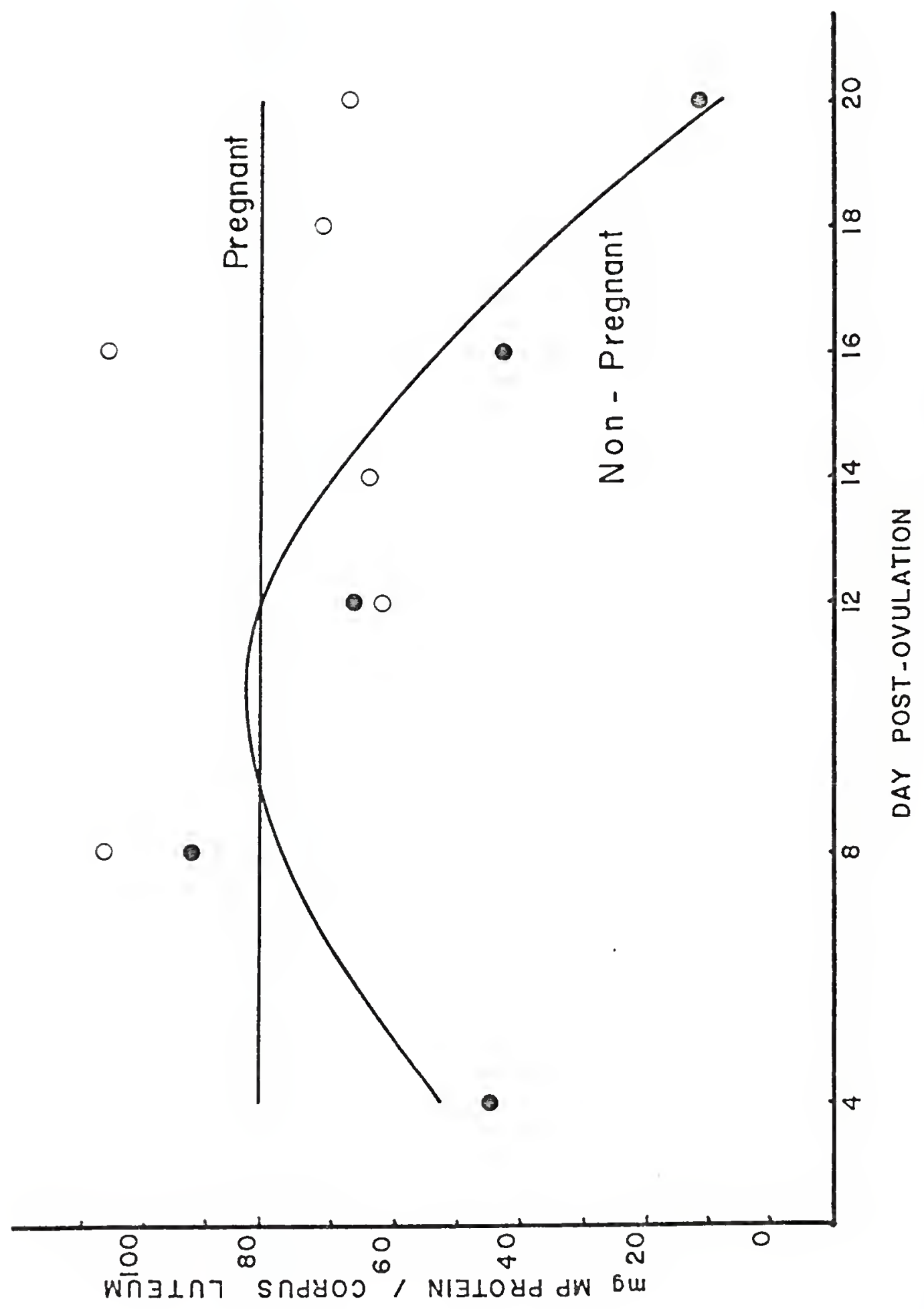




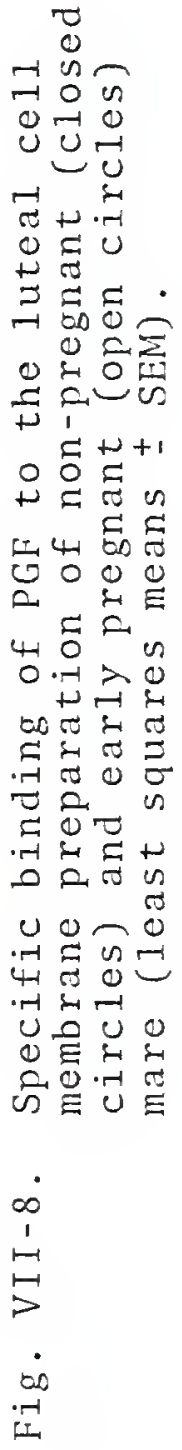


$-114-$

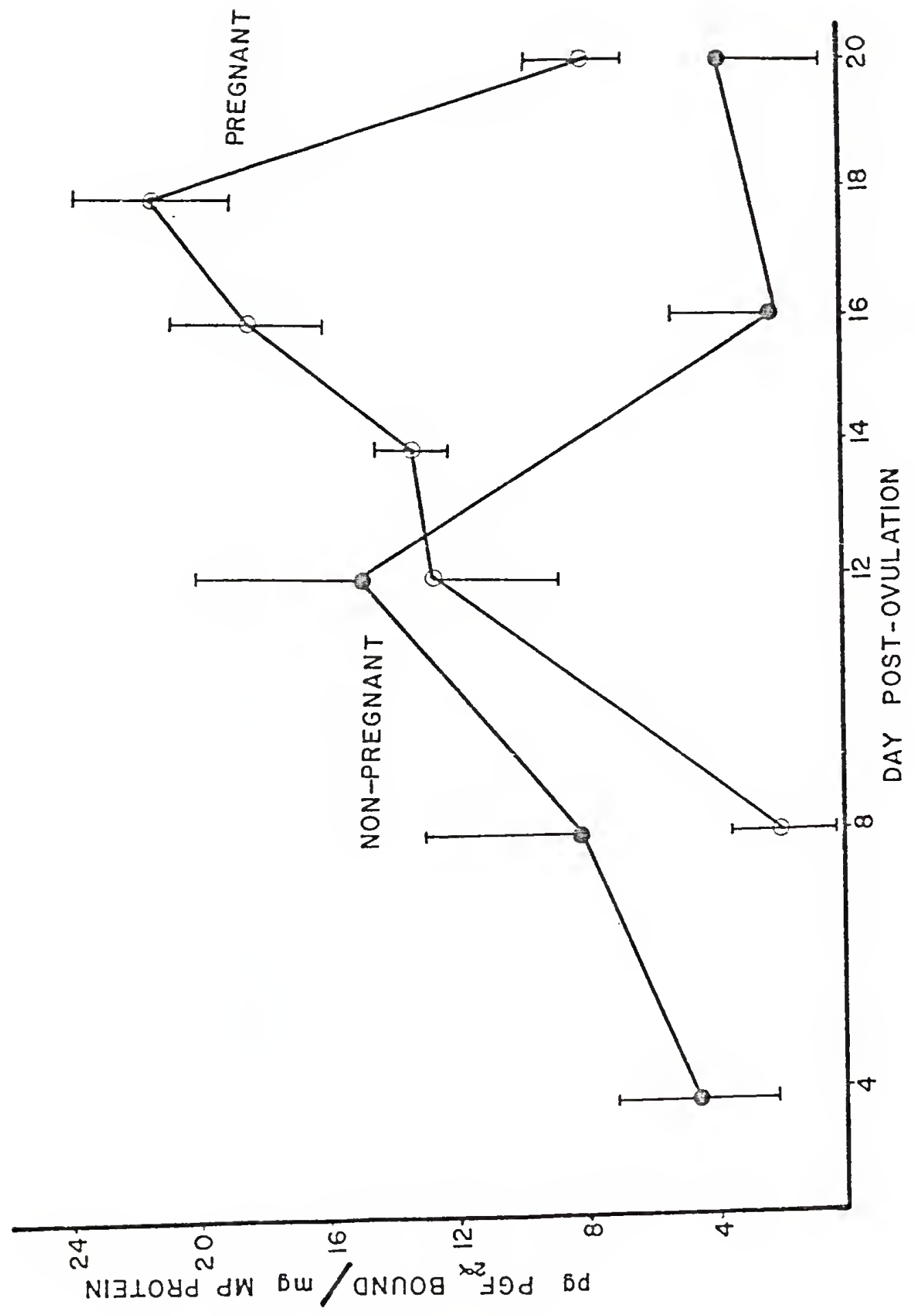


to respond to exogenous PGF (Douglas \& Ginther, 1972; Ginther \& Meckley, 1972; Oxender et al., 1975). Prostaglandin $\mathrm{F}_{2 \alpha}$ recognition by the $\mathrm{CL}$ may require receptor interactions and CAMP production (Marsh, 1971), and a lack of receptors would certainly diminish sensitivity. The low binding on Day 16 and 18 may be a result of decreased binding capacity or possibly the result of competition from endogenous PGF. To answer this question, a study of the percent occupancy of the receptor by endogenous PGF was conducted by qualifying the amount of PGF present in a membrane preparation. However, the membrane preparations utilized in this study contained an unknown substance that competed with PGF during radioimmunoassay (unpublished observation). The specific binding of PGF to the luteal receptor of pregnant mares increased $(\mathrm{P}<.0013)$ until Day 18 and declined on Day 20. The high PGF binding capability on Day 14 of pregnancy suggests that CL maintenance during pregnancy is unlikely to result from altered PGF receptor binding. Indeed, exogenous PGF is luteolytic in the pregnant mare (Kooistra \& Ginther, 1976). As discussed in Chapter III, the prevention of Iuteolysis in pregnancy may be due to failure of PGF to reach the CL (Douglas \& Ginther, 1976; Bazer \& Thatcher, $1977)$. 
CHAPTER VIII

SUMMARY AND CONCLUSIONS

Additional information has been collected which supports the hypothesis that uterine prostaglandin $F_{2 \alpha}$ (PGF) is the luteolytic substance of the mare. The PGF production capacity and content of endometria collected from non-pregnant pony mares on various days post-ovulation were found to be related temporally to the process of luteolysis (Fig. III-2). Endometrial PGF concentrations increased from the early stages of the estrous cycle until Day 16 post-ovulation and then declined. Thus maximal endometrial PGF production occurred at a time that corresponded to the expected time of luteolysis (i.e., Day 14) .

In pregnant mares, PGF production and content were observed to be high throughout early pregnancy (Fig. III-4). The PGF concentrations increased during the first 16 days of pregnancy in a pattern similar to that of the non-pregnant mare; however, there was no decline in concentrations on Days 18 and 20; instead, PGF production continued to increase. Since luteostasis is required for maintenance of early pregnancy, this finding appeared contrary to the physiology of the corpus luteum (CL). However, since uterine venous PGF levels are lower in pregnancy than in non-pregnancy 
(Douglas \& Ginther, 1976), the endometrium of pregnancy may be producing large amounts of PGF that are retained within the uterus. It is possible that PGF is not playing a role in luteal physiology but instead is involved in fetal-placental physiology.

That PGF was secreted in a pattern associated temporally with the reproductive status of the mare, implied that uterine PGF production was under the control of extra-uterine factors. It has been demonstrated that ovarian steroids modulate the secretion of uterine PGF in the rat (Castracane $\&$ Jordan, 1975). The in vitro effect of estradiol and progesterone upon endometrial PGF production by the non-pregnant mare indicated that production was unaltered by progesterone, but that estrogen stimulated the late luteal phase endometrium (Fig. III-6). In light of the fact that exogenous estrogen and progesterone have both been shown to be stimulatory to PGF secretion (Castracane $\&$ Jordan, 1975), it appeared that the effects of estrogen and progesterone may vary in a manner that is dependent upon whether the steroid was given systemically (exogenous injection) or during an incubation. When ovariectomized mares were injected for three weeks with estradio1, progesterone, or estradiol plus progesterone (1 week of estradiol followed by 2 weeks of progesterone), it was verified that all in vivo steroid combinations were stimulatory to the PGF synthetase system (Fig. IV-1). However, when endometrium from these same animals were treated for 2 hr in vitro with three levels of estradiol and one 
level of progesterone, the in vitro progesterone treatment was without effect but the in vitro estrogen treatment increased dramatically, in a dose-dependent fashion, endometrial PGF production. Thus, maximal PGF production occurred in mares receiving exogenous (systemic) progesterone and in vitro estrogen. This is consistent with the aforementioned PGF secretory patterns of the pregnant and non-pregnant mare. In pregnancy, the high concentrations of PGF within the Day 18 to 20 endometrium may be a reflection of prolonged systemic progesterone (Allen \& Hadley, 1974) and 1ocal fetal and endometrial estrogens. The equine conceptus has been shown to contain (Zavy $\underline{\text { et }} \underline{\text { al }} ., 1979$ ) and produce (Mayer et $\underline{\text { al }}$., 1977) estradiol. In addition, Seamens and co-workers (1979) indicated that both the endometrium and conceptus have the ability to convert progesterone- ${ }^{3} \mathrm{H}$ into estrone- ${ }^{3} \mathrm{H}$. Hershman and Douglas (1978) have shown that the early embryo can produce progesterone, which might also be converted by the endometrium into estrogen. In the non-pregnant mare maximal PGF production occurred in a (systemically) progesterone primed uterus that may have been under the influence of intra-luminal estrogens. Zavy and co-workers (1979) indicated that estrogen concentrations within the non-pregnant uterus are not as high as in the pregnant animal, but nevertheless are maximal on Days 14 to 16 , two to four days prior to peak peripheral estrogen levels (Fig. VIII-1 $\&$ VIII-2). The apparent increase in intra-luminal estrogens, prior to systemic increases, implies that these estrogens 


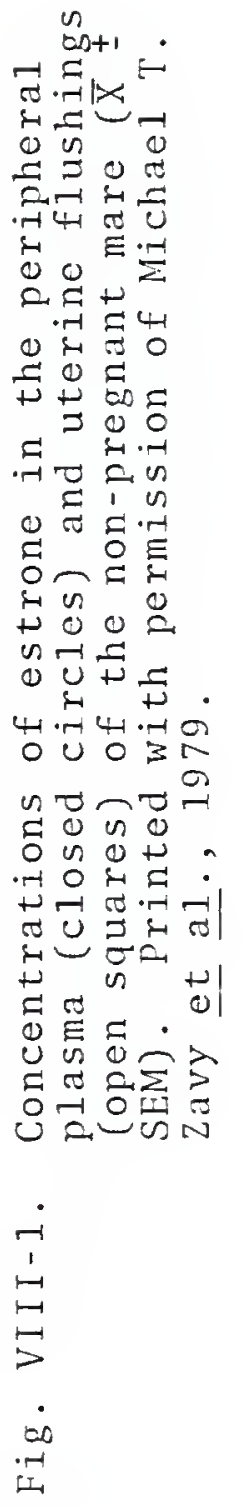




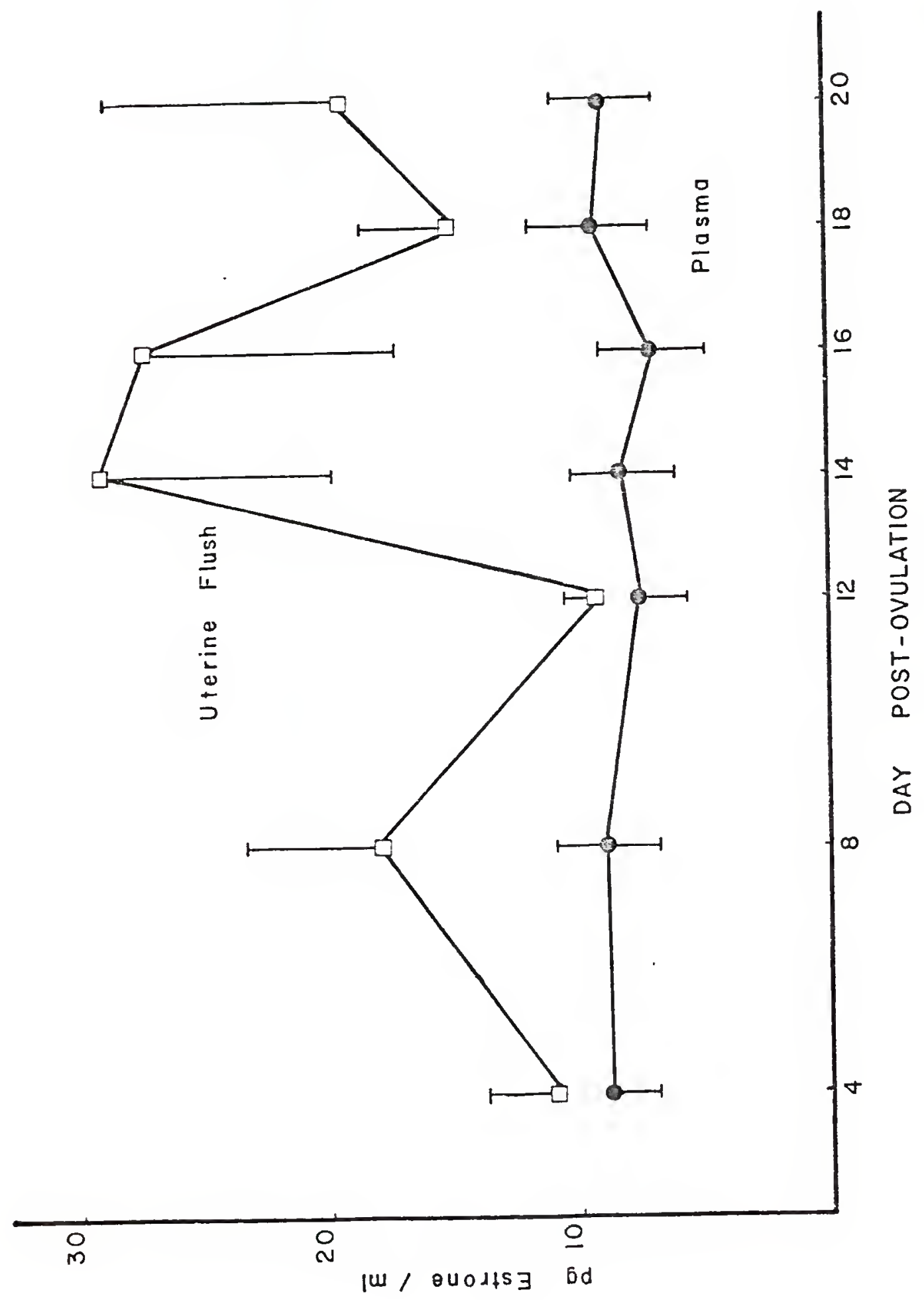




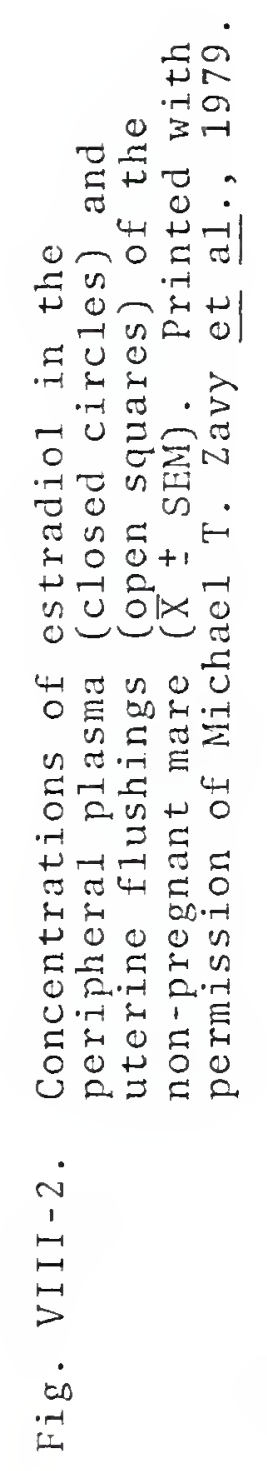




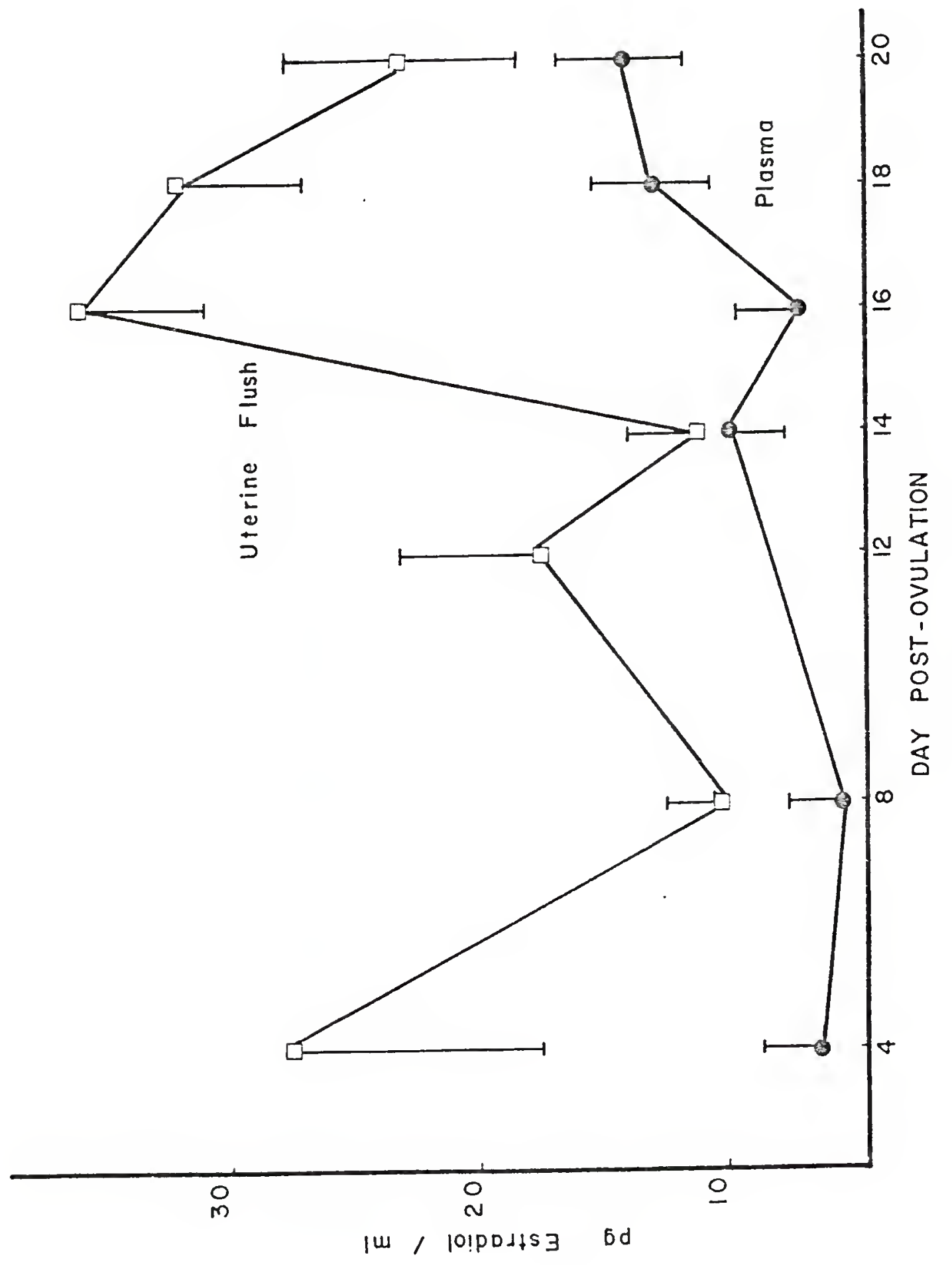


may not be of follicular origin. The presence of the endometrial aromatase enzymes (Seamans et al., 1979) indicates that the intra-luminal estrogens could be, at least in part, a product of the conversion of luteal progesterone into estrogen.

When the endometrium of the estrous cycle (Chapter III) was incubated in the presence of steroids, progesterone was ineffective in a1tering PGF production, while estrogen had little or no effect on Days 4 to 12 but was stimulatory on Days 16 and 20 (Fig. III-6). The stimulatory effect of estrogen may be effective only on a uterus that has had prior (prolonged systemic) progesterone exposure.

As previously established, the equine conceptus has the ability to produce estrogen and progesterone. The steroidogenic capability of the equine conceptus was also suggested by Flood and Marrable (1975) with the histochemical localization of several hydroxysteroid dehydrogenase (HSD) enzymes within the trophoblast. Also of particular interest was the appearance of high levels of $17 \beta-H S D$ on those areas of the uterine endometrium directly apposed to the trophoblast (Flood et al., 1979). This suggests a local influence of the conceptus upon the endometrium. Although not quantified, it has been noted that the gross morphology of the endometrial surface, that is in apposition to the Day 12 to 18 embryo, differed from the surrounding endometrium (M.W. Vernon $\varepsilon$ D.C. Sharp, unpublished data). Since PGF production by the endometrium may be enhanced locally by trophoblastic 
estrogens, PGF production by endometrium associated with the trophoblast was compared with the PGF production by endometrium in the uterine horn contralateral to the embryo. The trophoblast elicited a local, two-fold increase in PGF production, a phenomenon not seen in endometrium of opposite uterine horns of the non-pregnant animal (Fig. V-1). Enhanced production of PGF in those areas of the equine endometrium that are in intimate contact with the trophoblast suggests that PGF may be utilized by the embryo, although this has not been studied critically in the mare. Indeed PGF has been demonstrated to be present within the equine yolk sac fluids (Zavy et al., 1979). Additionally, PGF has been demonstrated to be metabolized by the porcine conceptus (Walker et al., 1977) and is required for implantation in mice (Saksena et al., 1976).

Control of luteolysis was first thought to solely reside in the adenohypophysis. Nalbandov (1961) set forth the theory that the ovulatory surge of $\mathrm{LH}$ was responsible for the formation of the $\mathrm{CL}$ and that the subsequent luteal regression was a function of aging. This concept was short-lived and was replaced by the hypothesis that luteal regression was a result of a uterine luteolysin (Short, 1964), now believed to be PGF (Pharriss \& Wyngarden, 1969; Goding, 1974). As described above, the modulation and production of PGF may be under the control of ovarian steroids which are secreted in a cyclic rhythm established by the pituitary gonadotropins. Since the 
pituitary gonadotropins are controlled by the cyclic centers of the hypothalmus, control of luteolysis may be at the level of the uterus, but with direction from the central nervous system.

Since the CL is a target tissue for PGF it would follow that exogenous PGF would localize within the CL. Luteal phase ovaries were perfused with $57.30 \mathrm{ng}$ of $\mathrm{PGF}^{3}{ }^{3} \mathrm{H}$ and, of the ovarian tissues studied, the CL sequestered the largest amount (Fig. VI-1). These results are supportive of the hypothesis that PGF is involved in luteal physiology; however, interpretation of these findings is mitigated by the fact that the perfused $\mathrm{PGF}-{ }^{3} \mathrm{H}$ may have been metabolized or altered molecularly prior to binding. To assess further the binding characteristics of PGF to the CL, a high speed $(100,000 \mathrm{G})$ luteal cell membrane fraction was prepared by ultracentrifugation. Studies of rates of association and dissociation indicated that PGF- ${ }^{3} \mathrm{H}$ was bound specifically and reversibly to the membrane preparation (MP) (Fig. VII-2). Furthermore, competitive displacement studies between $\mathrm{PGF}-{ }^{3} \mathrm{H}$ and various naturally occurring PGF analogues implicated the $9 \alpha-\mathrm{OH}$ and 5,6 cis double bond as major contributors to PGF receptor recognition (Table VII-4). The metabolites (13,14dihydro-PGF and 13,14-dihydro-15-keto-PGF) were the most competitive analogues. Since these metabolites have a low biological activity and a long half life, their affinity for the PGF receptor suggests that they may function as endogenous competitive inhibitors of PGF action. The PGEs were very 
poor competitors for the PGF receptor, a finding that is consistent with bovine research, indicating that the PGF and PGE receptors are different (Rao, 1974). The MP appeared to contain at least two receptor populations, having dissociation constants $(\mathrm{Kd})$ and binding capacities $(\mathrm{BC})$ of: $\mathrm{Kd}_{1}=$ $4.19 \times 10^{-11}[\mathrm{M}], B C_{1}=1.4 \times 10^{-13}[\mathrm{M}] / \mathrm{mg} \mathrm{MP}$ for the first population and $\mathrm{Kd}_{2}=9.11 \times 10^{-10}[\mathrm{M}], \mathrm{BC}=7.52 \times 10^{-13}$ $[\mathrm{M}] / \mathrm{mg}$ MP for the second population (Fig. VII-3). Since the MP was derived from potentially more than one cell type, i.e., Iuteal cells, endothelial cells, and plasma cells, the apparent heterogeneity may also be a reflection of this mixture. Alternatively, the heterogeneity may reflect more than one population of receptor on the luteal cell. The affinity constants reported herein are higher than those reported by others for the cow $\left(1 \times 10^{-8}\right.$ to $1 \times 10^{-9}$ [M]) and ewe $\left(1 \times 10^{-7}[\mathrm{M}]\right)$. This high affinity may partly explain the high sensitivity of mares to exogenous prostaglandins relative to other species and may also lend support to the concept that endogenous PGF is transported to the ovary through a systemic pathway (Ginther \& First, 1971). It is likely that the membrane receptor may play a role in 1uteal regression in the non-pregnant mare, or in prevention of luteal demise in the pregnant mare. In the nonpregnant mare, specific binding of PGF was maximal at the expected time of luteolysis, i.e., binding increased from Day 4 to Day 12 and declined dramatically on Days 16 and 20 (Fig. VII-8). The high PGF binding on Day 12 presumably 
reflects the readiness of the CL to bind PGF, while the low binding potential on Days 16 and 20 may reflect either the presence of endogenous1y bound PGF or an actual decrease in receptors due to the process of Iuteolysis. The paucity of PGF binding by the early (Day 4) CL possibly accounts for the refractoriness of the early CL to respond to exogenous PGF. Prostaglandin F recognition by the CL may require receptor interactions and cyclic AMP production (Marsh, 1971; Channing, 1970), and a lack of receptor binding would certainly diminish sensitivity. In the pregnant mare, PGF binding capacity was high throughout the period studied. The high PGF binding capability of the CL of early pregnancy suggests that luteal maintenance is unlikely to be the result of altered PGF receptor binding. Instead, prevention of luteolysis during early pregnancy may be due to failure of PGF to reach the CL (Bazer \& Thatcher, 1977), since the concentration of uterine venous PGF is low during pregnancy (Douglas \& Ginther, 1976).

Based on the data contained in this dissertation, the following interrelationships are believed to exist between the ovary and uterus of the non-pregnant mare (Fig. VIII-3). At the time of ovulation, both the granulosa and thecal cells undergo metabolic changes and begin to produce progesterone. The peripheral concentrations of progesterone increase during the following 7 to 10 days and this increase is responsible for a corresponding increase in the endometrial 
Fig. VIII-3. Diagram of the proposed interrelationships between the ovary and uterus of the nonpregnant mare. 


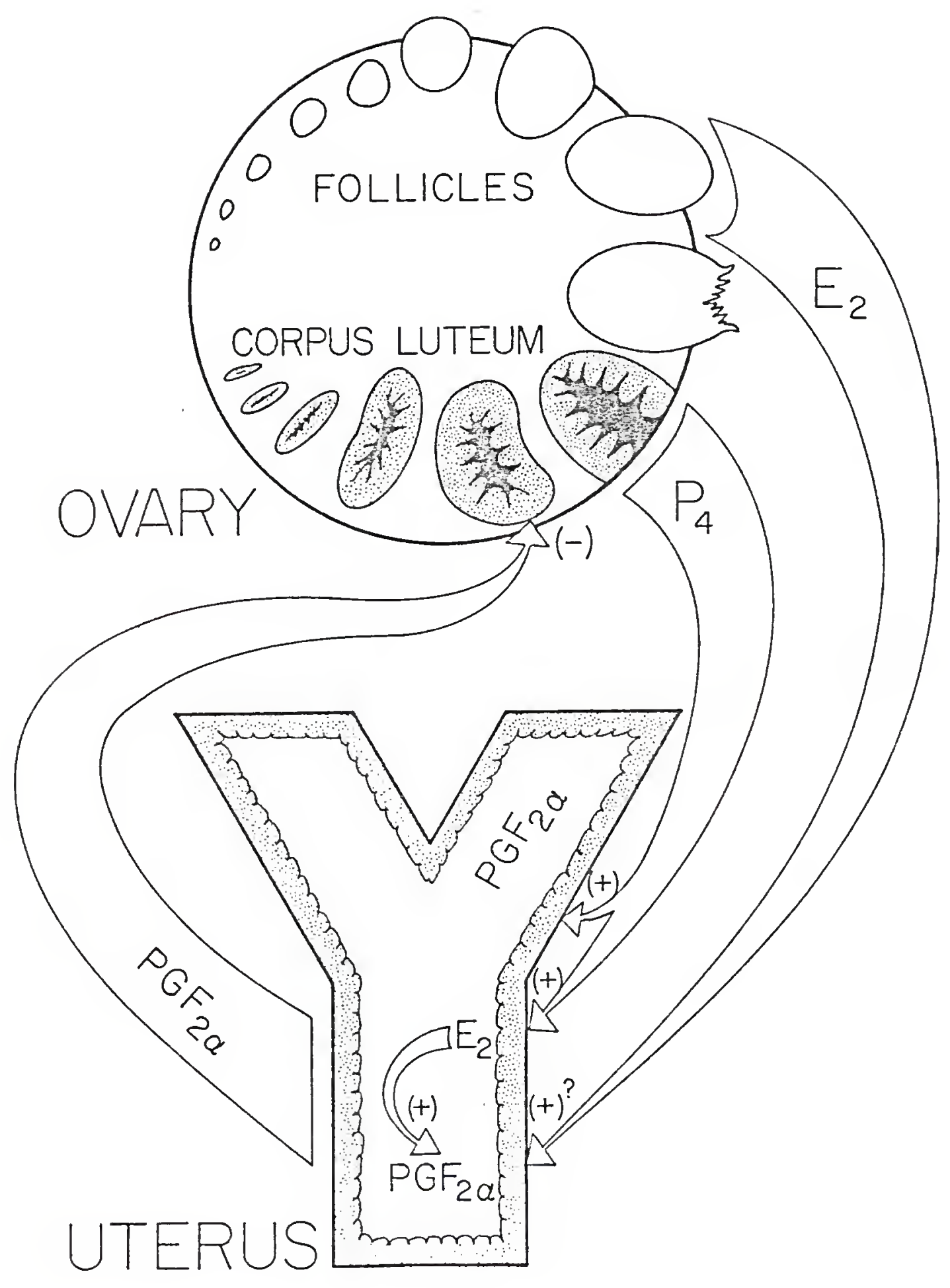


PGF synthetase enzymes. Likewise, during this same time period, the luteal membrane is undergoing conformational changes and the numbers of PGF receptors increase. At the expected time of luteolysis (Day 14 post-ovulation), the uterus is exposed to a transitory intra-luminal increase in estrogen which, in turn, activates a surge in PGF production. The intra-luminal estrogen may be either a product of conversion of luteal progesterone by the endometrial aromatase enzymes, or it may represent the direct entrance of follicular estrogens or both. The estrogen induced surge of PGF is released into the systemic vasculature and eventually binds to the luteal PGF receptor. Prostaglandin F binding initiates a sequence of reactions, mediated by the adenyl cyclase system and/or lysosomes, that ultimately lead to luteal regression and the formation of the corpus albicans. In pregnancy (Fig. VII-4), enhancement of the PGF synthetase system by luteal progesterone again occurs; however, the presence of the embryo somehow interferes with the subsequent process of luteolysis. Copious amounts of estrogen (10 times that seen in the non-pregnant uterus) and some progesterone are produced by the early embryo. These steroids may again potentiate the production of endometrial PGF, but this time the PGF is sequestered and/or metabolized within the uterine Iumen and does not reach the luteal receptor. The direction of PGF movement may be controlled by the high intra-luminal levels of fetal estrogens. Although it has yet to be demonstrated in the mare, it has been proposed elsewhere (Bazer 
Fig. VIII-4. Diagram of the proposed interrelationships between the ovary and uterus of the early pregnant mare. 


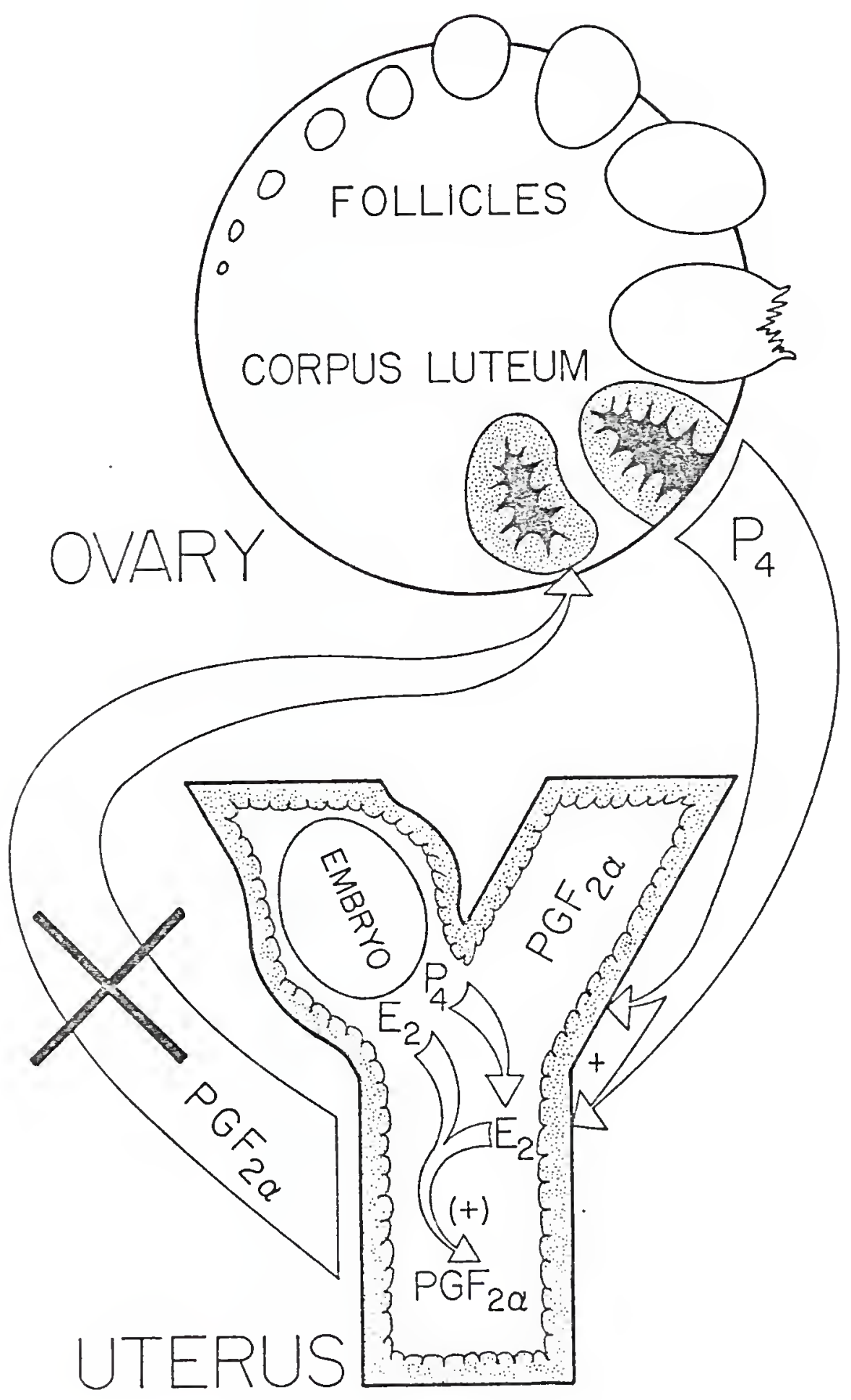


\& Thatcher, 1977) that pregnancy alters the direction of movement of endometrial PGF from a vascular direction to an intra-luminal direction. Alternately the low systemic concentrations of PGF during early pregnancy may be a result of immediate fetal utilization. With the endometrial PGF sequestered within the uterus, the luteal receptor remains unoccupied and luteolys is is absent. 
APPENDIX

COMMERCIAL SOURCES OF MATERIALS CITED

Acepromazine Maleate, injectable, No. 5229, Ayerst Laboratories, Inc./New York, N.Y. 10017.

Betadine Veterinary Solution, The Purdue Fredrich Co./Norwalk, conn. 06856 .

Dubnoff Metabolic Shaking Incubator, No. 66722, GCA/Precision Scientific/Chicago, I11. 60647.

Fluothane-a brand of Halothane, No. NDC00046-3125-82, Ayerst Laboratories Inc./New York, N.Y. 10017.

General Purpose Automatic Refrigerated Centrifuge, No. RC-3, Sorval1 Co./Newtown, Conn.

Goat antirabbit IgG ( 1 ight \& heavy chains), No. 0112-1214, Cappel Labs, Inc., Thud Ridge Farm,/Cochranville, Pa. 19330 .

Liquid Scintillator System, No. LS-335, Beckman Instruments Inc./Irivie, Ca. 92664.

Mi11ipore U1trafilters, No. HAWP02500/ Bedrord, Mass. 01730.

Prostaglandin $\mathrm{F}_{2} \alpha 9-{ }^{3} \mathrm{H}(\mathrm{N}), 5-15 \mathrm{Ci} / \mathrm{mmol}$ in Ethanol:water solution ( $7: 3)$, under nitrogen, No. NET 345, New England Nuclear/Boston, Mass. 02118.

Monroe Statistical Programmable Printing Calculator, No. 1860 , Litton Business Systems, Inc./Orange, New Jersey.

Steroids-Delestrogen (Estradiol Valerate)/E.R. Squibb \& Sons, Inc./Princeton, N.J. 08541. Estradiol 17B, No. E950, and progesterone, No. Q2600, Steraloids Inc./Wilton, N.H.

Surital, injectab1e, No. 85-178-25, Parke-Davis \& Co.,/ Detroit, Mich. 48232 .

Tissue Grinder, Kimax* brand (Kimble \#43950) from Scientific Products, No. T4017-15/McGaw Park, I11. 60085.

U1tra-1ow Revco Refrigerator, No. ULT-659-1, Industrial products Division of Revco/Columbia, S.C. 


\section{LIST OF REFERENCES}

\section{Allen, W.R. E L.E. Rowson. 1973. Control of the mare's oestrous cycle by prostaglandins. J. Reprod. Fert. $33: 539$.}

Allen, W.E. E J.C. Hadley. 1974. Blood progesterone concentrations in pregnant and non-pregnant mares. Equine Vet. J. $6: 87$.

Anderson, L.L., K.P. Bland, \& R.M. Melampy. 1969. Comparative aspects of uterine-luteal relationships. Recent Prog. Horm. Res. 25:57.

Asdel1, S.A. \& J. Hammond. 1933. The effects of prolonging the 1 ife of the corpus luteum in the rabbit by hysterectomy. Amer. J. Physiol. 3:600.

Barcikowski, B., J.C. Carlson, L. Wilson, \& J.A. McCracken. 1974. The effects of endogenous and exogenous estradiol$17 \beta$ on the release of prostaglandin $F_{2 \alpha}$ from the ovine uterus. Endocrinol. 95:1340.

Bazer, F.W. E W.W. Thatcher. 1977. Theory of maternal recognition of pregnancy in swine based on estrogen controlled endocrine versus exocrine secretion of prostaglandin $F_{2 \alpha}$ by the uterine endometrium. Prostaglandins $2: 265$.

Behrman, H.R., K. Yoshinaga, H. Wyman, \& R.O. Greep. 1971. Effects of prostaglandin on ovarian steroid secretion and biosynthesis during pregnancy. Amer. J. Physiol. $221: 189$.

Bland, K.P., W.E. Horton, \& N.L. Poyser. 1971. Levels of prostaglandin $F_{2 \alpha}$ in the uterine venous blood of sheep during the oestrous cycle. Life Sciences 10:509.

Blatchley, F.R. \& B.T. Donovan. 1972. The effects of prostaglandin $\mathrm{F}_{2 \alpha}$ upon luteal function and ovulation in the guinea-pig. J. Endocrinol. 53:493.

Blatchley, F.R., B.T. Donovan, E.W. Horton, E N.L. Poyser. 1972. The release of prostaglandins and progestins into the utero-ovarian venous blood of guinea-pigs during the oestrous cycle and following estrogen treatment. J. Physiol. 223:69. 
Caldwell, B.V. 1970. Uterine factors influencing corpus luteum function. In: Advances in biosciences 4:399. Ed. G. Raspe. Pergammon Press, Vieweg.

Caldwe11, B.V. E R.M. Moor. 1971. Further studies on the role of the uterus in the regulation of corpus luteum function in sheep. J. Reprod. Fert. 26:133.

Caldwel1, B.V., S. Tillson, W. Brock, \& L. Speroff. 1972. The effect of exogenous progesterone and estradiol on prostaglandin F levels in ovariectomized ewes.

Prostaglandins $1: 217$.

Carminati, P., F. Luzzani, A. Soffientini, \& L. Lerner. 1975. Influence of day of pregnancy on rat placental, uterine, and ovarian prostaglandin synthesis and metabolism. Endocrinol. 97:1071.

Castracane, V.D. E V.C. Jordan. 1975. The effect of estrogen and progesterone on uterine prostaglandin biosynthesis in the ovariectomized rat. Biol. Reprod.13:587.

Cerini, M., W. Chamley, J. Findlay, \& J. Goding. 1972. Luteolysin in sheep with ovarian autotransplants following concurrent infusions of luteinizing hormone and prostaglandin $F_{2 \alpha}$ into the ovarian artery. Prostaglandins $2: 433$.

Chaichareon, D.P., P.E. Meckley, \& O.J. Ginther. 1974. Effect of prostaglandin $F_{2} \alpha$ on corpora lutea in guineapigs and mongolian gerbils. Amer. J. Vet. Res. 35:685.

Channing, C.P. 1970. Influences of the in vitro and in vivo hormonal environment upon luteinizat $\overline{i o n} \overline{\text { of }}$ granulosa cells in tissue culture. Recent Prog. Horm. Res. $26: 589$.

Channing, C.P. \& J.F. Seymour. 1970. Effects of dibutyl cyclic 3'5'ANP and other agents upon luteinization of porcine granulosa cells in culture. Endocrinol. $87: 165$.

Chen, T.T., F.W. Bazer, B. Gebhardt, \& R.M. Roberts. 1975. Uterine secretion in mammals: Synthesis and placental transport of a purple acid phosphatase in pigs. Biol. Reprod. 13:304.

Chen, T.T., D.B. Endres, J.H. Abe1, G G.D. Niswender. 1978. Binding and degradation of human chorionic gonadotropin by ovine luteal cells. Proc. 60th Ann. Meeting Endocrine Soc., Abst. 337. p. 24.3, Miami. 
Cornette, J.C., K.T. Kirton, K.L. Barr, \& A.D. Forbes. 1972. Radioimmunoassay of prostaglandins. J. Reprod. Med. 9:355.

Deane, H.W., M.F. Hay, R. Moor, L. Rowson, \& R.V. Short. 1966. The corpus luteum of the sheep: Relationship between morphology and function during the estrous cycle. Acta Endocrinol. 51:245.

Demers, L.M., K. Yochinoga, \& R.O. Greep. 1974. Prostaglandin $F$ in monkey uterine fluid during the menstrual cycle and following steroid treatment. Prostaglandins $5: 513$.

Denamur, R., J. Martinet, \& R.V. Short. 1966. Secretion de 1 a progesterone par les corps jaunes de la brebis apres hypophysectomie section de la tige pituitaire et hysterectomie. Acta Endocrinol. 52:72.

Douglas, R.H. E O.J. Ginther. 1972. Effects of prostaglandin $\mathrm{F}_{2} \alpha$ on length of diestrus in mares. Prostaglandins $2: 265$.

Douglas, R.H. E O.J. Ginther. 1973. Luteolysis following a single injection of prostaglandin $F_{2} \alpha$ in sheep. J. Anim. Sci. $37: 990$.

Douglas, R.H. \& O.J. Ginther. 1975. Route of prostaglandin $F_{2 \alpha}$ injection and luteolys is in mares. Proc. Soc. Exp. Biol. Med. 145:263.

Douglas, R.H. \& O.J. Ginther. 1976. Concentration of prostaglandin $F$ in uterine venous plasma of anesthetized mares during the estrous cycle and early pregnancy. Prostaglandins 11:251.

Douglas, R.H., M.R. Del Campo, \& O.J. Ginther. 1976. Luteolysis following carotid or ovarian arterial injection of prostaglandin $F_{2 \alpha}$ in mares. Biol. Reprod. 14:472.

du Mesnil du Buisson, F. 1966. Contribution a l'etude du maintien du corps jaune de la truie. Ph.D. Dissertation. Institut National de la Recherche Agronomique. Nouzilly, France.

Durrant, E.P. 1926. The effect of hysterectomy on the oestrous cycle in the white rat. Amer. J. Physiol. $76: 234$.

Fenwick, L., R.L. Jones, B. Nalyor, N.L. Poyser, E N.H. Wilson. 1977. Production of prostaglandins by the pseudopregnant rat uterus in vitro, and the effect of tamoxifen with the identification of 6 keto prostaglandin $\mathrm{F}_{1 \alpha}$ as a major product. Br. J. Pharmac. 59:19I. 
Flood, P.G. \& A.W. Marrable. 1975. A histochemical study of steroid metabolism in the equine fetus and placenta. J. Reprod. Fert., Supp1. 23:569.

Flood, P.F., K.J. Betteridge, \& D.S. Irvine. 1979. Evidence of steroid production by the equine conceptus during the second and third week of gestation. J. Reprod. Fert., Supp1. 27. In press.

Ford, S.P., C.W. Weems, P.E. Pitts, J.E. Pexton, R.L. Butcher, \& E.K. Inskeep. 1975. Effects of estradiol$17 \beta$ and progesterone on prostaglandin $F$ in sheep uteri and uterine venous plasma. J. Anim. Sci. 41:1407.

Frank, M., F.W. Bazer, W.W. Thatcher, \& C.J. Wilcox. 1978. A study of prostaglandin $\mathrm{F}_{2} \alpha$ as the luteolysin in swine: IV. An explanation for the luteotrophic effect of estradiol. Prostaglandins 15:151.

Garren, D.L., G.N. Gil1, H. Masui, \& G.M. Walton. 1971. On the mechanism of action of ACTH. Recent Prog. Horm. Res. $27: 433$.

Ginther, O.J. 1967. Local utero-ovarian relationships. J. Anim. Sci. 26:578.

Ginther, O.J. \& N.L. First. 1971. Maintenance of the corpus luteum in hysterectomized mares. Amer. J. Vet. Res. $32: 1687$.

Ginther, O.J. \& P.E. Meckley. 1972. Effect of intrauterine infusion on length of diestrus in cows and mares. Vet. Med. Sma11 Anim. C1in. 67:751.

Ginther, O.J. \& C.H. Del Campo. 1974. Vascular anatomy of the uterus and ovaries and the unilateral luteolytic effect of the uterus: Cattle. Amer. J. Vet. Res. $35: 193$.

Gleeson, A.R., G.D. Thornburn, \& R.I. Cox. 1974. Prostaglandin $F$ concentration in the utero-ovarian venous plasma of the sow during the late luteal phase of the oestrous cycle. Prostaglandins 5:521.

Goding, J.R. 1974. The demonstration that PGF $2 \alpha$ is the uterine luteolysin in the ewe. J. Reprod. Fertil. $38: 261$.

Greenwald, G.S. 1967. Luteotropic complex of the hamster. Endocrinol. 80:11s. 
Gutknecht, G.D., J.C. Cornette, E B.B. Pharriss. 1966. Antifertility properties of prostaglandin $F_{2 \alpha}$. Biol. Reprod. 1:367.

Hafez, E.S. 1974. Reproduction in farm animals. Lea and Febiger Co., Philadelphia.

Hallford, D.M., R.P. Wettemen, F.J. Turnman, \& I.T. Onevent. 1974. Luteal function in gilts after prostaglandin $F_{2 \alpha}$. J. Anim. Sci. 28:213.

Hanse1, W., P.W. Concannon, \& J.R. Lukaszewska. 1973. Corpora lutea of the large domestic animals. Biol. Reprod. 8:222.

Henderson, C.R. E A.J. McAllister. 1978. The missing subclass problem in two-way fixed models. J. Anim. Sci. $46: 1125$.

Henderson, K.M. E K.P. McNatty. 1975. A biochemical hypothesis to explain the mechanism of luteal regression. Prostaglandins 9:779.

Hershman, L. ER.H. Douglas. 1978. The critical period for maternal recognition of pregnancy in mares. Proc. 2nd Inter. Symposium on Equine Reprod. Presentation No. 59, Davis, Calif.

Hichens, M., D.L. Grinwich, \& H.R. Behrman. 1974. Prostaglandin $F_{2} \alpha$ induced loss of corpus luteum gonadotropin receptors. Prostaglandins $7: 449$.

Holtan, D.W., T.M. Nett, \& V.L. Estergreen. 1975. Plasma progestagens in pregnant mares. J. Reprod. Fert., Suppl. $23: 419$.

Innskeep, E.K., M.M. Oloufa, B.E. Howland, A.L. Pope, \& L.E. Casida. 1962. Effect of experimental uterine distention on estrual cycle lengths in ewe. J. Anim. Sci. $21: 331$.

Janson, P.O., I. Albrecht, $\xi$ K. Ahren. 1975. Effect of luteinizing hormone on blood flow in the follicular rabbit ovary, as measured by radioactive microspheres. Acta Endocrino1. 79:122.

Johnson, J.O. E K.K. Hunter. 1970. Prostaglandin F $2 \alpha$ mode of action in pregnant hamsters. Physiologist $13: 235$.

Kenney, R.M., V.K. Ganjam, W.L. Cooper, E J.W. Lauderdale. 1975. The use of prostaglandin $F_{2} \alpha^{- \text {tham }}$ salt in mares in ciinical anoestrus. J. Reprod. Fert., Suppl. 23:247. 
Kimba11, F.A. \& J.W. Lauderdale. 1975. Prostaglandin $E_{1}$ and F2a specific binding in bovine corpora lutea: Comparison with luteolytic effects. Prostaglandins 10:313.

Kimball, F.A. \& L.J. Wyngarden. 1977. Prostaglandin F2a specific binding in equine corpora lutea. Prostaglandins $13: 553$.

Kiracobe, G.H., C.S. Menzies, H.T. Gier, \& H.S. Spies. 1966. Effect of uterine extracts and uterine or ovarian blood vessel ligation on ovarian function in ewes. J. Anim. Sci. 25:1159.

Kirton, K.T., B.B. Pharriss, \& A.D. Forbes, 1970. Some effects of prostaglandins $E_{2}$ and $F_{2} \alpha$ on the pregnant rhesus monkey. Biol. Reprod. 3:163.

Knight, J.W., F.W. Bazer, W.W. Thatcher, D.E. Franke, \& H.D. Wallace. 1977. Conceptus development in intact and unilateral hysterectomized ovariectomized gilts: Interrelations among hormonal status, placental development, fetal fluids and fetal growth. J. Anim. Sci. 44:620.

Kooistra, L.H. \& O.J. Ginther. 1976. Termination of pseudopregnancy by administration of prostaglandin $F_{2} \alpha$ and termination of early pregnancy by administration of prostaglandin $F_{2} \alpha$ or colchicine or by removal of embryo in mares. Amer. J. Vet. Res. 37:35.

KuehI, F.A., J.L. Humes, J. Tarnoff, V.J. Cirillo, \& E.A. Ham. 1970. Prostaglandin receptor site: Evidence for an essential role in the action of luteinizing hormone. Science 169:883.

Kueh1, F.A. E J.L. Humes. 1972. Direct evidence for a prostaglandin receptor and its application to prostaglandin measurements. Proc. Nat. Acad. Sci. 69:480.

Labsethwar, A.P. 1970. Effects of prostaglandin $F_{2 \alpha}$ on pituitary luteinizing hormone content of pregnant rats: A possible explanation for the luteolytic effect. J. Reprod. Fert. 23:155.

Lauderdale, J.W. 1972. Effects of PGF on pregnancy and estrous cycle of cattle. J. Anim. Sci. 35:246.

Leavitt, W.W. \& R. Acheson. 1972. The effect of luteinizing hormone on plasma progestin: Relationships in the pituitary-autografted rat. Endocrino1. 90:415.

Lewis, G.S., L. Wilson, J. Wilks, J. Pexton, R. Fogwell, S. Ford, R. Butcher, W. Thayne, \& E.K. Inskeep. 1977. $\mathrm{PGF}_{2} \alpha$ and its metabolites in uterine and jugular venous plasma and endometrium of ewes during early pregnancy. J. Anim. Sci. 45:320. 
Loeb, L. 1923. The effect of extirpation of the uterus on the 1 ife and function of the corpus luteum in the guinea pig. Proc. Soc. Expt. Bio1. Med. 20:441.

Lowry, O.H., N.J. Rosebrough, A.L. Farr, E R.J. Randall. 1951. Protein measurements with the folin phenol reagent. J. Biol. Chem. 193:265.

Lukaszewska, J.H. \&W. Hanse1. 1970: Extraction and partial purification of luteolytic activity from bovine endometrial tissue. Endocrinol. 86:261.

Marsh, J. 1971. The effect of prostaglandins on the adenyl cyciase of the bovine corpus luteum. Ann. N.Y. Acad. Sci. 180:416.

Nayer, R.E., M.W. Vernon, M.T. Zavy, F.W. Bazer, \& D.C. Sharp. 1977. Estrogen production by the equine conceptus. Proc. 69th Ann. Meeting Amer. Soc. Anim. Sci., Abstr. 466, Madison.

Mazer, R.S. E P.A. Wright. 1968. A hamster uterine luteoiytic extract. Endocrinol. 83:1065.

McCracken, J.A., M.E. G1ew, \& R.J. Scaramuzzi. 1970. Corpus luteum regression induced by prostaglandin $\mathrm{F}_{2 \alpha}$. J. C1in. Endocrino1. Metab. 30:544.

McCracken, J.A., D.T. Baird, \&M.R. Goding. 1971. Factors affecting the secretion of steroids from the transplanted ovary in the sheep. Recent. Prog. Horm. Res. $27: 537$.

Melven, P.V. \& W. Hansel. 1964. Ovarian function in dairy heifers following hysterectomy. J. Dairy Sci. 47:1388.

Moeljono, M.P.E. 1975. A study of prostaglandin $\mathrm{F}_{2} \alpha$ as the luteolysin in swine. Ph.D. Dissertation, University of Florida.

Moeljono, M.P.E., F.W. Bazer, \&W.W. Thatcher. 1976. A study of prostaglandin $F_{2} \alpha$ as the luteolysin in swine: I. Effect of prostaglandin $F_{2} \alpha$ in hysterectomized gilts. Prostaglandins 11:737.

Moeljono, M.P.E., W.W. Thatcher, F.W. Bazer, M. Frank, L.J. Owens, $\varepsilon_{\text {F }}$ C.J. Wilcox. 1977. A study of prostaglandin $\mathrm{F}_{2 \alpha}$ as the lutcolysin in swine: II. Characterization and comparison of prostaglandin $F$, estrogen and progestin concentrations in utero-ovarian vein plasma of nonpregnant and pregnant gilts. Prostaglandins 14:543.

Nalbandov, A.V. 1961. Comparative physiology and endocrinology of domestic animals. Recent Prog. Horm. Res. $17: 119$. 
Ogra, S.S., K.T. Kirton, T.B. Tomasi, \& J. Lippes. 1974. prostaglandins in the human fallopian tube. Fertil. Steril. 25:250.

O'Grady, J.P., E.I. Kohorn, R.H. Glass, B.V. Caldwe11, W.A. Brock, \&L. Speroff. 1972. Inhibition of progesterone synthesis in vitro by prostaglandin $F_{2 \alpha} \cdot \mathrm{J}$. Reprod. Fert. $30: 1 \overline{5 j}$.

Oxender, W.D., P.A. Noden, \& H.D. Hafs. 1975. Oestrus, ovulation and plasma hormones after prostaglandin $F_{2} \alpha$ in mares. J. Reprod. Fert., Supp1. 23:251.

Perry, J.S., R.B. Heap, \& E.C. Amoroso. 1973. Steroid hormone production in pig blastocyst. Nature 245:45.

Perry, J.S., R.B. Heap, R.D. Burton, \& J.E. Gadsby: 1976. Endocrinology of the blastocyst and its role in the establishment of pregnancy. J. Reprod. Fert., Suppl. $25: 85$.

Pharriss, B.B. 1970. The possible vascular regulation of luteal function. Perspectives Biol. Med. 13:434.

Pharriss, B.B. \& L.J. Wyngarden. 1969. The effects of $\mathrm{PGF}_{2 \alpha}$ on the progesterone content of ovaries from pseudopregnant rats. Proc. Soc. Expt. Biol. Med. $130: 92$.

Pickles, V.R. 1959. Myometrial response to the menstrual plain-muscle stimulant. J. Endocrinol. 19:150.

Pineda, M.H., O.J. Ginther, ६ W.H. McShan. 1972. Regression of the corpus luteum in mares treated with an antisera against equine pituitary. Amer. J. Vet. Res. 33:1767.

Powe11, W., S. Hammarstrom, \& B. Samuelsson. 1974. Prostaglandin $F_{2 \alpha}$ receptor in ovine corpora lutea. Eur. J. Biochem. 41:103.

Rao, C.V. 1974. Characterization of prostaglandin receptors in the bovine corpus luteum cell membranes. J. Biological Chem. 249:7203.

Rao, C.V. 1976. Discrete prostaglandin receptors in the outer membrane of bovine corpora lutea. Adv. Prostaglandin Thromboxane Res. 1:247.

Rao, C.V. 1977. Prostaglandin F $2 \alpha$ binding sites in human corpora lutea. J. C1in. Endocrinol. Netab. 44:1032.

Rao, C.V. E S. Mitra. 1977. Subcellular distribution of prostaglandin and gonadotropin receptors in bovine corpora lutea. Biochem. Biophysical Res. Communication $76: 656$. 
Rao, C.V. \& S. Mitra. 1978. Receptors for gonadotropins and prostaglandins in lysomes of bovine corpora lutea. Arch. Biochem. Biophysics 186:126.

Rowson, L.E.A., R. Tervst, \& A. Brand. 1972. The use of prostaglandin for synchronization of oestrus in cattle. J. Reprod. Fert. 29:145.

Saksena, S.K. E M.J. Harper. 1972a. Levels of F-prostaglandin in peripheral plasma and uterine tissue of cyclic rats. Prostaglandins 2:511.

Saksena, S.K. \& M.J. Harper. 1972b. Leve1s of F-prostaglandin (PGF) in uterine tissue during the estrous cycle of hamster: Effects of estradiol and progesterone. Prostaglandins 2:405.

Saksena, S.K. \& I.F. Lau. 1973. Effects of exogenous estradiol and progesterone on the uterine tissue levels of prostaglandin $\mathrm{F}_{2 \alpha}$ (PGF) in ovariectomized mice. Prostaglandins $3: 31 \%$.

Saksena, S.K., I.F. Lau, \& A.A. Shaikh. 1974. Cyclic changes in the uterine tissue content of F-prostaglandin and the role of prostaglandins in ovulation in mice. Fert. \& Steril. 25:636.

Saksena, S.K., I.F. Lau, \& M.C. Chang. 1976. Relationship between, oestrogen, prostaglandin $\mathrm{F}_{2 \alpha}$, and histamine in delayed implantation in the mouse. Acta Endocrinol. $81: 801$.

Scatchard, G. 1949. The attraction of proteins for small molecules and ions. Ann. N.Y. Acad. Sci. 51:660.

Seamans, K.W., M.J. Fields, F.W. Bazer, M.W. Vernon, \& D.C. Sharp. 1979. In vitro aromatase of pregnant and nonpregnant equine endometrium and conceptus membranes. Proc. 71st Ann. Meeting Amer. Soc. Anim. Sci., Tucson.

Sharp, D.C. E D.L. Black. 1973. Changes in peripheral plasma progesterone throughout the oestrous cycle of the pony mare. J. Reprod. Fert. $33: 535$.

Shemesh, M., J. Hixon, \&W. Hansel. 1974. Isolation and identification of endometrial luteolysin. J. Anim. Sci. $39: 225$.

Shemesh, M. E W. Hanse1. 1975. Levels of prostaglandin F (PGF) in bovine endometrium, uterine venous, ovarian arterial and jugular plasma during the estrous cycle. Proc. Soc. Expt. Bio1. Med. 148:123. 
Shomberg, D.W. 1967. A demonstration in vitro of luteolytic activity in pig uterine flushings. J. Endocrinol. $38: 359$.

Short, R.V. 1964. Ovarian steroid synthesis and secretion in vivo. Recent Prog. Horm. Res. 20:303.

Singer, S.J. E G.L. Nicholson. 1972. The fluid mosaic model of the structure of cell membranes. Science 175:720.

Singh, E.J., I. Baccarini, E F.P. Zuspan. 1975. Levels of prostaglandin $\mathrm{F}_{2 \alpha}$ and $\mathrm{E}_{2}$ in human endometrium during the menstrual cycle. Amer. J. Obstet. Gynecol. 121:1003.

Speroff, L. E P.W. Ramwe11. 1970. Prostaglandin stimulation of in vitro progesterone synthesis. J. C1in. Endocrinol. $30: \overline{34} 5$.

Spincemaille, J., M. Coryn, D. Vandekerckhove, \& M. Vandeplassche. 1975. The use of prostaglandin $F_{2 \alpha}$ in controlling the oestrous cycle of the mare and steroid changes in the peripheral blood. J. Reprod. Fert., Supp1. $23: 263$.

Squires, E.L., R.H. Douglas, W.P. Steffenhagen, \& O.J. Ginther. $1974 \mathrm{a}$. Ovarian changes during the estrous cycle and pregnancy in mares. J. Anim. Sci. 38:330.

Squires, E.L., B.L. Wentworth, \& O.J. Ginther. 1974 b. Progesterone concentration in the blood of mares during the estrous cycle, pregnancy and after hysterectomy. J. Anim. Sci. 39:759.

Steel, R.G. \& J.H. Torrie. 1960. Principles and procedures of statistics. McGraw-Hill Book Co., Inc., New York. p. 347 .

Stormshak, F. ॄ L.E. Casida. 1965. Effects of LH and ovarian hormones on corpora lutea of pregnant rabbits. Endocrino1. $77: 337$.

Szego, C.M. 1974. The lysosome as a mediator of hormone action. Recent Prog. Horm. Res. 30:171.

Thatcher, W.W., M. Terqui, J. Thimonier, J.P. Ravault, \& P. Maulcon. 1979. 15 keto PGF and hormonal responses to injection of estradiol in heifers. Proc. Amer. Soc. Anim. Sci. Southern Section, Abst. 109, New Orleans.

Umbreit, W.W., R.H. Burris, \& J.F. Stauffer. 1957. Manometric techniques. Burgess Publishing Co., Minneapolis. 
van Niekerk, C.H., J.C. Morgenthal, \& W.H. Gerneke. 1975. Relationship between the morphology of and progesterone production by the corpus luteum of the mare. J. Reprod. Fert., Suppl. 23:171.

Walker, F.M. \& N.L. Poyser. 1974. Production of prostaglandins by the early pregnant guinea-pig uterus in vitro. J. Endocrinol. 61:265.

Walker, F.M., C.E. Patek, C.F. Leof, \& J. Watson. 1977. The metabolism of prostaglandin $F_{2 \alpha}$ and $E_{2}$ by the nonpregnant porcine endometrium and luteal tissue and early pregnant porcine endometrium, luteal tissue and conceptuses in vitro. Prostaglandins 14:557.

Wilson, L., R.J. Cenedella, R.L. Butcher, \& E.K. Innskeep. 1972. Levels of prostaglandins in the uterine endometrium during the ovine estrous cycle. J. Anim. Sci. 34:93.

Wiltbank, J.N. \& L.E. Casida. 1956. Alteration of ovarian activity by hysterectomy. J. Anim. Sci. 15:134.

Wiquist, N., M. Bydeman, \& K. Kirton. 1970. In: Nobel symposium: Control of human fertility. Ed. E. Diczfalusy \&V. Borell. John Wiley \& Sons, New York 15:137.

Zavy, M.T., F.W. Bazer, D.C. Sharp, M. Frank, \&W.W. Thatcher. 1978. Uterine luminal prostaglandin $F$ in cycling mares. Prostaglandins 16:643.

Zavy, M.T., M.W. Vernon, F.W. Bazer, \& D.C. Sharp. 1979. Endocrine aspects of the uterine environment and yolk sac fluid in the pony mare. Proc. 71st Ann. Meeting Amer. Soc. Anim. Sci., Tucson. 


\section{BIOGRAPHICAL SKETCH}

Michael Walter Vernon was born March 29, 1949, in Phillipsburg, New Jersey, the son of Matthew M. and Ann A. Vernon. He graduated from Lexington Catholic High School, Lexington, Kentucky, in May 1967. He received the Bachelor of Science degree from the University of Kentucky, with a major in zoology, in May 1971, and completed the requirements for the Master of Science degree from Eastern Kentucky University in biology in August 1973. The topic of his thesis was "The Competitive Protein Binding Assay of Progesterone in the Breeding and Non-Breeding Urodele in Response to Chorionic Gonadotropin." Currently, he is a member in good standing of the Society for the Study of Reproduction, American Society of Animal Science, Florida Track Club, Audubon Society, and Sierra Club. He has been the recipient of a Sigma Xi Grant-in-Aid of Research (1977) and NSF and Nato grants to attend the 2nd International Symposium on "Advances in Prostaglandins" held in Erice, Italy (1976). He has accepted a post-doctoral NRSA trainceship in the Regional Primate Research Center at the University of Wisconsin . 
I certify that I have read this study and that in my opinion it conforms to acceptable standards of scholarly presentation and is fully adequate, in scope and quality, as a dissertation for the degree of Doctor of Philosophy.

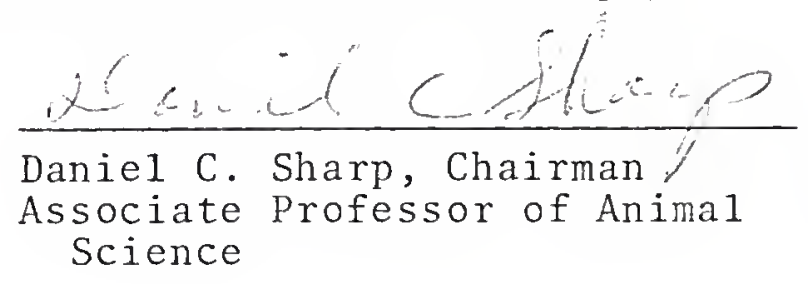

I certify that I have read this study and that in my opinion it conforms to acceptable standards of scholarly presentation and is fully adequate, in scope and quality, as a dissertation for the degree of Doctor of Philosophy.

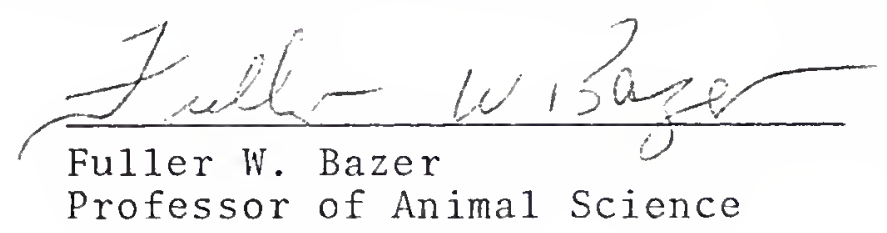

I certify that I have read this study and that in my opinion it conforms to acceptable standards of scholarly presentation and is fully adequate, in scope and quality, as a dissertation for the degree of Doctor of Philosophy.

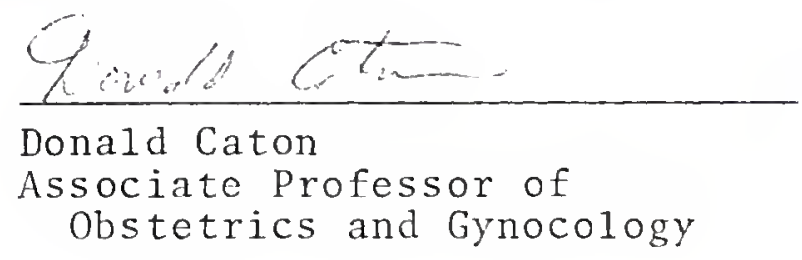


I certify that I have read this study and that in my opinion it conforms to acceptable standards of scholarly presentation and is fully adequate, in scope and quality, as a dissertation for the degree of Doctor of Philosophy.

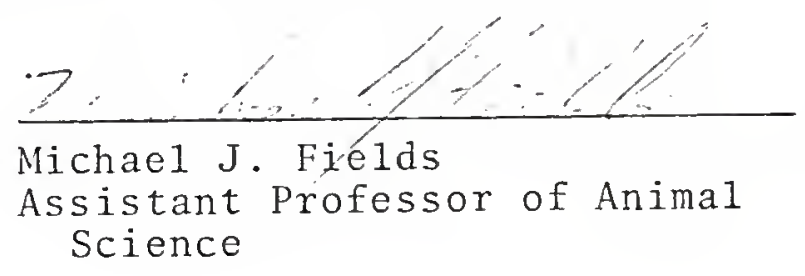

I certify that I have read this study and that in my opinion it conforms to acceptable standards of scholarly presentation and is fully adequate, in scope and quality, as a dissertation for the degree of Doctor of Philosophy.

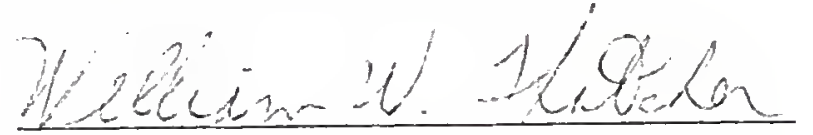

William W. Thatcher

Professor of Dairy Science

This dissertation was submitted to the Graduate Faculty of the College of Agriculture and to the Graduate Council, and was accepted as partial fulfillment of the requirements for the degree of Doctor of Philosophy.

June, 1979

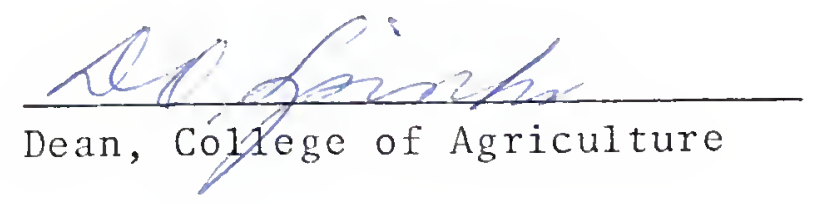

Dean, Graduate School 


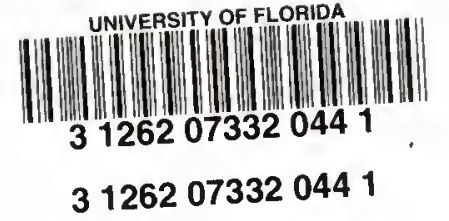

